\title{
Synthesis and Characterization of Functional and High Performance Polyimides
}

By

\author{
Fatima Hasanain \\ B.Sc. (Carleton University) \\ A thesis submitted to the faculty of the Graduate studies and Research \\ In partial fulfillment of the requirements \\ For the degree of \\ Masters of Chemistry \\ The Department of Chemistry \\ Carleton University \\ Ottawa, Ontario, Canada, \\ August 2008 \\ (C) copyright 2008, Fatima Hasanain
}




$\begin{array}{ll}\begin{array}{l}\text { Library and } \\ \text { Archives Canada }\end{array} & \begin{array}{l}\text { Bibliothèque et } \\ \text { Archives Canada }\end{array} \\ \begin{array}{l}\text { Published Heritage } \\ \text { Branch }\end{array} & \begin{array}{l}\text { Direction du } \\ \text { Patrimoine de l'édition }\end{array} \\ \begin{array}{l}\text { 395 Wellington Street } \\ \text { Ottawa ON K1A 0N4 } \\ \text { Canada }\end{array} & \begin{array}{l}\text { 395, rue Wellington } \\ \text { Ottawa ON K1A 0N4 } \\ \text { Canada }\end{array}\end{array}$

Your file Votre référence ISBN: 978-0-494-44125-1 Our file Notre référence ISBN: 978-0-494-44125-1

NOTICE:

The author has granted a nonexclusive license allowing Library and Archives Canada to reproduce, publish, archive, preserve, conserve, communicate to the public by telecommunication or on the Internet, loan, distribute and sell theses worldwide, for commercial or noncommercial purposes, in microform, paper, electronic and/or any other formats.

The author retains copyright ownership and moral rights in this thesis. Neither the thesis nor substantial extracts from it may be printed or otherwise reproduced without the author's permission.
AVIS:

L'auteur a accordé une licence non exclusive permettant à la Bibliothèque et Archives Canada de reproduire, publier, archiver, sauvegarder, conserver, transmettre au public par télécommunication ou par l'Internet, prêter, distribuer et vendre des thèses partout dans le monde, à des fins commerciales ou autres, sur support microforme, papier, électronique et/ou autres formats.

L'auteur conserve la propriété du droit d'auteur et des droits moraux qui protège cette thèse. $\mathrm{Ni}$ la thèse ni des extraits substantiels de celle-ci ne doivent être imprimés ou autrement reproduits sans son autorisation.
In compliance with the Canadian Privacy Act some supporting forms may have been removed from this thesis.

While these forms may be included in the document page count, their removal does not represent any loss of content from the thesis.
Conformément à la loi canadienne sur la protection de la vie privée, quelques formulaires secondaires ont été enlevés de cette thèse.

Bien que ces formulaires aient inclus dans la pagination, il n'y aura aucun contenu manquant.

\section{Canada}


The undersigned recommend to the

Faculty of Graduate Studies and Research acceptance of the thesis

\title{
Synthesis and Characterization of Functional and High Performance Polyimides
}

\author{
Submitted by \\ Fatima Hasanain, B.Sc. (Carleton University) \\ In partial fulfillment of the requirements for the degree of \\ Masters of Chemistry
}

Prof. Z.Y. Wang, Thesis supervisor

Prof. R.C. Burk, Chair, Department of Chemistry

Carleton University

August, 2008 


\section{Abstract}

Polyimides are an important class of materials due to their desirable characteristics such as high thermal stability, low dielectric constant, excellent mechanical properties and good processability. Therefore, polyimides have found applications in various fields such as aerospace, microelectronics and optoelectronics.

This thesis project constitutes of two parts; new one-step synthesis of polyimides in salicylic acid, and synthesis and properties of near-infrared (NIR) electrochromic polyimides. In the first part, a new polymerization in the melt of salicylic acid has been developed for the one-step synthesis of polyimides from various diamines and dianhydrides. The polymerization is carried out in high solid content up to $40-50 \mathrm{wt} / \mathrm{v} \%$ at $200^{\circ} \mathrm{C}$ and affords the completely cyclized polyimides with high molecular weights in 1-2 hours. The preliminary studies on some of the polymerization variables (e.g., concentration and time) suggest that the imidization is very fast and the chain growth is likely to proceed via the addition of the growing imide segments.

In the second part, a series of NIR electrochromic and photoluminescent polyimides containing dinuclear ruthenium complexes in the mainchain were synthesized and characterized. All the polyimides are NIR electrochromic and show an intense absorption centred at $1600 \mathrm{~nm}$ upon the oxidation of the ruthenium complex to the mixed-valence state. 


\section{Acknowledgments}

Upon the completion of this Masters degree, I would like to express my gratitude and sincere appreciation to many people, without whom this thesis would have not finished. I am indebted to my supervisor, Professor Wayne Wang, for his guidance, support, encouragement and criticism over the last two years. I am deeply impressed by his broad knowledge and skills in many areas, his continuous devotion to his students and his sincerity and patience both as a teacher and a scholar. This experience has benefited me in my personal and professional growth. I should profoundly say Thank you!

I also would like to thank Dr. Jane Gao for the thrilling conversations and encouragements along the way. I also extend my appreciation to all my colleagues and friends for the helpful suggestions and fun time we enjoyed in the past years: Gaetan, Yuxing, Huy, Li, Daniel, Xianguo, Shidi, Tang, Ying, Wendy, Cathy, David, Karen, Ning, Qiao and Mathieu.

Most of all, I would like to express the kind of appreciation for which there are no word to the people who made all of this possible and to whom I dedicate this work: my family. Thank you Mom, Dad, brothers and sisters for the endless support through my entire life.

"Education is the passport to the future, for tomorrow belongs to those

$$
\text { who }
$$

prepare for it today" (Malcom X) 


\section{Table of Content}

\section{Page}

Abstract

Acknowledgments

iv

List of tables

vii

List of figures

vii

List of schemes

viii

List of abbreviations

ix

\section{Chapter 1. Introduction}

1.1 Background

1.2 Polyimides in General

1.3 Synthetic Methods of Polyimides

1.3.1 Two-step polymerization method

1.3.2 One-step polymerization method

1.3.3 Other synthetic methods

1.4 Near-Infrared and Electrochromic Materials

1.4.1 Electrochromism

1.4.2 Types of electrochromic materials

1.4.3 NIR electrochromic material

Chapter 2. New One-step Synthesis of Polyimides in salicylic acid

2.1 Rationale and Objective 
2.2.1 Polymerization conditions

$\begin{array}{ll}\text { 2.2.2 Kinetics study } & 32\end{array}$

2.2.3 Effect of co-solvent and catalyst on the polymerization 33

2.3 Polymer Characterization $\quad 34$

$\begin{array}{lll}\text { 2.3.1 } & \text { Spectroscopic analysis } & 34\end{array}$

$\begin{array}{lll}\text { 2.3.2 Thermal analysis } & 35\end{array}$

$\begin{array}{ll}2.4 \text { Conclusion } & 36\end{array}$

2.5 Experimental $\quad 36$

$\begin{array}{ll}2.6 \text { References } & 42\end{array}$

Chapter 3. Synthesis and Properties of Near-Infrared Electrochromic

Polyimides

3.1 Rationale and Objective $\quad 43$

3.2 Monomer Synthesis $\quad 46$

$\begin{array}{ll}3.3 \text { Polymer Synthesis } & 47\end{array}$

$\begin{array}{ll}3.4 \text { Characterization } & 49\end{array}$

3.5 Spectroelectrochemical Study $\quad 54$

$\begin{array}{ll}\text { 3.6 Photoluminescent Property } & 57\end{array}$

$\begin{array}{ll}3.7 \text { Conclusion } & 57\end{array}$

$\begin{array}{ll}3.8 \text { Experimental } & 58\end{array}$

$\begin{array}{ll}3.9 \text { References } & 65\end{array}$

$\begin{array}{ll}\text { Future work } & 66\end{array}$

Appendix A

Appendix B $\quad$ V 


\section{List of Tables}

$\begin{array}{lll}\text { Table 2.1. } & \text { Characterizations of the homopolyimides made in salicylic acid } & 29\end{array}$ at $200{ }^{\circ} \mathrm{C}$ within two hours.

Table 2.2. Characterizations of copolyimides made in salicylic acid at $200 \quad 31$ ${ }^{\circ} \mathrm{C}$ within two hours.

Table 3.1. Characterization of the DCH-Ru polyimides synthesized in two- 51 step method.

Table 3.2. Oxidation potentials for the ruthenium complex monomers and 52 polymers

Table 3.3. Attenuation values of complex monomer and polymers.

\section{List of Figures}

Figure 1.1. Generic structure of aromatic polyimides. $\quad 1$

Figure 1.2. Some commercially available polyimides 2

Figure 1.3. Polyimide from PMDA dianhydride and PPD diamine. 3

Figure 1.4. Some of the dianhydrides used for polyimide synthesis 4

Figure 1.5. Some of the diamines used for polyimide synthesis 4

Figure 1.6. Isomeric ODA and APB diamines 5

Figure 1.7. a) Cyclic voltammetric three-electrode system in a glass cell. b) 15 photo of OTTLE cell for spectroelectrochemical analysis.

Figure 1.8. Electrochromism in methyl viologen upon reduction. 16

$\begin{array}{lll}\text { Figure 1.9. Examples of mixed-valence dinuclear metal complexes. } & 18\end{array}$

Figure 1.10. Generic structure of square planar bis-dithiolene complexe, $\quad 19$ where $\mathrm{M}$ is a metal such as $\mathrm{Ni}, \mathrm{Pd}$ and $\mathrm{Pt}$

Figure 1.11. General structure of substituted polythiophenes. 19

Figure 1.12. The structure of poly(pyrrole). 20

Figure 1.13. An example of polyaniline, emeraldine base. 20 
Figure 2.1. a) Flexible film processed directly from the polymerization solution (PI-12 polyimide), b) Fibres drawn directly from the polymerization solution (PI-12 polyimide).

Figure 2.2. Formation of PI-12 in salicylic acid at $200^{\circ} \mathrm{C}$ (a) inherent viscosity taken at 2 hours vs. polymerization concentration (b) inherent viscosity vs. polymerization time at a concentration of $50 \mathrm{wt} / \mathrm{v} \%$.

Figure 2.3. IR spectra of some polyimides synthesized in salicylic acid at $200^{\circ} \mathrm{C}$.

Figure 3.1. Generic structure of dinuclear DCH-Ru complex 45

Figure 3.2. Mass spectrometry spectrum of the DCH-Ru diamine. 47

Figure 3.3. UV/vis/NIR spectra of DCH-Ru diamine a) OTTLE cell and b) 48 crosslinked DCH-Ru diamine in different oxidation states

Figure 3.4. IR spectrum of PRu-III 50

Figure 3.5. Cyclic voltammograms of (a) DCH-Ru diamine and (b) PRu-I 53 from the 6FDA dianhydride and DCH-Ru diamine.

Figure 3.6. UV/vis/NIR spectra of PRu-I in different oxidation states 55

Figure 3.7. Changes in transmittance at $1550 \mathrm{~nm}$ of (a) diamine III and (b) 56 PRu-I

Figure 3.8. PL spectra of (a) DCH-Ru diamine III and (b) PRu-I

\section{List of Schemes}

Scheme 1.1. Two-step synthetic routes to polyimides. 6

Scheme 1.2. Mechanism for the synthesis of polyamic acid. 8

$\begin{array}{lll}\text { Scheme 1.3. Possible imidization pathways. } & 10\end{array}$

Scheme 1.4. General reaction of one step method 11

Scheme 1.5. Nucleophilic displacement polymerization 12

Scheme 1.6. Condensation polymerization BTDA and diisocyanate. 13

Scheme 2.1. One-step synthesis of polyimides in salicylic acid 26 
Scheme 3.1. Synthesis of Ru-complex polyimides by two-step method.

\section{List of abbreviations}

6FDA

$\mathrm{ACN}$

APB

BAPB

BAPF

BEPA

BAPS

BPDA

BTDA

$\mathrm{CV}$

DAP

DDS

DMAc

DMF

DSC

FT-IR

HOMO

ITO

IVCT

LMCT

LUMO

MLCT

MMCT

$\eta_{\mathrm{jnh}}$

NIR
2,2-Bis(3,4-dicarboxyphenyl)hexafluoropropane dianhydride Acetonitrile

Bis(aminophenoxy) benzenes

4,4'-Bis(4-aminophenoxy)biphenyl

9,9-Bis(4-aminophenyl)fluorene

4,4'-(4,4'-Isopropylidenediphenoxy)bis(phthalic anhydride)

Bis[4-(4-aminophenyoxy) phenyl] sulfone

3,3',4,4'-Biphenyltetracarboxylic dianhydride

3,3',4,4'-Benzophenonetetracarboxylic dianhydride

Cyclic voltammetry

Diaminophenol

Diaminodiphenylsulfone

N,N-Dimethylacetamide

N,N-Dimethylformamide

Differential scanning calorimetry

Fourier Transform Infrared

Highest Occupied Molecular Orbital

Tin indium oxide

Intervalence charge transfer

Ligand-to-metal charge transfer

Lowest Unoccupied Molecular Orbital

Metal-to-ligand charge transfer

Metal-to-metal charge transfer

Inherent viscosity

Near-infrared 
NMP

ODA

ODPA

OTTLE

PI

PL

PMDA

PPD

$\mathrm{PRu}$

$\mathrm{T}_{\mathrm{g}}$

$T_{d}$

TBAH

TGA

THF
N-Methylpyrrolidone

Oxydianiline

4,4'-Oxidiphthalic dianhydride

Optically Transparent Thin-Layer Electrochemical

Polyimide

Photoluminescence

Pyromellitic dianhydride

p-Phenylenediamine

Polyimide-Ruthenium

Glass transition temperature

Decomposition temperature

Tetra-n-butylammonium hexafluorophosphate

Thermogravimetric analysis

Tetrahydrofuran 


\section{Chapter 1. Introduction}

\section{$1.1 \quad$ Background}

Polyimides are a class of high-performance polymers that have many outstanding characteristics such as low dielectric constant, excellent mechanical strength, high thermal stability and chemical resistance [1-3]. These polymers can also retain their exceptional properties for a long period of time even upon the exposure to harsh conditions such as high temperature. The following is a generic structure of aromatic polyimides.

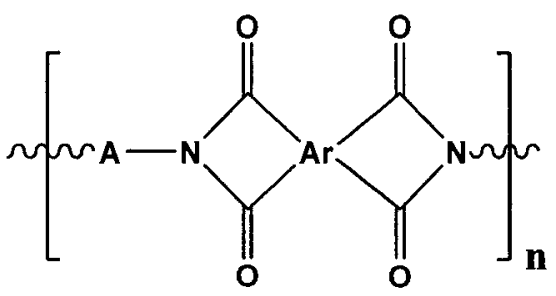

Figure 1.1. Generic structure of aromatic polyimides.

The earliest research on polyimides was carried out in the I.E. DuPont de Nemours and Company Inc. in 1965 by Sroog et al. to obtain the first high molecular weight aromatic polyimide [4]. The polypyromellitimides were prepared from the condensation reaction of pyromellitic dianhydride (PMDA) with various aromatic diamines in N,N-dimethylacetamide (DMAc) as a solvent to form the soluble polyamic acid and then convert it to insoluble polyimides. This new discovery initiated the development of polyimides and led to the preparation of many commercially available polyimides such as Kapton, Ultem, LaRC-TPI/NASA Langley, etc (Figure 1.2). During this period of invention, DuPont published a few patents in 1955 [5] and 1959 [6-8], disclosing new structural polyimides and crystalline polyimides. These new polyimides 
have been accompanied by many new applications in the many areas such as electronics (1-3), foams, fibres, coating and composites [3].

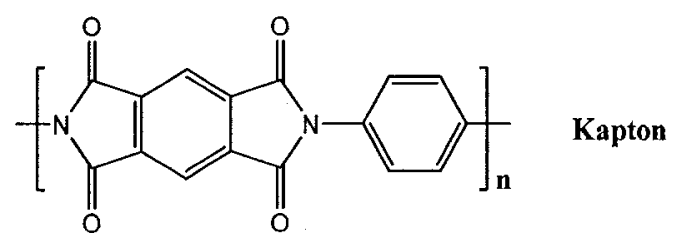<smiles>Cc1cccc(N2C(=O)c3ccc(Oc4ccc(C(C)(C)c5ccc(Oc6ccc7c(c6)C(=O)N(C)C7=O)cc5)cc4)cc3C2=O)c1</smiles><smiles>CN1C(=O)c2ccc(C(=O)c3ccc4c(c3)C(=O)N(c3cccc(C(=O)c5cccc(C(C)(C)C)c5)c3)C4=O)cc2C1=O</smiles><smiles>CCCCN1C(=O)C2C3C=CC(C3)C2C(=O)N1c1ccc(Cc2ccc(N3C(=O)c4ccc(C(=O)c5ccc6c7ccc(N8C(=O)C8C8C=CC9CC(=O)C98)ccc(=O)n(c(=O)c6c5)-c5ccc(cc5)C7)cc4C3=O)cc2)cc1</smiles>

Figure 1.2. Some commercially available polyimides.

\subsection{Polyimides in general}

The high molecular weight polyimides prepared by Sroog in 1965 were not processable due to their insolubility and meltability [4]. Therefore, they were synthesized via a two-step method by forming the polyamic acid precursor first and then casting into films. The insolubility of the resultant polyimide is due to high rigidity of the polyimide backbone leading to strong $\pi$-acid/ $\pi$-base interaction between the electron deficient dianhydride and electron rich phenyl rings in diamine within the polyimide backbone (Figure 1.3). 


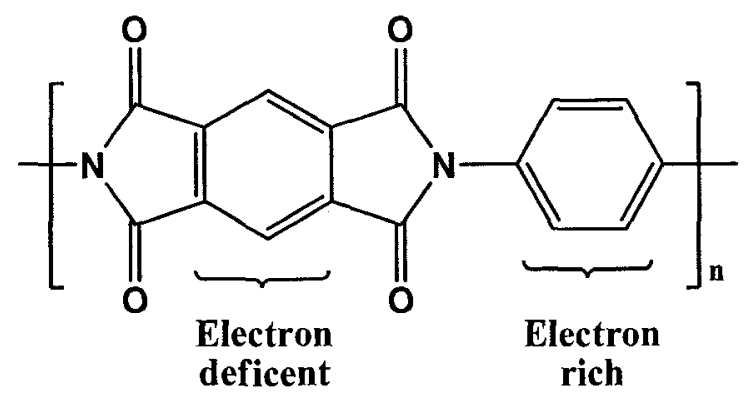

Figure 1.3. Polyimide from PMDA dianhydride and PPD diamine.

The research on polyimides has focused mainly on the structural modification to improve their solubility and processability while maintaining their thermal and mechanical properties. Introducing a kink, ortho or meta catenation, in the diamine and the dianhydride can decrease the chain-chain interaction and improve the flexibility, solubility and processability [1,2,9]. Para catenation results in the least soluble polyimides, hence less linear polymers are more soluble. The electron-withdrawing units in the diamine and electron-donating units in the dianhydride tend to decrease their Lewis-base and Lewis-acid characters, respectively. The more electrophilic the dianhydride, the more susceptible it is to the nucleophilic attack. Breaking the conjugation of the aromatic rings makes the polymer chain more flexible while still retains their thermal and mechanical properties. Examples of commercially available dianhydrides and diamines are shown below in figures 1.4 and 1.5 , respectively. 
<smiles>O=C1OC(=O)c2cc(C(c3ccc4c(c3)C(=O)OC4=O)(C(F)(F)F)C(F)(F)F)ccc21</smiles><smiles>O=C1OC(=O)c2cc(-c3ccc4c(c3)C(=O)OC4=O)ccc21</smiles><smiles>O=C1OC(=O)c2cc(S(=O)(=O)c3ccc4c(c3)C(=O)OC4=O)ccc21</smiles><smiles>CCCCOc1ccc2c(c1)C(=O)OC2=O</smiles><smiles>O=C(c1ccc2c(c1)C(=O)OC2=O)c1ccc2c(c1)C(=O)OC2=O</smiles>

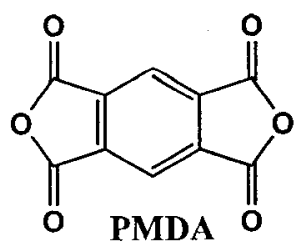

Figure 1.4. Some of the dianhydrides used for polyimide synthesis<smiles>Nc1ccc(Oc2ccc(N)cc2)cc1</smiles>

ODA<smiles>Nc1ccc(S(=O)(=O)c2ccc(N)cc2)cc1</smiles>

4,4-DDS<smiles>Nc1ccc(Cc2ccc(N)cc2)cc1</smiles>

MDA

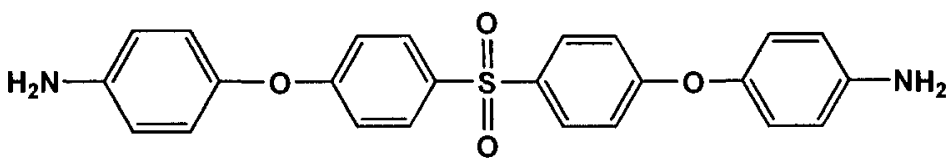

BAPS<smiles>Nc1ccc(Oc2ccc(-c3ccc(Oc4ccc(N)cc4)cc3)cc2)cc1</smiles>

BAPB

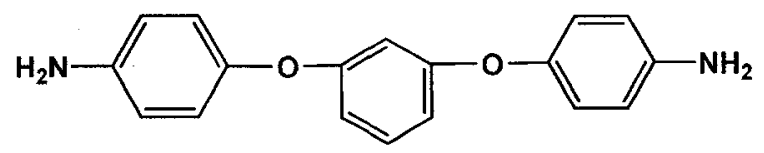

TPE-R

Figure 1.5. Some of the diamines used for polyimide synthesis

The use of isomeric monomers also leads to improved solubility and morphological change while maintaining their mechanical and thermal properties. Isomers of the monomers play an important role in the control of the planarity and flexibility of the resultant polyimides. For example, St. Clair and St. Clair treated 6FDA and ODPA with different isomeric oxydianilines (ODA) and bis(aminophenoxy) benzenes (APB) (Figure 1.6) to yield soluble polyimides and compared their solublities 
in different common organic solvents [10]. They have found out that meta catenation on the outer ring of $\mathrm{APB}(1,3(3)$-APB and 1,3(4)-APB) are more soluble than the para catenation $(1,4(4)-\mathrm{APB}$ and $1,4(3)-\mathrm{APB})[10]$, hence indicating that the overall chain flexibility contributes to the solubility.<smiles>Nc1ccc(Oc2ccc(N)cc2)cc1</smiles><smiles>Nc1cccc(Oc2cccc(N)c2)c1</smiles><smiles>Nc1ccc(Oc2cccc(N)c2)cc1</smiles><smiles>Nc1ccc(Oc2ccccc2N)cc1</smiles><smiles>Nc1cccc(Oc2cccc(Oc3cccc(N)c3)c2)c1</smiles><smiles>Nc1cccc(Oc2ccc(Oc3cccc(N)c3)cc2)c1</smiles><smiles>Nc1ccc(Oc2cccc(Oc3ccc(N)cc3)c2)cc1</smiles>

1,3(4)-APB

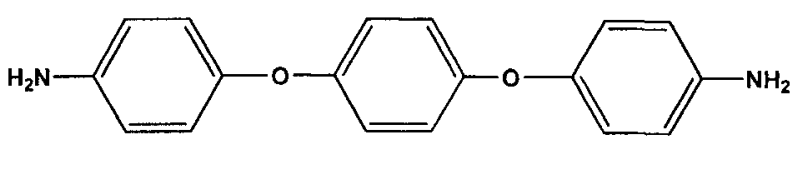

1,4(4)-APB

Figure 1.6. Isomeric ODA and APB diamines

Another approach is the addition of pendant groups to the backbone, which will decrease the chain packing and chain-chain interaction due to the increase in the steric repulsion. For example, the addition of a polar or non-polar pendant group makes the polyimide more soluble in non-polar or polar solvents respectively [11]. Therefore, the polyimides solubility will increase while maintaining the high thermal properties and rigidity of the polymer backbone. 
Copolymerization is another way of modifying the polymer structure. Basically, interruption in the repeating regularity can reduce the chain-chain interaction and crystallinity of the polymer and maintain the rigidity of the polymer. For instance, to maintain the rigidity of the polyimides from PMDA, a second dianhydride is introduced in a small ratio to make a soluble copolyimide while retaining the original properties [12].

1.3 Synthetic methods of polyimides

\subsubsection{Two-step polymerization method}

Most polyimides possess the rigid, planar aromatic and heteroaromatic structure, that can impart insolubility and infusibility to the polyimides. Thus, to solve this problem a soluble precursor, polyamic acid, is made to be processable and then converted to polyimide. In this method, the dianhydride reacts with the diamine in a polar aprotic solvent such as N,N-dimethylformamide (DMF), DMAc and N-methylpyrrolidone (NMP) at room temperature to form the polyamic acid (Scheme 1.1) $[1-4,13]$. The resulted polyamic acid is then converted to cyclized polyimide by dehydration at high temperatures (above $300^{\circ} \mathrm{C}$ ) or using a chemical dehydrating agent.

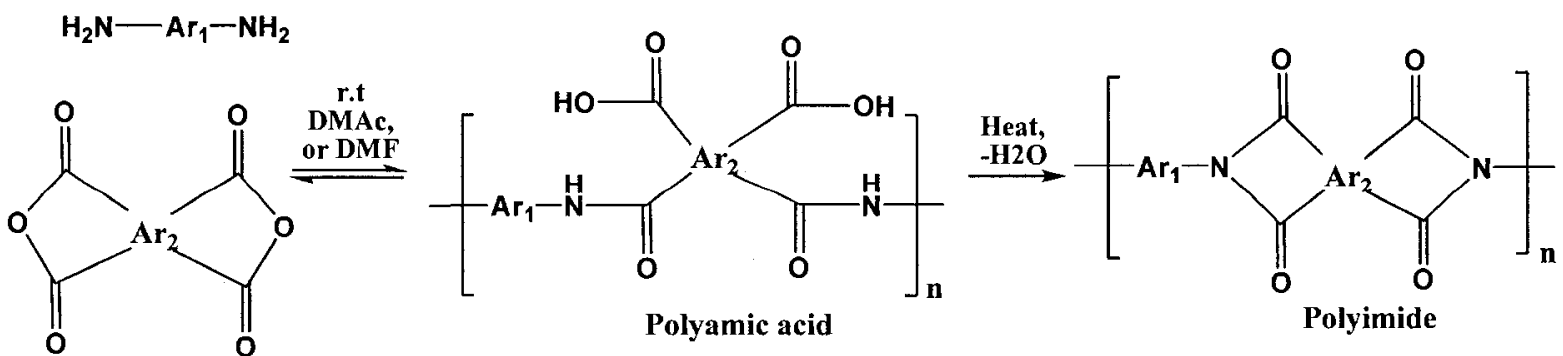

Scheme 1.1. Two-step synthetic routes to polyimides. 
The mechanism for this reaction involves the formation of the charge transfer complex between the dianhydride and the diamine followed by nucleophilic substitution at one of the anhydride's carbonyl carbon atoms $[1,14]$. Thus, the amine nucleophile attacks the $\mathrm{sp}^{2}$ carbon and displaces the adjacent carboxylate moiety where the byproduct is chemically attached to the product. When using polar aprotic solvent, it forms strong hydrogen bond with the carboxyl groups, thus hinders the reverse acylation by preventing the transfer of the carboxyl proton to the adjacent carboamide group. The reaction is exothermic at room temperature and the amount of heat depends on the solvent basicity [1]. Thus, the equilibrium is shifted to the left and molecular weight decreases when temperature is increased. To obtain high molecular weight product, lower temperature is required to shift the reaction to the right. The rate of the reaction is dependent on the solvent and increases as the solvent becomes more polar and basic. For example, it was observed that THF $<$ acetonitrile $<$ DMAc $<$ m-cresol based on their polarity and basicity $[1,15]$. It is also important to note that the reaction appears to be irreversible due to quick formation of high molecular weight polyamic acid. This is clearly due to the faster forward reaction than the reverse one. The acylation reaction of amines in an exothermic reaction and the equilibrium is favoured at lower temperature. Thus, the equilibrium is favoured at high monomer concentrations to form high molecular weight polymer. 

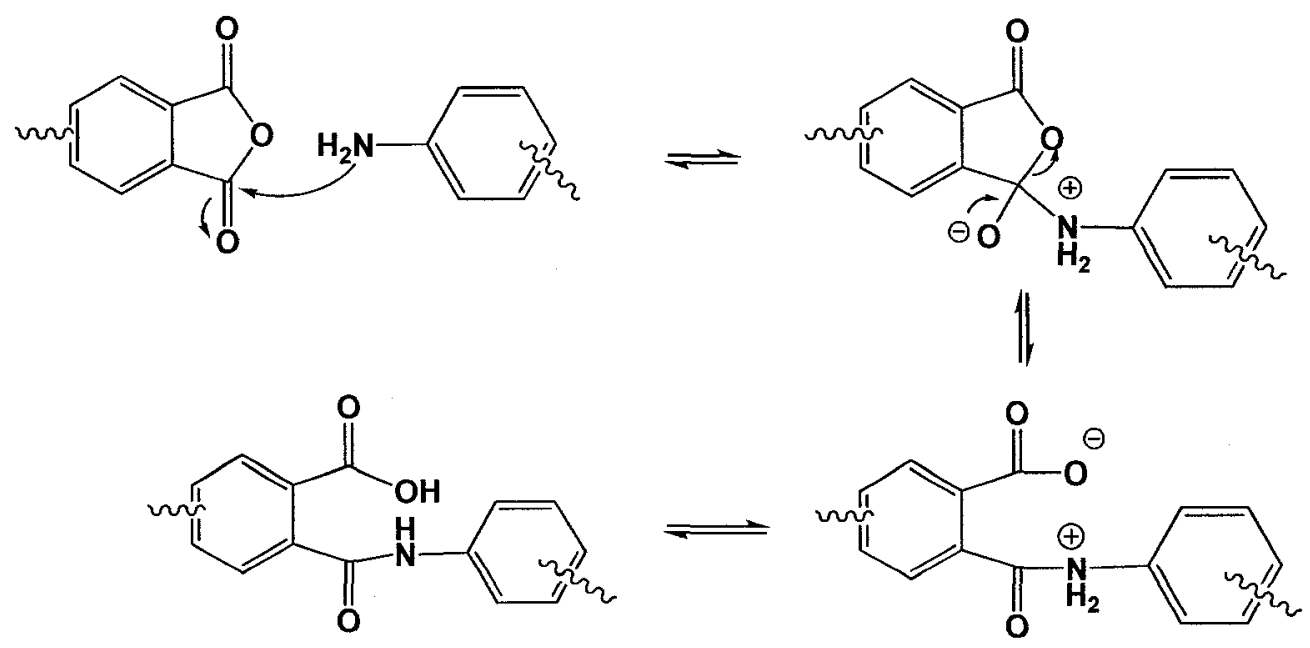

Scheme 1.2. Mechanism for the synthesis of polyamic acid.

From the above mechanism it is clear that the reaction rate depends on the electrophilicity of the carbonyl group of the dianhydride and the nucleophilicity of the amino nitrogen of the diamine. The phthalic anhydride group is a strong electron acceptor, thus a strong Lewis acid. From this conclusion, PMDA is the most reactive and has a high tendency to accept an electron. Because of the strong electron accepting property of the dianhydride and high electron density of the amino group in the diamine, the charge transfer interaction and electrostatic interaction between the dianhydride and diamine contribute to the reactivity $[1,2,9]$.

The molecular weight of the polyamic acid made by this method was influenced by several factors. For instance, higher molecular weight was obtained when using higher concentration of monomers due to the decrease of the solvent impurities that would interfere with the increase of the molecular weight and increase the opportunities for transimidisation reactions between the polyamic acid and the solvent [16]. It was also found out that the molecular weight was influenced by the order of the monomer addition 
when adding the dianhydride to solution of diamines [15]. This is due to the fact that aromatic dianhydrides react with water and other impurities. But since reacting with the diamine is faster, the competition was reduced by adding the solid dianhydride to diamine solution. Another factor is temperature, which was found to be best between -20 and 70 ${ }^{\circ} \mathrm{C}[1,4]$.

The second step to convert the polyamic acid to polyimide involves heating the polyamic acid in the solid state between $250-400{ }^{\circ} \mathrm{C}$. The degree of imidization is usually monitored by IR spectroscopy, typically for the bands used at $1780 \mathrm{~cm}^{-1}$ (unsymmetrical $\mathrm{C}=\mathrm{O}$ stretch), $1720 \mathrm{~cm}^{-1}$ (symmetrical $\mathrm{C}=\mathrm{O}$ stretch), $1380 \mathrm{~cm}^{-1}\left(\mathrm{C}-\mathrm{N}\right.$ stretch) and $725 \mathrm{~cm}^{-1}$ (C-N-C of imide). There are two possible pathways for the imidization process, which differ in the time of losing the proton attached to the nitrogen (Scheme 1.3) [1]. In the first pathway, the proton is lost after cyclization while in the second it is lost prior to cyclization. 
a)

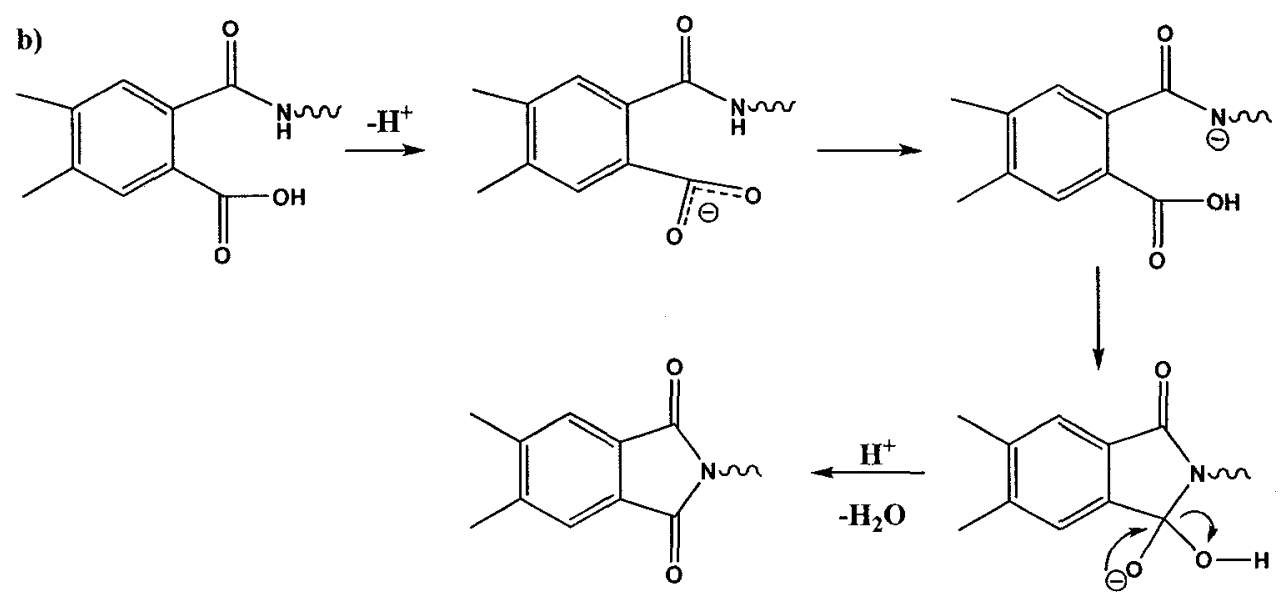

Scheme 1.3. Possible imidization pathways

This step proceeds faster in amide solvents because the solvent molecules allow the reacting species to reach favourable conformation of the cyclization and help in removing the proton [17]. In other words, the amide solvent forms strong hydrogen bond complex with the carboxyl groups. Thus, the transfer of the proton to the basic solvent under the imidization conditions would be easier. In the absence of solvent, ring closure may proceed via the attack of the neutral amide on the undissociated acid. Imidization proceeds faster in solution than in the solid state. For example, thicker films cure to a higher degree of imidization than thinner films due to the entrapped solvent. Imidization can also occur chemically at room temperature when treated with acetic anhydride and triethylamine or pyridine. In this case, the degree of polymerization depends on the solubility of the polyimide formed. 


\subsubsection{One-step polymerization method}

This method uses phenolic solvents such as m-cresol, p-chlorophenol and nitrobenzene at high temperature in the presence of a tertiary amine catalyst such as isoquinoline [2]. It has the advantage of synthesizing polyimides directly in one-step from the diamines and dianhydrides and polymerizing unreactive monomers due to steric hindrance. Using this method, soluble polyimides are usually prepared. The chain growth and imidization occur spontaneously and the water generated is removed from the reaction mixture $[1,2]$. The polyamic acid is not detected by IR, indicating that the polymerization proceeds via simultaneous imidization with propagation (Scheme 1.4).

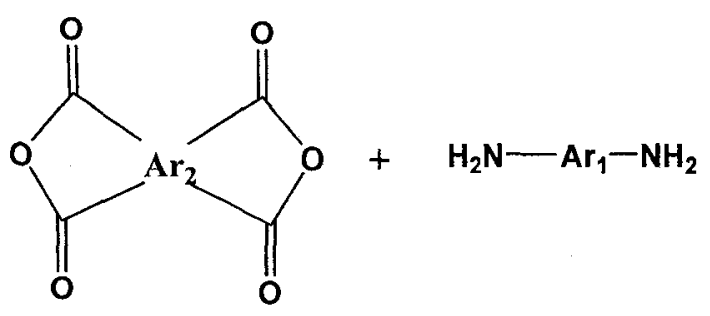

Scheme 1.4

\subsubsection{Other synthetic methods}

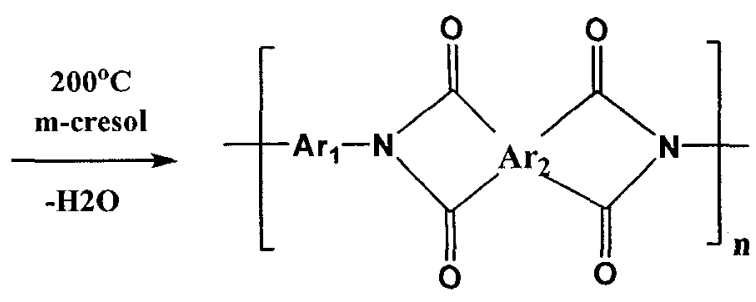

Polyimide

Polyimides can also be synthesized by nucleophilic displacement polymerization of a bis-nitrophthalimide with a phenoxide salt (Scheme 1.5). The bis-nitrophthalimide is prepared from a functionalized diamine [18]. This method is limited to the synthesis of poly(ether imide)s. The disadvantage of this method is due to the fact that sodium or potassium nitrate produced in this reaction decomposes the imide functionalities at high temperature. Thus, careful control of the temperature is necessary to ensure the formation of the final product. 
<smiles>[R2]c1ccc(Oc2ccc3c(c2)C(=O)N([R7]N2C(=O)c4ccc(C(C)(C)C)cc4C2=O)C3=O)cc1</smiles>

Scheme 1.5. Nucleophilic displacement polymerization

Another method is condensation of a dianhydride with a diisocyanate in the presence of a tertiary amine as a catalyst in a dipolar solvent $[17,19]$. High molecular weights are obtained only when part of the dianhydride is hydrolyzed by the addition of a controlled amount of water before addition of the diamine. Using this method, Ghatage and Mulik synthesized soluble polyimides with moderate molecular weights from BTDA and various 4,4'-diisocyanatodiphenylalkanes in DMAc (Scheme 1.6) [18]. 


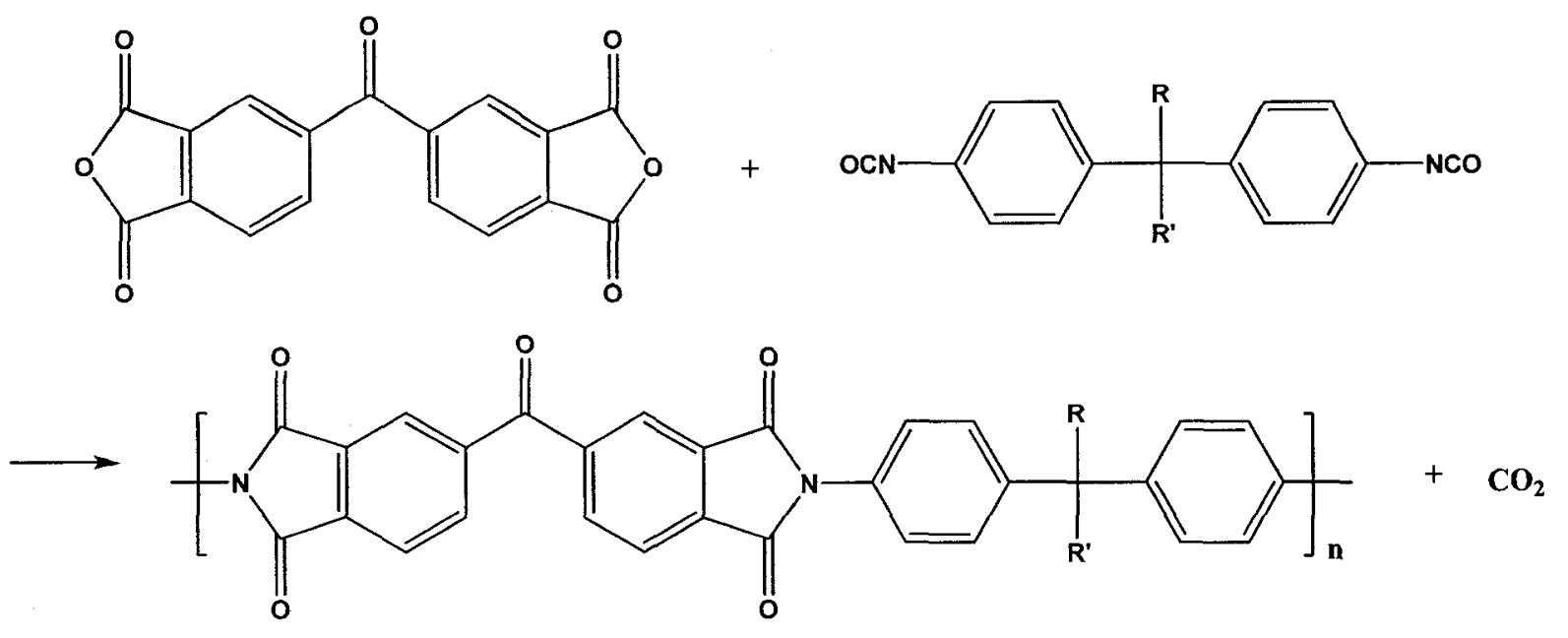

Scheme 1.6. Condensation polymerization BTDA and diisocyanate.

\subsection{Near-Infrared (NIR) and Electrochromic Materials}

\subsubsection{Electrochromism}

Electrochromism is phenomenon of reversible coloration exhibited by an electroactive species due to an electron transfer or redox reaction where it either loses or gains an electron, thus goes under oxidation or reduction when potential is applied. The term "electrochromism" was first mentioned in 1961 by Platt, indicating color generated via a molecular Stark effect where the orbital energies are shifted by an electric field [20]. However, electrochromic phenomenon was observed very early in time. In 1815, Berzelius showed that pure tungsten trioxide $\left(\mathrm{WO}_{3}\right)$ changes color from pale yellow when warmed under a flow of dry hydrogen gas due to the reduction [21]. In 1842, Herschel established a new method by generating Prussian blue $\mathrm{KFe}^{\mathrm{III}}\left[\mathrm{Fe}^{\mathrm{II}}(\mathrm{CN})_{6}\right](\mathrm{s})$ from mist paper pre-impregnated with ferric ammonium citrate and potassium ferricyanide, forming yellow Prussian brown $\mathrm{Fe}^{3+}\left[\mathrm{Fe}(\mathrm{CN})_{6}\right]^{3-}$ or $\mathrm{Fe}^{\mathrm{III}}\left[\mathrm{Fe}^{\mathrm{III}}(\mathrm{CN})_{6}\right][20]$.

$$
\mathrm{Fe}^{3+}\left[\mathrm{Fe}^{\mathrm{lll}}(\mathrm{CN})_{6}\right]^{3-}(\mathrm{s})+\mathrm{K}^{+}(\mathrm{aq})+\mathrm{e}^{-}(h v) \rightarrow \mathrm{KFe}^{\mathrm{III}}\left[\mathrm{Fe}^{\mathrm{Il}}(\mathrm{CN})_{6}\right](\mathrm{s})
$$


In 1843, Bain patented a primitive form of fax transmission that again relied on the generation of a Prussian blue compound [21]. In 1930, Kobosew and Nekrassow recorded color change of $\mathrm{WO}_{3}$ solid when electrochemically reduced [22].

$$
\mathrm{WO}_{3}(\mathrm{~s})+x\left(\mathrm{H}^{+}+\mathrm{e}^{-}\right) \rightarrow \mathrm{H}_{x} \mathrm{WO}_{3}(\mathrm{~s})
$$

In 1942, Talmay had a patent for electrochromic printing and called it electrolytic writing paper [23]. Paper was impregnated with particulate $\mathrm{MoO}_{3}$ and/or $\mathrm{WO}_{3}$ forming a blue-grey image following electron transfer reaction. In 1971, when applying electricity to opposing faces of doped, crystalline $\mathrm{SrTiO}_{3}$, Blanc and Staebler observed electrochromic color moving into the crystal from the two electrodes [24]. In 1975, Faughnan et al. reported $\mathrm{WO}_{3}$ undergoing reversible electrochromic color changes while immersed in aqueous sulfuric acid [25]. In 1978, Mohapatra of the Bell Laboratories published the first description of the reversible electro-insertion of lithium ion to tungsten trioxide $\mathrm{WO}_{3}[26]$.

$$
\mathrm{WO}_{3}(\mathrm{~s})+x\left(\mathrm{Li}^{+}(\mathrm{aq})+\mathrm{e}^{-}\right) \rightarrow \mathrm{Li}_{x} \mathrm{WO}_{3}(\mathrm{~s})
$$

Electrochromic effects are also found in organic and polymeric materials. In 1979, Diaz et al. announced the electro synthesis of poly(pyrrole) thin-film, which is considered the first account of electrochromic conducting polymer [27]. In 1980, Grant studied the reversible electrochromism of methoxy-substituted fluorene which gives an intense color upon oxidation [28]. In 2008, Qiao et al. developed a new NIR electrochromic anthraquinone imides acquiring reversible electrochromic behaviour upon reduction and absorb in the range of $700-1600 \mathrm{~nm}$ [29]. The details of electrochromic switch experiments mentioned above are beyond the requirements of this thesis. 
Electrochromic materials are usually examined in solution by cyclic voltammetry (CV) and in-situ spectroelectrochemical analysis. In a CV experiment, the material is usually dissolved in an electrolyte solution or coated on the working electrode in a threeelectrode system, having a working electrode (Pt or $\mathrm{Au}$ ), counter electrode (Pt) and reference electrode $\left(\mathrm{Ag}^{+}\right)$(Figure 1.7). In-situ spectroelectrochemical analysis is done on an optical transparent thin layer electrochemical or OTTLE cell. In the former case, the film is inserted in cuvette containing an electrolyte solution while the latter in solution.

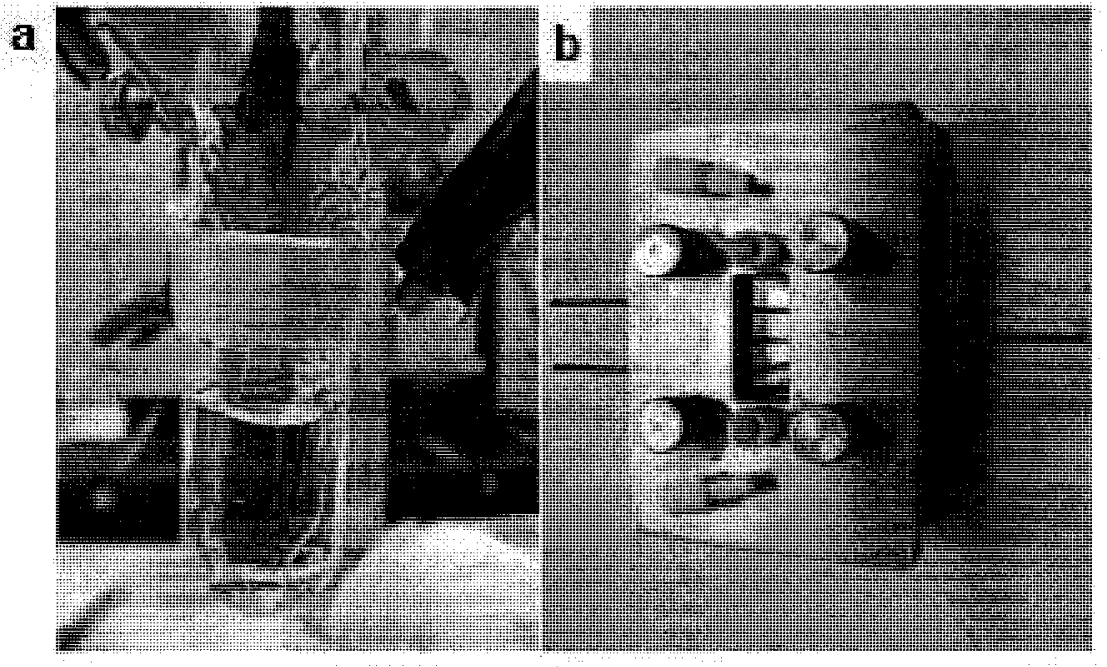

Figure 1.7. a) Cyclic voltammetric three-electrode system in a glass cell. b) photo of OTTLE cell for spectroelectrochemical analysis.

To measure the stability and efficiency of the electrochromic switching, repeated square wave potential steps are applied across one redox couple. Thus, if the material is unstable upon redox switching the current amplitude will decrease over time. 


\subsubsection{Types of Electrochromic Materials}

Three types of electrochromes are classified based on the phases present initially and hence formed electrochemically, which indicates the form of the current-time relationship during the coloration [30].

Type I: Electrochrome is soluble and remains soluble in solution during the electrochromic usage. The electrochemical electron-transfer reaction occurs at the solidliquid interface. During this process, the electroactive species in solution encounters the solid electrode, undergoes the electron transfer reaction, cathodic reduction or anodic oxidation, then it moves away from the electrode in the new form returning to the solution. For example, methyl viologen (MV) can become intensely colored on reduction [20] (Figure 1.8, X can be any halide or complex anion such as $\mathrm{BF}_{4}$ ).

$$
\mathrm{MV}^{2+}(\mathrm{aq})+\mathrm{e}^{-} \rightarrow \mathrm{MV}^{+\cdot}(\mathrm{aq})
$$

Colorless intense blue

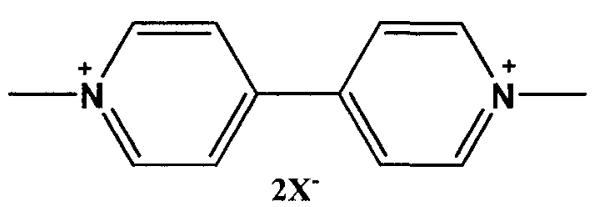

Figure 1.8. Electrochromism in methyl viologen upon reduction.

Type II: Electrochromes are soluble in their colorless forms but form a colored solid on the surface of the electrode following electron transfer. An example is heptyl viologen (HV) in water [31]. This is in fact a two-step process involving an electron transfer and a subsequent precipitation of the colored radical salt on reduction.

$$
\begin{gathered}
\mathrm{HV}^{2+}(\mathrm{aq})+\mathrm{e}^{-}+\mathrm{Br}^{-}(\mathrm{aq}) \rightarrow\left(\mathrm{HV}^{+} \cdot\right) \mathrm{Br}^{-}(\text {solid }) \\
\text { Pale Yellow }
\end{gathered}
$$


Type III: Electrochromes remain solid all the times. An example of this type is metal oxides or Prussian blue where electrogenerated color appears as a consequence of an optical charge-transfer transition between the metal centres in the solid lattice (M is metal such as Mo, Ni or W).

$$
\begin{array}{ll}
\mathrm{MO}_{\mathrm{y}}(\mathrm{s})+x\left(\mathrm{H}^{+}(\mathrm{soln})+\mathrm{e}^{-}\right) & \rightarrow \mathrm{H}_{\mathrm{x}} \mathrm{MO}_{\mathrm{y}}(\mathrm{s}) \\
\text { colorless } & \text { intense color }
\end{array}
$$

In all the above mentioned electrochromic materials, oxidation of solid films is accompanied by anion incorporation from the surrounding electrolyte or cation expulsion from the film, while reduction involves cation incorporation or anion expulsion.

Electrochromic materials have widespread applications in light attenuation, displays and analysis. They are also divided on the basis of the coloring mode as either cathodic or anodic where the anodic material switches upon the oxidation and cathodic material switches upon reduction. Electrochromic materials are being studied in conducting polymers, transition metal oxides, and metal-containing polymers for the applications such as Smart windows, night vision safety mirrors and NIR attenuators for fiber-optic communication.

\subsubsection{NIR Electrochromic Materials}

Electrochromism in the visible region of the spectrum is of interest for use in display devices and windows. Electrochromism in the near-infrared (NIR) region (800$2000 \mathrm{~nm}$ ) is an area which has attracted interest because of the significant technological importance of this region of the spectrum. NIR radiation has been used in various 
applications such as in telecommunications for optical signal transmission in 1300-1550 $\mathrm{nm}$ [20] and in medicine for photodynamic therapy of living tissues around $800 \mathrm{~nm}$ [32]. It can also be used in smart windows to reflect the radiant heat [33].

A known class of metal complexes showing NIR electrochromism is a series of dinuclear mixed-valence ruthenium complexes, in which the strong electronic coupling between the metal centres makes a stable $\mathrm{Ru}^{\mathrm{II}}-\mathrm{R} \mathrm{U}^{\mathrm{III}}$ mixed valence state possible. These complexes are interesting because the IVCT transition provides quantitative information on the magnitude of the electronic coupling between the metal centres. However, the position and intensity in some cases indicates that these complexes can be used for optical applications. These facts are not limited to ruthenium complexes although they are the most known due to their significant electrochemical properties. Examples of the mixed-valence dinuclear complexes are shown in Figure 1.9 [34-37].

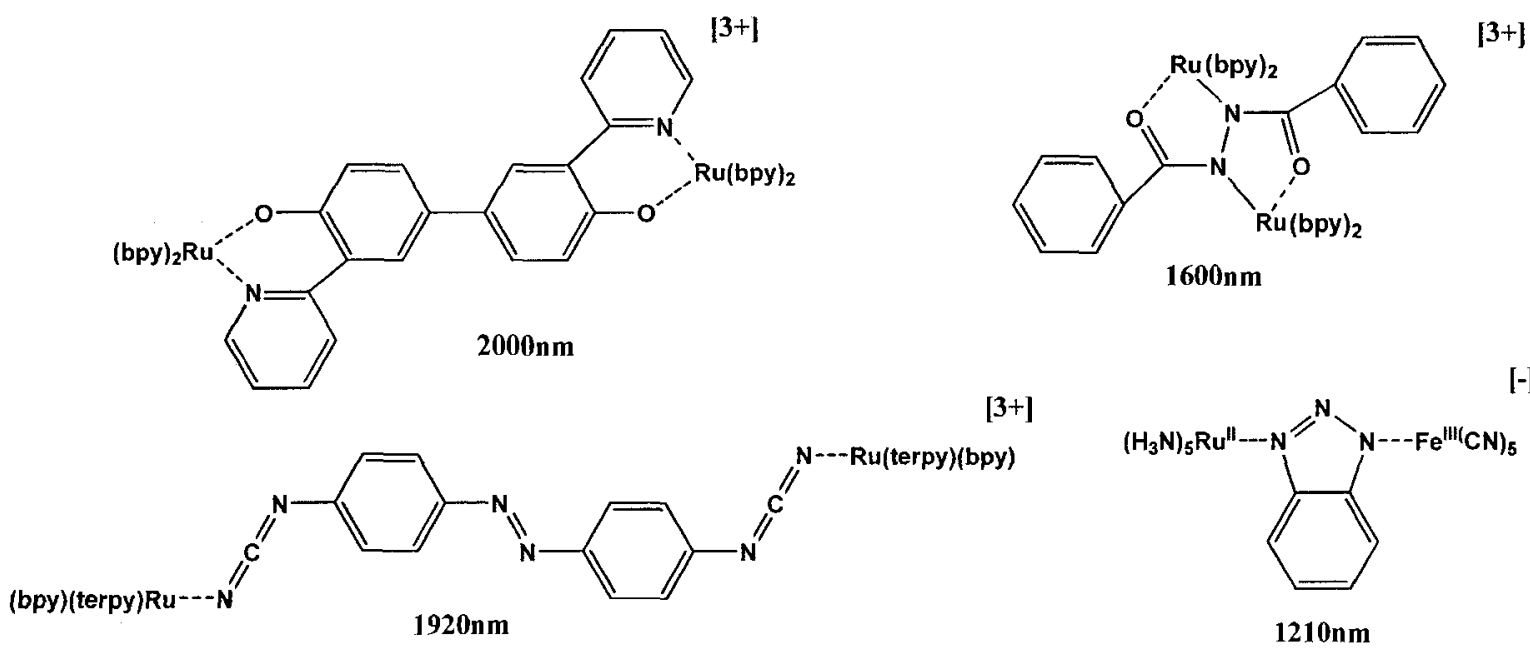

Figure 1.9. Examples of mixed-valence dinuclear metal complexes

Metal complexes show a strong redox-dependent NIR absorption in the well studied set of square planar bis-dithiolene complexes of Ni, Pd and Pt ( Figure 1.10) [38]. 
These examples have reversible redox processes connecting the neutral monoanionic and dianionic species. The positions of the NIR absorptions are highly sensitive to the substituents on the dithiolene ligands with a maximum wavelength up to $1400 \mathrm{~nm}$. The main application for the strong NIR absorbing dyes is to induce Q-switching of NIR laser such as ND-YAG (1064nm) due to their high thermal and photochemical stabilities.

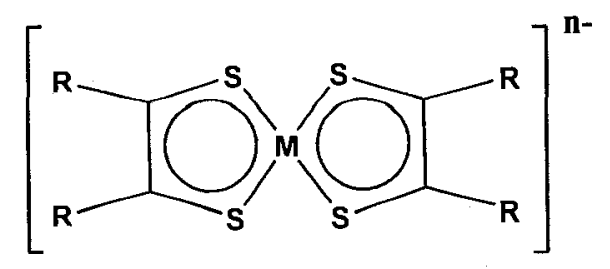

Figure 1.10. Generic structure of square planar bis-dithiolene complexes, where $\mathrm{M}$ is a metal such as $\mathrm{Ni}, \mathrm{Pd}$ and $\mathrm{Pt}$

Conjugated conducting polymers such as polyaniline, polythiophene and polypyrrole are also reported as electrochromic materials. Substituted polythiophenes have attracted interest due to their simple chemical and electrochemical synthesis, stability and processability [39]. The substitution on 3-position of the thiophene ring increases the polymer conjugation length and the electronic conductivity (Figure 1.11). The color in these polymers depends on the R group and linearity of the chain.

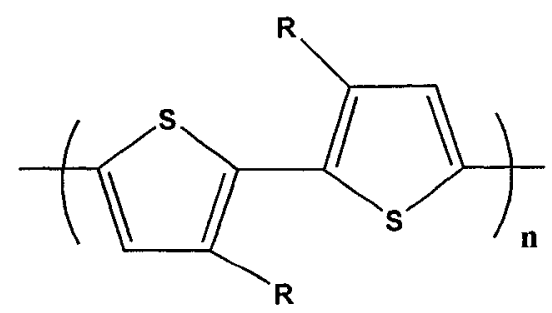

Figure 1.11. General structure of substituted polythiophenes. 
Poly(pyrrole)s (Figure 1.12) have also been studied for their electrochromic properties and can be easily synthesized. They have a lower oxidation potential than polythiophenes [40].

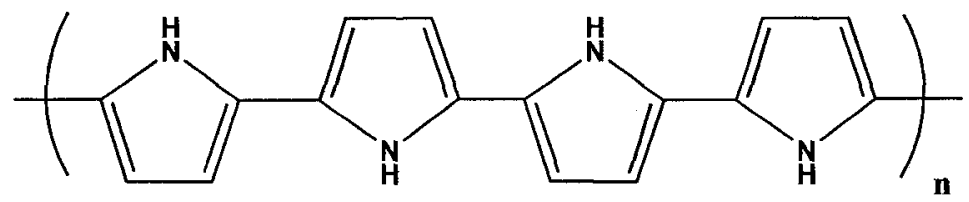

Figure 1.12. The structure of poly(pyrrole).

Polyanilines exhibit electrochromism and are generally prepared from aqueous solution of aniline. Polyaniline in the emeraldine base form is electrically conductive (Figure 1.13). Polyaniline films are electrochromic and show reversible color changes as the potential varies.<smiles>CC(C)(C)N=C1C=CC(=Nc2ccc(Nc3ccc(Nc4ccc(C(C)(C)C)cc4)cc3)cc2)C=C1</smiles>

Figure 1.13. An example of polyaniline, emeraldine base. 


\subsection{References}

1. Wilson D, Stenzenberger HD, Hergenrother PM. Polyimides. Glasgow: Blackie and Son; 1990.

2. Harris FW, Norris SO, Lanier LH, Reinfardt BA, Case RD, Varaprath S, Padaki SM, Torres M, Feld WA. Polyimides: Synthesis, Characterization and applications 1984; Vol 1\&2 Ed. Mittal KL. Plenum, New York

3. Sroog CE. Prog. Polym. Sci. 1991; 16: 561.

4. Sroog CE, Endrey AL, Abramo SV, Berr CE, Edwards WM, and Olivier KL. J. Polym. Sci. Part A 1965; 3:1373

5. Edwards WM, Robinson IM. US Patent 2,170,853 (1955)

6. Edwards WM, Robinson IM. US Patent 2,880,230 (1959)

7. Edwards WM, Robinson IM. US Patent 2,867,609 (1959)

8. Edwards WM, Robinson IM. US Patent 2,900,369 (1959)

9. Cassidy PE. J. Macromol. Sci. Part C, Polym Rev. 1994; C34: 1

10. St. Clair AK, St. Clair TL. Polymers for High Technology, eds. Bowden MJ and Turner SR., American Chemical Society Symposium Series No. 437, 1987

11. Imai Y, Koga H. J. Polym. Sci. A. Polym. Chem. 1973; 11: 2623

12. Rhee SB, Park JW, Moon BS, Chang JY. Macromolecules 1993; $26: 404$

13. Ghosh MK, Mittal KL. Polyimides Fundamentals and Applications. New York, Marcel Dekker Inc. 1996

14. Svetlichnyi VM, Kalnin'sh KK, Kudryavtsev VV, Koton MM. Dokl. Akad. Nauuk SSSR 1972; 204(4): 473 
15. Solomin VA, Karash IE, Snagovskii YS, Messerle, Zhubanov BA, Pravednik AN. Dokl. Akad. Nauk SSSR 1977; 236(1): 510

16. Dine-Hart RA, Wright WW. J. Appl. Polym. Sci. 1967; 11:609

17. Kreuz JA, Endrey AL, Gay FP, Sroog CE. J. Polym. Sci. 1966; A-1,4: 2607

18. Takekoshi T, Kochanowski JE, Manello JS, Webber MJ. J. Polym. Sci. Polym. Chem. 1985; 23: 1759

19. Ghatge ND, Mulik UP. J. of Poly. Sci., Polym. Chem. Ed. 1980; 18:1905

20. Platt JR. J. of Chem. Phy. 1961; 34: 862

21. Monk PMS, Mortimer RJ and Rossenisky DR. Electrochromism and Electrochromic Devices. Cambridge University press; 2007

22. Kobosew N, Nekrassow NIZ. Electrochem. 1930; 36:529, as cited in ref 21.

23. Talmay P. US Patent 2,281,013 (1942)

24. Blanc J, Staebler DL. Phys. Rev. 1971; B4: 3548-57, as cited in ref 21.

25. Faughnan BW, Crandall RS, Heyman PM. RCA Rev. 1975; 36:177

26. Mohapatra S. K. J. Electrochem. Soc. 1978; 125(2): 284

27. Kanazawa KK, Diaz AF, Geiss RH, Gill WD, Kwak JF, Logan JA, Rabolt JF, Street GB. J. Chem. Commun. 1979; 19: 854

28. Grant B, Clecak NJ, Oxsen M. J. Org. Chem. 1980; 45: 702

29. Qiao W, Zheng J, Wang Y, Zheng Y, Song N, Wan X, Wang ZY. Org. Lett. $2008 ; 10(4): 641$

30. Chang IF, Gilbert BL, Sun TI. J. Electrochem. Soc 1975; 122(7): 955

31. Fletcher S, Duff L, Barradas RG. J. Electroanal. Chem. Inter. Electrochem. 1979; 100: 759 
32. Bonnett R. Comprehensive Coordination Chemistry II 2004; 9: 945-1003, as referenced in 21

33. Nazeeruddin MK, Graetzel M. Comprehensive Coordination Chemistry II 2004; 9: 719 , as referenced in 21

34. Laye RH, Couchman SM and Ward MD. Inorg. Chem. 2001; 40(16): 4089

35. Rastegar MF, Todd EK, Tang H and Wang ZY. Org Let. 2004; 6(24): 4519

36. Rocha RC, Toma HE. Can. J. Chem. 2001; 79(2): 145

37. Mosher PJ, Yap GPA, Crutchley RJ. Inorgan. Chem. 2001; 40(6): 1189

38. McCleverty JA. Prog. Inorg. Chem. 1968; 10: 49-221, as cited in reference 21

39. Barbarella G, Melucci M and Sotgiu G. Adv. Mater. 2005; 17(13): 1581

40. Diaz AF, Castillo JI, Logan JA and Lee WY. J. of Electroanal. Chem. Inter. Electrochem. 1981; 129(1-2): 115

41. Monk PMS, Mortimer RJ, Rosseinsky DR. Electrochromism: Fundamentals and Applications. Weinheim; 1995 


\section{Chapter 2. New One-step Synthesis of Polyimides in Salicylic Acid}

\subsection{Rationale and Objective}

The recent trend in polyimide research seems to focus more on the development of structural and functional polyimides with new properties without addressing the limitations of the current synthetic methods. However, advances in polymer research, in general, are led not only by the creation of a new structure but also pushed by the invention of a new synthetic method. There are two main synthetic routes to polyimides, namely one-step and two-step polymerizations. In the one-step polymerization, completely cyclized polyimides are obtained directly, from their corresponding tetracarboxylic acid dianhydride and diamine, using high boiling solvents, such as $\mathrm{m}$ cresol and p-chlorophenol [1-3]. This method is usually used when working with soluble polyimides and is considered more practical for polymerizing less reactive dianhydrides and diamines. However, this method suffers from some enormous drawbacks, such as the use of very toxic carcinogen solvents and a rather low polymerization concentration (usually less than $10 \mathrm{wt} / \mathrm{v} \%$ ), which hampers direct processing of the polyimides into the final products (e.g., films and fibres) from their polymerization solutions, and a long reaction time (typically over $18 \mathrm{~h}$ ). In the two-step polymerization, the polyamic acid is first prepared from dianhydride and diamine in a polar aprotic solvent, such as N,Ndimethylacetamide (DMAc) or N,N-dimethylformamide (DMF) [1-3]. During this step, the self-catalyzed cyclization to form polyimides cannot occur due to the strong interaction between the amic acid and the basic solvent or the larger acylation equilibrium constant $[1,4]$. In the second step, the polyamic acid is cyclodehydrated at elevated temperatures or by adding a cyclizing agent such as acetic anhydride [1,3-5]. 
Main advantages of this method over the one-step polymerization are the use of less toxic solvents and direct processing of the soluble polyamic acids to form the final polyimide products such as films and fibers after thermal imidization. However, the stability of polyamic acid on storage and control of thermal imidization are still important issues. In 2000 , Kuznetsov reported the use of the melt of benzoic acid as a solvent at $140{ }^{\circ} \mathrm{C}$ in one-step polymerization for the synthesis of aromatic polyimides with reasonably high molecular weights [4], Benzoic acid is less powerful in solvating aromatic polyimides and thus it is difficult to run the polymerization at a concentration more than $12 \mathrm{wt} / \mathrm{v} \%$. In addition, benzoic acid begins to sublime readily at $100{ }^{\circ} \mathrm{C}$ under ambient atmosphere, which makes it necessary to run the polymerization in a sealed tube completely immersed in a heated oil bath.

Salicylic acid is used as a preservative in food products, antiseptic and anti-fungal agents, starting material for various medicinal uses (e.g., aspirin). Salicylic acid contains both the acidic and phenolic groups resembling m-cresol and benzoic acid. Since it is more acidic $(\mathrm{pKa}=2.97)$ than benzoic acid $(\mathrm{pKa}=4.19)$ and $\mathrm{m}$-cresol $(\mathrm{pKa}=10.09)$, salicylic acid should be a much more powerful solvent for a variety of aromatic polyimides than those common solvents for polyimides. Furthermore, salicylic acid melts at about $160{ }^{\circ} \mathrm{C}$, lower than its isomers, 3-hydroxybenzoic acid $\left(\mathrm{mp}=200-203{ }^{\circ} \mathrm{C}\right)$ and 4 hydroxybenzoic acid $\left(\mathrm{mp}=213-217^{\circ} \mathrm{C}\right)$. It boils at $211^{\circ} \mathrm{C}$, being between the boiling temperatures of the two solvents for polyimide synthesis, m-cresol $\left(203{ }^{\circ} \mathrm{C}\right)$ and $\mathrm{p}$ chlorophenol $\left(220^{\circ} \mathrm{C}\right)$ and is suitable for the synthesis of the most aromatic polyimides. Thus, to test its feasibility and suitability as a solvent for polymerization, a series of dianhydrides and diamines were selected and polymerized (Scheme 2.1). 

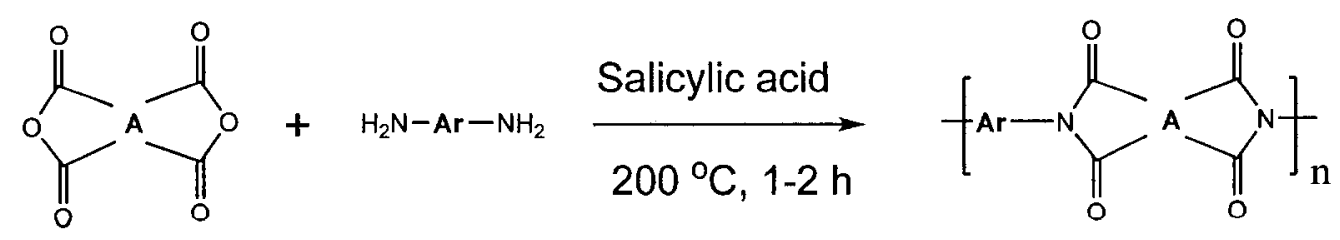

\section{Pl-1-15}

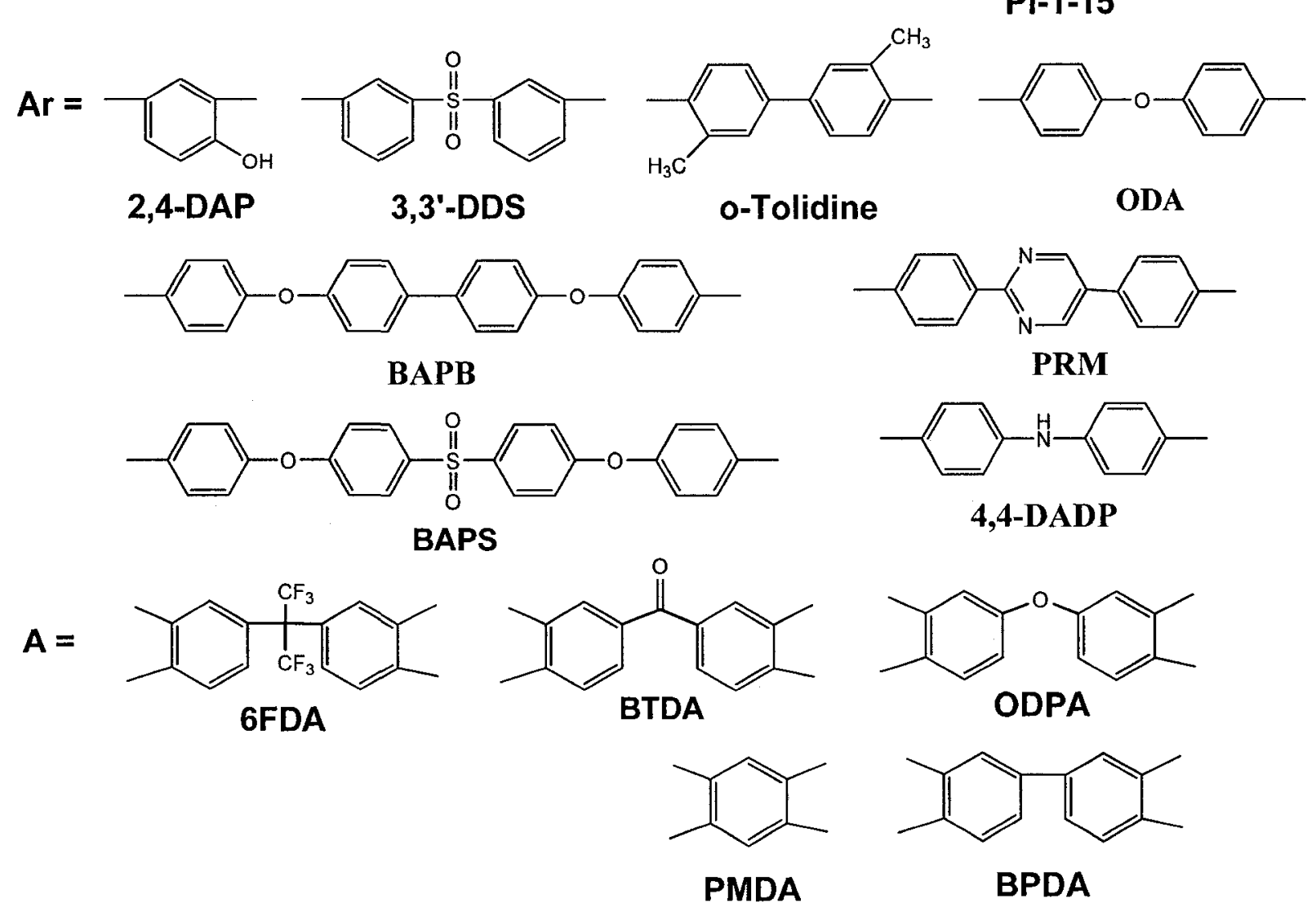

Scheme 2.1. One-step synthesis of polyimides in salicylic acid

In this chapter, a new synthetic method for the one-step synthesis of completely cyclized polyimides with high molecular weights is described using salicylic acid as a solvent. This solvent system offers many advantages for one-step polyimide synthesis, due to its high acidity, low volatility and excellent solvating power, on comparison with m-cresol, p-chlorophenol, and benzoic acid. 


\subsection{Polymer Synthesis}

\subsubsection{Polymerization conditions}

The polymerization was carried out in salicylic acid at $200^{\circ} \mathrm{C}$ at a concentration of $30-45 \mathrm{wt} / \mathrm{v} \%$ to afford a series of polyimides (Scheme 2.1 ). Once salicylic acid melted in a thick-walled glass tube ( $35 \mathrm{~mm}$ in outer diameter and $250 \mathrm{~mm}$ in length), a stoichiometric amount of dianhydride and diamine monomers (typically in a 3-mmol scale) were added, followed by addition of a few drops of isoquinoline. After all the monomers were dissolved in the melt of salicylic acid, the reaction tube was closed tightly (with a crew cap) and the portion of the tube containing the reaction mixtures (about $1 / 3$ in length) was immersed in an oil bath at $200{ }^{\circ} \mathrm{C}$ for $1-2 \mathrm{~h}$. The resulting polyimides remained soluble in salicylic acid during the course of polymerization. The viscosity of the polymerization solution increased rapidly, indicating the polymer chain growth and an increase in the molecular weight. After cooling to about $150^{\circ} \mathrm{C}$, the tube cap was removed. The polymerization solution could be poured directly onto a large metal or glass plate and the reaction mixture solidifies on cooling to room temperature. Salicylic acid can be easily removed by repeated washing in a Soxhlet extractor with ethanol or acetone and recovered after removal of low-boiling solvents. Alternatively, the hot polymerization solution could be poured into methanol and the precipitated polymers were collected by filtration, which were re-dissolved in DMAc (or m-cresol) and precipitated out from methanol.

Polyimides are known for their poor solubility, due to the rigidity of the polyimide backbone and strong interchain interaction $[1,2]$. Thus, polymerization in $\mathrm{m}-$ cresol is usually carried out at the concentration less than $15 \mathrm{wt} / \mathrm{v} \%$ to prevent physical 
gelation. In comparison, five dianhydrides, 6FDA, BTDA, BPDA, ODPA and PMDA, were readily polymerized with various diamines in salicylic acid without gelation (except for PI-4) at a concentration up to $45 \mathrm{wt} / \mathrm{v} \%$ during the course of polymerization (Table 2.1), demonstrating the solvating power of salicylic acid. Some polyimides such as PI-12 derived from BTDA and 3,3'-DDS can even be polymerized at a concentration as high as 50-60 wt/v\%. The polyimides derived from PMDA and the diamines as listed in Table 2.1 were obtained in low molecular weights, due to their limited solubility in the melt of salicylic acid. It should be noted that one-step polymerization in salicylic acid also allows for the direct use of the $\mathrm{HCl}$ salt of 2,4-diaminophenol (2,4-DAP) as a monomer, which implies that many other air-sensitive diamines could be converted to the corresponding more air stable $\mathrm{HCl}$ salts as monomers for making polyimides. 
Table 2.1. Characterizations of the homopolyimides made in salicylic acid at $200{ }^{\circ} \mathrm{C}$ within two hours.

\begin{tabular}{|c|c|c|c|c|c|c|}
\hline Dianhydride & Diamine & PI & $\begin{array}{l}\text { Conc. } \\
\text { (wt/v \%) }\end{array}$ & $\begin{array}{l}\eta_{\text {inh }} \\
(d L / g)\end{array}$ & $\begin{array}{l}\mathrm{T}_{\mathrm{d}}{ }^{\mathrm{a}} \\
\left({ }^{\circ} \mathrm{C}\right)\end{array}$ & $\begin{array}{l}\mathrm{T}_{\mathrm{g}}{ }^{\mathrm{b}} \\
\left({ }^{\circ} \mathrm{C}\right)\end{array}$ \\
\hline \multirow[t]{6}{*}{$6 \mathrm{FDA}$} & $2,4-\mathrm{DAP}(2 \mathrm{HCl})$ & PI-1 & 35 & $0.65^{\mathrm{c}}$ & 567 & 349 \\
\hline & 3,3'-DDS & PI-2 & 45 & $0.50^{\mathrm{c}}$ & 495 & 280 \\
\hline & ODA & PI-3 & 45 & $0.55^{\mathrm{c}}$ & 536 & 317 \\
\hline & o-tolidine & PI-4 & 16 & $0.95^{\mathrm{c}}$ & 534 & 248 \\
\hline & BAPB & PI-5 & 40 & $0.51^{\mathrm{c}}$ & 518 & 296 \\
\hline & BAPS & PI-6 & 40 & $0.46^{\mathrm{c}}$ & 538 & 299 \\
\hline \multirow[t]{4}{*}{ ODPA } & 2,4-DAP $(2 \mathrm{HCl})$ & PI-7 & 30 & $0.66^{\mathrm{c}}$ & 572 & 248 \\
\hline & 3,3'-DDS & PI-8 & 45 & $0.49^{\mathrm{c}}$ & 553 & 257 \\
\hline & ODA & PI-9 & 40 & $0.99^{\mathrm{c}}$ & 558 & 273 \\
\hline & BAPS & PI-10 & 40 & $0.87^{\mathrm{d}}$ & 527 & 297 \\
\hline \multirow[t]{3}{*}{ BTDA } & 2,4-DAP $(2 \mathrm{HCl})$ & PI-11 & 40 & $0.97^{\mathrm{c}}$ & 470 & 336 \\
\hline & 3,3'-DDS & PI-12 & 45 & $1.00^{\mathrm{c}}$ & 550 & 276 \\
\hline & BAPS & PI-13 & 30 & $0.73^{\mathrm{e}}$ & 556 & 289 \\
\hline \multirow[t]{2}{*}{ BPDA } & 3,3'-DDS & PI-14 & 40 & $0.45^{\mathrm{d}}$ & 527 & 293 \\
\hline & BAPS & PI-15 & 40 & $0.70^{\mathrm{d}}$ & 573 & 294 \\
\hline \multirow[t]{2}{*}{ PMDA } & 4,4'-DADP & PI-16 & 20 & --- & 473 & $>400$ \\
\hline & 4,4'-DADP(2HCl) & PI-17 & 20 & --- & 554 & $>400$ \\
\hline
\end{tabular}

$\bar{a}$ Onset temperature for $5 \%$ weight loss by TGA in nitrogen with a heating rate of 10 ${ }^{\circ} \mathrm{C} / \mathrm{min}$.

${ }^{\mathrm{b}}$ Glass transition temperature by DSC in nitrogen at a heating rate of $10^{\circ} \mathrm{C} / \mathrm{min}$.

${ }^{\mathrm{c}}$ Inherent viscosity measured in DMAc at $30 \pm 0.1{ }^{\circ} \mathrm{C}$ with a concentration of $0.5 \mathrm{~g} / \mathrm{dL}$.

${ }^{\mathrm{d}}$ Inherent viscosity measured in NMP at $30 \pm 0.1{ }^{\circ} \mathrm{C}$ with a concentration of $0.5 \mathrm{~g} / \mathrm{dL}$.

${ }^{\mathrm{e}}$ Inherent viscosity measured in m-cresol at $30 \pm 0.1^{\circ} \mathrm{C}$ with a concentration of $0.5 \mathrm{~g} / \mathrm{dL}$. 
High molecular weight polyimides were readily obtained within $2 \mathrm{~h}$, as evident from their high viscosity values (Table 2.1). The inherent viscosities of the synthesized polyimides ranged from 0.43 to $1.0 \mathrm{dL} / \mathrm{g}$, which are higher or comparable to those of the same polyimides synthesized by other one-step methods. For example, St. Clair and Slemp reported PI-2 and PI-8 with the viscosity of $0.47 \mathrm{dL} / \mathrm{g}$ in DMAc $[1,6]$, which are quite similar to what we have obtained after polymerization in only $2 \mathrm{~h}$. In 2000 , Kuznetsov reported PI-9 with a viscosity of $0.42 \mathrm{dL} / \mathrm{g}$ in DMAc [4], while the same polyimide made in the melt of salicylic acid had an inherent viscosity of $0.95 \mathrm{dL} / \mathrm{g}$. PI-12 was reported before for a viscosity of $0.42 \mathrm{dL} / \mathrm{g}$ in DMAc [1], which is much lower than what we have obtained $(1.0 \mathrm{dL} / \mathrm{g})$ but using m-cresol due to the insolubility of PI-12 in DMAc. No direct comparison was made for the rest of the polyimides, as they were previously synthesized in a two-step process.

It is worth mentioning that this method also allows for the synthesis of polyimide from PMDA but with only low molecular weight indicated by the inherent viscosity. This is due to the poor solubility of the synthesized polymer in salicylic acid even at the low reaction concentrations. The reaction seems to start spontaneously when using PMDA with the corresponding diamine. But due to the insolubility of the oligomers, the precipitate formed, which stops the chain growth. For example, PMDA was reacted with 4,4'-diaminodiphenylamine (4,4'-DADP) or its salt to give insoluble polyimide PI-16 and PI-17 respectively.

The new method can also be applied for the synthesis of copolyimides. For example, a copolymer was prepared from ODPA and ODA and 3,3'-DDS under the same conditions as for the homopolymers. The copolymer had an inherent viscosity of 0.67 
$\mathrm{dL} / \mathrm{g}$. To improve the solubility and molecular weight of the polyimides synthesized from PMDA, copolymers were synthesized with improved solubility but still in low molecular weight.

Table 2.2. Characterizations of copolyimides made in salicylic acid at $200{ }^{\circ} \mathrm{C}$ within $2 \mathrm{~h}$.

\begin{tabular}{|c|c|c|c|c|c|c|c|}
\hline $\begin{array}{l}\text { Type of } \\
\text { copolymer }\end{array}$ & Dianhydride & Diamine & PI & $\begin{array}{c}\text { Conc. } \\
\text { (wt/v \%) }\end{array}$ & $\begin{array}{c}\eta_{\text {inh }} \\
(\mathrm{dL} / \mathrm{g})\end{array}$ & $\begin{array}{l}\mathrm{T}_{\mathrm{d}}{ }^{\mathrm{a}} \\
\left({ }^{\circ} \mathrm{C}\right)\end{array}$ & $\begin{array}{l}\mathrm{T}_{\mathrm{g}}{ }^{\mathrm{b}} \\
\left({ }^{\circ} \mathrm{C}\right)\end{array}$ \\
\hline $\begin{array}{c}\text { Block } \\
\text { copolymer }\end{array}$ & ODPA & $\begin{array}{c}\text { ODA, } \\
\text { 3,3-DDS }\end{array}$ & PI-18 & 35 & $0.67^{c}$ & 530 & 263 \\
\hline \multirow[t]{2}{*}{$\begin{array}{l}\text { Random } \\
\text { copolymer }\end{array}$} & ODPA & ODA, PRM & PI-19 & 40 & $\cdots$ & 565 & $>400$ \\
\hline & $\begin{array}{l}\text { ODPA, } \\
\text { PMDA }\end{array}$ & 3,3'-DDS & PI-20 & 40 & $0.2^{c}$ & 520 & 278 \\
\hline
\end{tabular}

\footnotetext{
${ }^{a}$ Onset temperature for $5 \%$ weight loss by TGA in nitrogen with a heating rate of 10 ${ }^{\circ} \mathrm{C} / \mathrm{min}$.

${ }^{\mathrm{b}}$ Glass transition temperature by DSC in nitrogen at a heating rate of $10^{\circ} \mathrm{C} / \mathrm{min}$.

${ }^{\mathrm{c}}$ Inherent viscosity measured in DMAc at $30 \pm 0.1{ }^{\circ} \mathrm{C}$ with a concentration of $0.5 \mathrm{~g} / \mathrm{dL}$.
}

The one-step polymerization at high concentration allows for direct processing of the resulting polyimides from the polymerization solution. In our case, the preliminary tests confirmed that a tough, flexible film could be directly cast from the viscous polymer solution right after polymerization (e.g., PI-12) (Figure 2.1a). Because salicylic acid is volatile and can be effectively evaporated off during the film preparation at the elevated temperatures, such as $200{ }^{\circ} \mathrm{C}$, hair-like fibers could also be drawn from the hot viscous "honey-like" polymer solution (Figure $2.1 \mathrm{~b}$ ). The washing was necessary to remove 
salicylic acid. No further treatment such as thermal cure was done on the fibers and the fiber property was not evaluated.
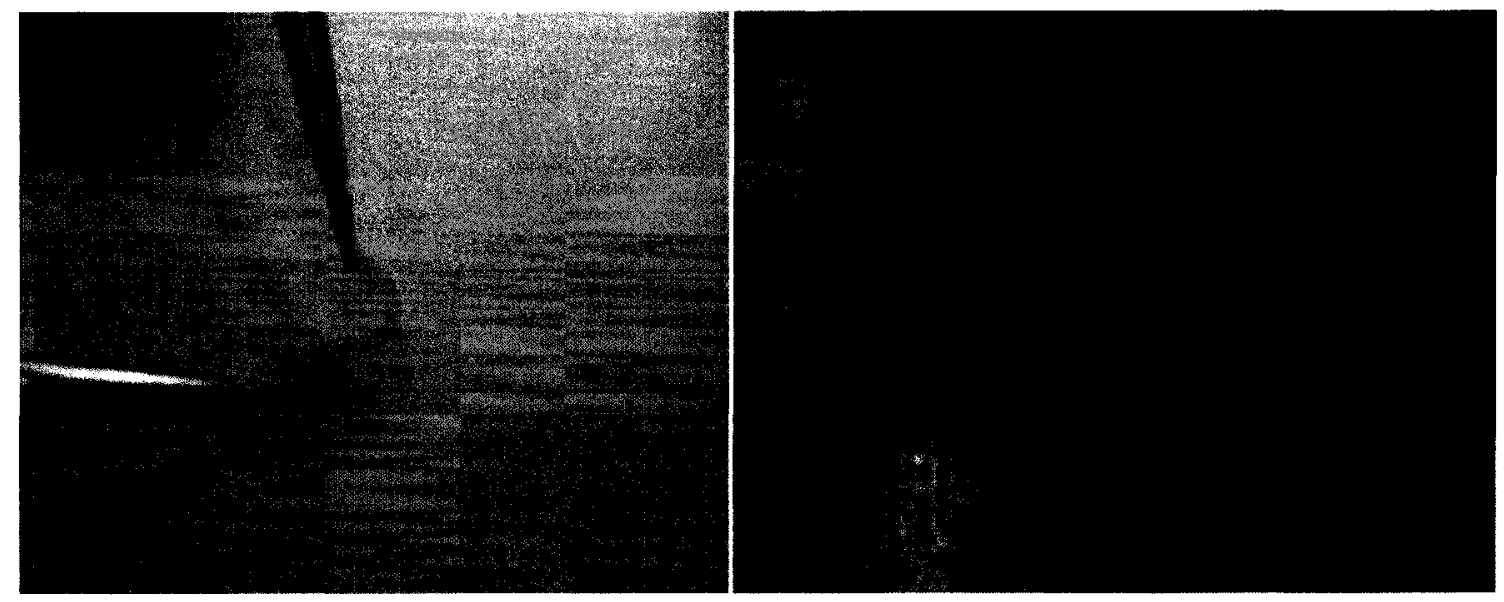

Figure 2.1. a) Flexible film processed directly from the polymerization solution (PI-12 polyimide), b) Fibres drawn directly from the polymerization solution (PI-12 polyimide).

\subsubsection{Kinetics study}

The effect of polymerization concentration on the chain growth or molecular weight was probed by varying the concentration from $20 \%$ to $60 \mathrm{wt} / \mathrm{v} \%$ in salicylic acid for the synthesis of PI-12 derived from BTDA and 3,3'-DDS within a given time of $2 \mathrm{~h}$ (Fig. 2.2a). A rapid increase in viscosity was found when the concentration reached 40 $\mathrm{wt} / \mathrm{v} \%$. At lower concentrations $(20-30 \%)$, the polymerization was obviously slower; while at the concentration over $50 \mathrm{wt} / \mathrm{v} \%$, a slight decrease in inherent viscosity was also observed, mainly due to partial gel formation. A kinetic study on the formation of PI-12 in salicylic acid was further done at a concentration of $50 \mathrm{wt} / \mathrm{v} \%$ by measuring the inherent viscosity at different polymerization times (Fig. 2.2b). The inherent viscosity increased rapidly and reached a maximal value of $1.0 \mathrm{dL} / \mathrm{g}$ in $1 \mathrm{~h}$. No further increase 
was observed after another $1 \mathrm{~h}$. Thus, the polymerization is complete within $1-2 \mathrm{~h}$ and the chain growth in this polymerization system is believed to proceed via the addition of the completely cyclized polyimide, similar to the one done in benzoic acid with the evidence from the IR analysis for the collected samples at early stage of the reaction [4].
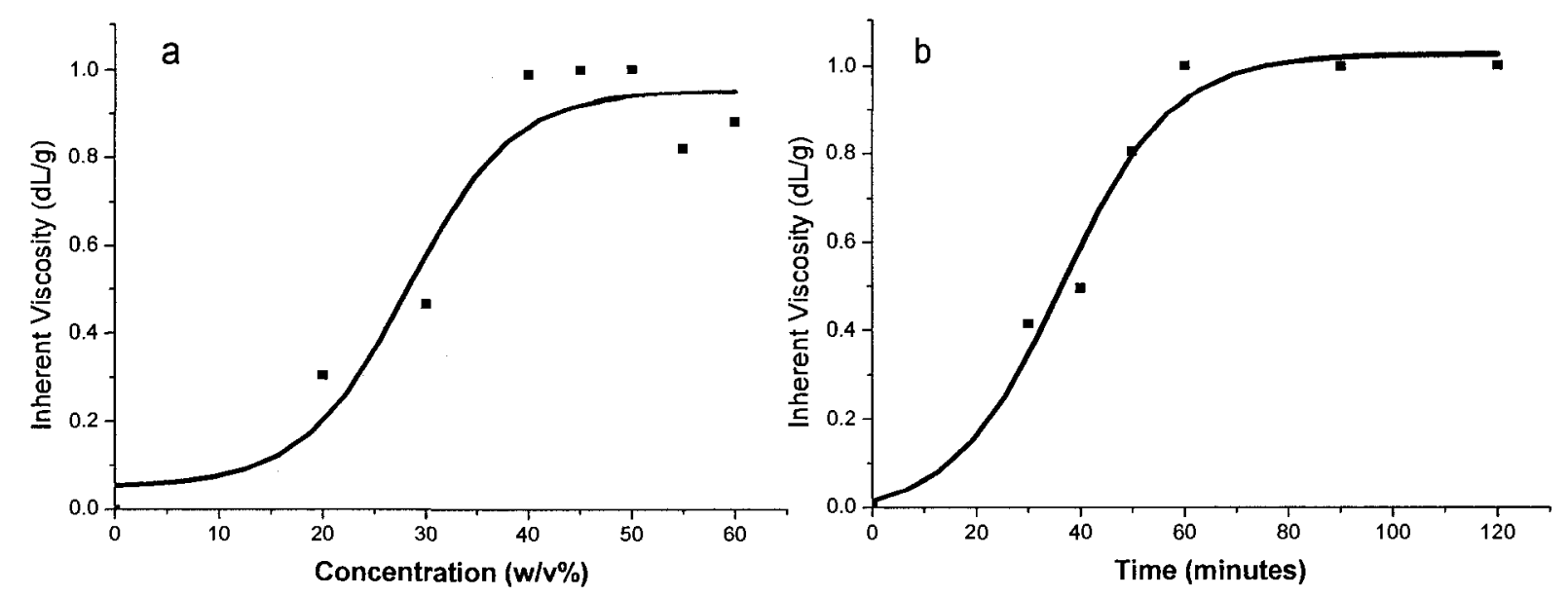

Figure 2.2. Formation of PI-12 in salicylic acid at $200^{\circ} \mathrm{C}$ (a) inherent viscosity taken at 2 hours vs. polymerization concentration (b) inherent viscosity vs. polymerization time at a concentration of $50 \mathrm{wt} / \mathrm{v} \%$.

\subsubsection{Effect of co-solvent and catalyst on the polymerization}

Two variables, co-solvent and catalyst, have been tested on the new polymerization system to determine their positive or negative effect on the molecular weight. The addition of some inert co-solvents such as 1,2-dichlorobenzene and $\mathrm{m}$-cresol in the polymerization was examined and resulted in lowering the molecular weights of the polyimides. For instance, the polymerization of ODPA and ODA was carried out in 1:1 (m-cresol : salicylic acid) for 2 hours and afforded lower molecular weight (inherent viscosity of $0.75 \mathrm{dL} / \mathrm{g}$ ) than in only salicylic acid (inherent viscosity of $0.99 \mathrm{dL} / \mathrm{g}$ ). 
The polymerization of BTDA and 3,3'-DDS was also carried out in absence of isoquinoline for $2 \mathrm{~h}$ and afforded PI-12 in much lower molecular weight (inherent viscosity of $0.2 \mathrm{dL} / \mathrm{g}$ ) than the one made in the presence of a small amount of isoquinoline (inherent viscosity of $1.0 \mathrm{dL} / \mathrm{g}$ ). The use of carboxylic acid as a catalyst for imidization has been studied and the study shows that the more acidic catalyst of salicylic acid $(\mathrm{pKa}=2.97)$ is less effective than other less acidic catalysts, e.g., benzoic acid (pKa $=4.19)$ and $\mathrm{p}$-hydroxybenzoic acid $(\mathrm{pKa}=4.48)$ [3]. Isoquinoline is often used in a small amount in one-step polymerization and as a base with acetic acid in the chemical imidization. However, the actual role that isoquinoline may play in this one-step polymerization and its exact nature in salicylic acid at $200{ }^{\circ} \mathrm{C}$ are still unclear. It seems that the more acidic nature of salicylic acid is in favour of solvating the polyimides, while isoquinoline facilitates the imidization and thus the rapid chain growth.

\subsection{Polymer Characterization}

\subsubsection{Spectroscopic analysis}

The complete imidization of the polyimides was confirmed by IR spectroscopy, as shown for PI-2,7,13,15 in Figure 2.3. The IR spectra exhibited the imide characteristics at $1782 \mathrm{~cm}^{-1}$ (unsymmetrical $\mathrm{C}=\mathrm{O}$ ), $1730 \mathrm{~cm}^{-1}($ symmetrical $\mathrm{C}=\mathrm{O}), 1380 \mathrm{~cm}^{-1}(\mathrm{C}-\mathrm{N})$ and $720 \mathrm{~cm}^{-1}$ (C-N-C). IR was also tested at early stages of the reaction but no carbonyl peaks appeared for the amic acid, thus direct cyclization occurs in the method. Similarly, the copolymers IRs indicated the complete imidization with the characteristic peaks at 1782 and $1730 \mathrm{~cm}^{-1}$. Other characterization methods (e.g., NMR) cannot be used due to the insolubility of the polymers in common organic solvents. 


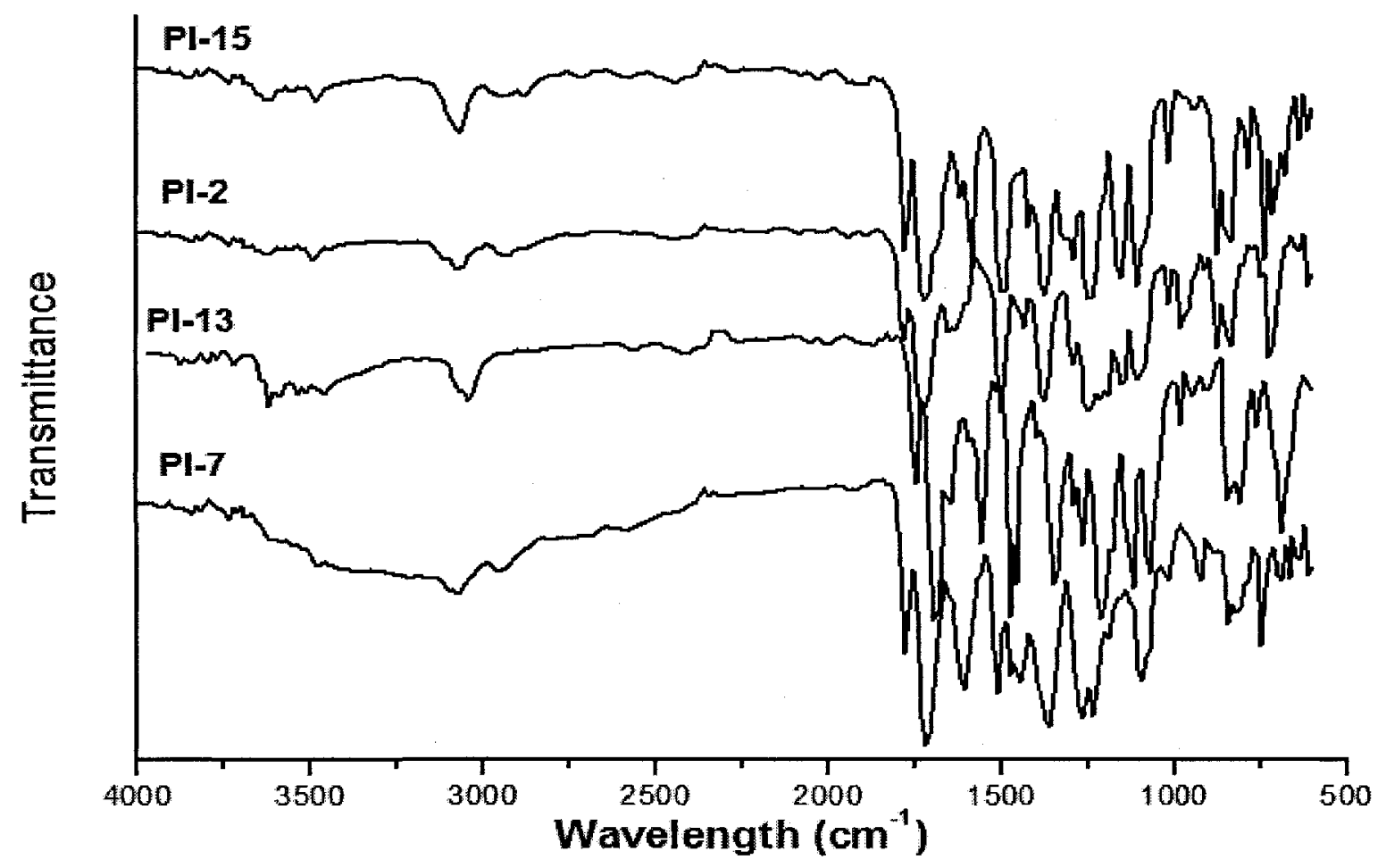

Figure 2.3. IR spectra of some polyimides synthesized in salicylic acid at $200{ }^{\circ} \mathrm{C}$

\subsubsection{Thermal analysis}

Thermal properties of these polyimides were determined by thermogravimetric analysis (TGA) and differential scanning calorimetry (DSC). The glass transition temperatures $(\mathrm{Tg})$ ranged from 248 to $336^{\circ} \mathrm{C}$, depending on the chemical structures of the dianhydrides and diamines used. All the polyimides were thermally stable up to 470 ${ }^{\circ} \mathrm{C}$ in nitrogen, as assessed by TGA for the onset temperatures for $5 \%$ weight loss (Table 2.1 ), indicative of the high rigidity of the polymer backbone. The thermal properties of PI-16 and PI-17 indicated that there is a $100{ }^{\circ} \mathrm{C}$ difference in the decomposition temperature (Td) between the polymers synthesized from the neutral diamine or its salt, hence higher molecular weight was obtained when using the salt diamine due to high sensitivity of the neutral diamine monomer to oxygen. The block copolymer PI-18 
showed a Tg of $263^{\circ} \mathrm{C}$ which lies between those of PI-8 $\left(257^{\circ} \mathrm{C}\right)$ and PI-9 $\left(273^{\circ} \mathrm{C}\right)$ of each block separately.

\subsection{Conclusion}

Salicylic acid is a powerful solvent for one-step synthesis of a variety of aromatic polyimides. The completely cyclized polyimides with high molecular weights are readily formed in less than $2 \mathrm{~h}$. The polymerization is easy to run and the solid solvent can be recovered and re-used. The preliminary studies on the effect of reaction concentration and time on the polymerization suggest that the imidization is very fast and the chain growth is likely to proceed via the addition of the growing imide segments.

\subsection{Experimental}

\section{Materials}

2,2-Bis(3,4-dicarboxyphenyl)hexafluoropropane dianhydride (6FDA) and 4,4'oxidiphthalic dianhydride (ODPA) were purchased from ChrisKEV company, Inc. and purified by recrystallization from acetic anhydride. 3,3',4,4'Benzophenonetetracarboxylic dianhydride (BTDA) and 3,3',4,4'-biphenyltetracarboxylic dianhydride (BPDA) were purchased from Allco Chemical Corporation and Aldrich Chemicals Inc., respectively, and dried in oven at $100^{\circ} \mathrm{C}$ prior to use. Salicylic acid, 2,4Diaminophenol dihydrochloride (2,4-DAP-2HCl), and 4,4'-diaminodiphenylamine sulphate were purchased from Aldrich and used as received. 3,3-Diaminodiphenylsulfone (3,3-DDS) was purchased from TCI America and purified by recrystallization from ethanol. 4,4-Oxydianiline (4,4-ODA) and o-tolidine were purchased from Aldrich and 
purified by recrystallization from THF and ethanol, respectively. 4,4'-Bis(4aminophenoxy)biphenyl (BAPB) and bis[4-(4-aminophenyoxy) phenyl] sulfone (BAPS) were purchased form Ken Seika corporation and used with no further purification. Bis(ditert-butyl(4-dimethylaminophenyl)phosphine)dichloropalladium(II) (AmphpdCl 2$)$ was purchased from Aldrich and used as received.

\section{Characterization}

Fourier Transform Infrared (FTIR) measurements were performed on a Bomen FTIR spectrophotometer. The onset temperatures for 5\% weight loss of the polymers were determined using a TA thermogravimetric analyzer at a heating rate of $10{ }^{\circ} \mathrm{C} / \mathrm{min}$ in nitrogen. Glass transition temperature (Tg) was determined on a TA DSC Q100 at a heating rate of $10^{\circ} \mathrm{C} / \mathrm{min}$ in nitrogen. Inherent viscosities of polymers were measured with an Ubbelohde capillary viscometer at $30.0 \pm 0.1{ }^{\circ} \mathrm{C}$ with a concentration of $0.5 \mathrm{~g} / \mathrm{dL}$.

\section{Diamine synthesis}

\section{4,4'-Diaminodiphenylamine hydrochloride (DADP.2HCl)}

Crude $4,4^{\prime}$-diaminodiphenylamine sulphate $(4.0 \mathrm{~g}, 13.45 \mathrm{mmol})$ was added to $1 \%$ $\mathrm{KOH}$ solution $(100 \mathrm{~mL})$ with stirring for 10 minutes. The mixture was then extracted with ethyl acetate. The organic layer was evaporated to get the crude product and recrystallized from water to give shiny white-purplish crystals ( $1.05 \mathrm{~g}, 40 \%$ yield).

Crude 4,4'-diaminodiphenylamine $(1.0 \mathrm{~g}, 5 \mathrm{mmol})$ and $0.05 \mathrm{~g}$ palladium on carbon was dissolved in THF and kept for 4 hours in the hydrogenation shaker at 40 psi. Under the protection of argon the solution was filtered in a flask containing concentrated 
$\mathrm{HCl}$ to form white precipitate. Wash with excess $\mathrm{HCl}$ to get clear solution and remove the solvent by distillation to get whitish-grey product.

\section{4,4'-(Pyrimidine-2,5-diyl)dianiline (PRM)}

A $100 \mathrm{~mL}$ flame-dried round-bottomed flask was charged with 4-(4,4,5,5tetramethyl-1,3,2-dioxaborolan-2-yl)aniline $\quad(4.935 \mathrm{~g}, \quad 22.5 \mathrm{mmol}), \quad$ 5-bromo-2chloropyrimidine $(1.451 \mathrm{~g}, 7.50 \mathrm{mmol})$ and $100 \mathrm{~mL}$ freshly distilled THF under argon. The solution was evacuated for 3 minutes followed by adding $5 \%$ of (Amphos) $)_{2} \mathrm{pdCl}_{2}$ and re-evacuated for 5 minutes. After 1 hour of reflux at $65-70^{\circ} \mathrm{C}, 15 \mathrm{~mL}$ of degassed $1 \mathrm{M}$ sodium bicarbonate solution were added. The reaction was then refluxed for 48 hours while monitoring the reaction completion with TLC. The solvent was evaporated then minimum amount of THF was added to dissolve the product with gentle heating to form 2 layers. The top layer of THF was isolated and evaporated to dryness under low pressure. Finally, the solid was suspended in ether and filtered to collect $1.89 \mathrm{~g}$ of pure product $\left(96 \%\right.$ yield). Mp $263{ }^{\circ} \mathrm{C} .{ }^{1} \mathrm{HNMR}\left(\mathrm{d}_{6}-\mathrm{DMSO}\right) \delta 9.00(\mathrm{~s}, 2 \mathrm{H}), 8.11(\mathrm{~d}, 2 \mathrm{H}), 7.50$ $(\mathrm{d}, 2 \mathrm{H}), 6.67(\mathrm{dd}, 4 \mathrm{H}), 5.63(\mathrm{~s}, 2 \mathrm{H}), 5.40(\mathrm{~s}, 2 \mathrm{H}) .{ }^{13} \mathrm{CNMR}\left(\mathrm{d}_{6}\right.$-DMSO) $\delta 161.8,153.8$, $151.7,149.7,129.9,129.3,127.3,124.9,121.4,114.8,113.8$.

\section{Polyimides Synthesis}

Polyimides PI-1 - PI-17

Typical procedure for the synthesis of PI-9 is as follows: Salicylic acid (3.67 $\mathrm{g}$, $2.60 \mathrm{~mL})$ was placed in a pressure glass tube $(35 \mathrm{~mm}$ in outer diameter and $250 \mathrm{~mm}$ in length), melted and maintained at $200{ }^{\circ} \mathrm{C}$ for 10 min. 4,4'-Oxidiphthalic dianhydride 
(ODPA) $(0.62 \mathrm{~g}, 2.00 \mathrm{mmol})$ and 4,4-oxydianiline (4,4-ODA) $(0.40 \mathrm{~g}, 2.00 \mathrm{mmol})$ were introduced into the melt. The concentration of monomers in salicylic acid was $40 \mathrm{wt} / \mathrm{v} \%$, followed by addition of 8 drops of isoquinoline. Once all were dissolved, the reaction tube was closed tightly (with a crewcap) and the portion of the tube containing the reaction mixtures (about $1 / 3$ in length) was immersed in an oil bath at $200{ }^{\circ} \mathrm{C}$ for $1.5 \mathrm{~h}$. After cooling to about $150{ }^{\circ} \mathrm{C}$, the tube cap was removed carefully and the viscous transparent pale-yellow solution was poured slowly into methanol $(200 \mathrm{~mL})$ with vigorous stirring. The polymer PI-9 was collected by filtration, boiled in hot methanol for $1 \mathrm{~h}$, and dried in a vacuum oven at $120^{\circ} \mathrm{C}$ overnight.

PI-1: $74 \%$ yield. IR (film, $\mathrm{cm}^{-1}$ ): 1787 (unsymmetrical $\mathrm{C}=\mathrm{O}$ of imide), 1733 (symmetrical $\mathrm{C}=\mathrm{O}$ of imide), 1372 (C-N of imide), 723 (C-N-C of imide).

PI-2: 94\% yield. IR (film, $\mathrm{cm}^{-1}$ ): 1785 (unsymmetrical $\mathrm{C}=\mathrm{O}$ of imide), 1733 (symmetrical $\mathrm{C}=\mathrm{O}$ of imide), 1382 ( $\mathrm{C}-\mathrm{N}$ of imide), 723 (C-N-C of imide).

PI-3: 95\% yield. IR (film, $\mathrm{cm}^{-1}$ ): 1789 (unsymmetrical $\mathrm{C}=\mathrm{O}$ of imide), 1735 (symmetrical $\mathrm{C}=\mathrm{O}$ of imide), 1375 (C-N of imide), 721 (C-N-C of imide).

PI-4: 95\% yield. IR (film, $\mathrm{cm}^{-1}$ ): 1785 (unsymmetrical $\mathrm{C}=\mathrm{O}$ of imide), 1735 (symmetrical $\mathrm{C}=\mathrm{O}$ of imide), 1380 (C-N of imide), 725 (C-N-C of imide).

PI-5: 81\% yield. IR (film, $\mathrm{cm}^{-1}$ ): 1785 (unsymmetrical $\mathrm{C}=\mathrm{O}$ of imide), 1731 (symmetrical $\mathrm{C}=\mathrm{O}$ of imide), 1380 (C-N of imide), 723 (C-N-C of imide).

PI-6: $85 \%$ yield. IR (film, $\mathrm{cm}^{-1}$ ): 1785 (unsymmetrical $\mathrm{C}=\mathrm{O}$ of imide), 1733 (symmetrical $\mathrm{C}=\mathrm{O}$ of imide), 1382 (C-N of imide), 723 (C-N-C of imide).

PI-7: 93\% yield. IR (film, $\mathrm{cm}^{-1}$ ): 1782 (unsymmetrical $\mathrm{C}=\mathrm{O}$ of imide), 1728 (symmetrical $\mathrm{C}=\mathrm{O}$ of imide), 1375 ( $\mathrm{C}-\mathrm{N}$ of imide), 745 (C-N-C of imide). 
PI-8: $67 \%$ yield. IR (film, $\mathrm{cm}^{-1}$ ): 1784 (unsymmetrical $\mathrm{C}=\mathrm{O}$ of imide), 1733 (symmetrical $\mathrm{C}=\mathrm{O}$ of imide), 1375 (C-N of imide), 744 (C-N-C of imide).

PI-9: 99\% yield. IR (film, $\mathrm{cm}^{-1}$ ): 1778 (unsymmetrical $\mathrm{C}=\mathrm{O}$ of imide), 1726 (symmetrical $\mathrm{C}=\mathrm{O}$ of imide), 1382 ( $\mathrm{C}-\mathrm{N}$ of imide), 744 (C-N-C of imide).

PI-10: 85\% yield. IR (film, $\mathrm{cm}^{-1}$ ): 1775 (unsymmetrical $\mathrm{C}=\mathrm{O}$ of imide), 1724 (symmetrical $\mathrm{C}=\mathrm{O}$ of imide), 1380 ( $\mathrm{C}-\mathrm{N}$ of imide), 744 (C-N-C of imide).

PI-11: $79 \%$ yield. IR (film, $\mathrm{cm}^{-1}$ ): 1782 (unsymmetrical $\mathrm{C}=\mathrm{O}$ of imide), 1733 (symmetrical $\mathrm{C}=\mathrm{O}$ of imide), 1377 ( $\mathrm{C}-\mathrm{N}$ of imide), 727 (C-N-C of imide).

PI-12: $87 \%$ yield. IR (film, $\mathrm{cm}^{-1}$ ): 1784 (unsymmetrical $\mathrm{C}=\mathrm{O}$ of imide), 1733 (symmetrical C=O of imide), 1377 ( $\mathrm{C}-\mathrm{N}$ of imide), 721 (C-N-C of imide).

PI-13: $80 \%$ yield. IR (film, $\mathrm{cm}^{-1}$ ): 1780 (unsymmetrical $\mathrm{C}=\mathrm{O}$ of imide), 1731 (symmetrical C=O of imide), 1380 (C-N of imide), 723 (C-N-C of imide).

PI-14: 99\% yield. IR (film, $\mathrm{cm}^{-1}$ ): 1780 (unsymmetrical $\mathrm{C}=\mathrm{O}$ of imide), 1733 (symmetrical $\mathrm{C}=\mathrm{O}$ of imide), 1377 ( $\mathrm{C}-\mathrm{N}$ of imide), 733 (C-N-C of imide).

PI-15: 80\% yield. IR (film, $\mathrm{cm}^{-1}$ ): 1776 (unsymmetrical $\mathrm{C}=\mathrm{O}$ of imide), 1731 (symmetrical $\mathrm{C}=\mathrm{O}$ of imide), 1382 ( $\mathrm{C}-\mathrm{N}$ of imide), 740 (C-N-C of imide).

PI-16: $85 \%$ yield. IR (film, $\mathrm{cm}^{-1}$ ): 1772 (unsymmetrical $\mathrm{C}=\mathrm{O}$ of imide), 1728 (symmetrical $\mathrm{C}=\mathrm{O}$ of imide), 1382 (C-N of imide), 723 (C-N-C of imide).

PI-17: 77\% yield. IR (film, $\mathrm{cm}^{-1}$ ): 1776 (unsymmetrical $\mathrm{C}=\mathrm{O}$ of imide), 1724 (symmetrical $\mathrm{C}=\mathrm{O}$ of imide), 1384 (C-N of imide), 725 (C-N-C of imide). 


\section{Copolyimides Synthesis}

Random copolymer PI-20: Salicylic acid (14.75 g, $10.24 \mathrm{~mL})$ was placed in a thickwall pressure glass tube ( $35 \mathrm{~mm}$ in outer diameter and $250 \mathrm{~mm}$ in length), melted and maintained at $200^{\circ} \mathrm{C}$ for a few minutes. Then, ODPA $(0.465 \mathrm{~g}, 1.5 \mathrm{mmol}), 3,3$-DDS (0.744 g, $3.00 \mathrm{mmol})$, PMDA $(0.327 \mathrm{~g}, 1.5 \mathrm{mmol})$ and a few drops of isoquinoline were added to the melt. The concentration of the reaction mixture was $15 \mathrm{wt} / \mathrm{v} \%$. The reaction tube was closed tightly and the polymerization proceeded at $200^{\circ} \mathrm{C}$ for $2 \mathrm{~h}$. After the reaction tube was left at room temperature for cooling for about $5 \mathrm{~min}$, the viscous solution was poured slowly into methanol $(200 \mathrm{~mL})$ with stirring. The polymer product was collected by filtration, washed with hot methanol and dried in a vacuum oven at 120 ${ }^{\circ} \mathrm{C}$ overnight; 86\% yield; IR (film, $\mathrm{cm}^{-1}$ ): 1778 (unsymmetrical $\mathrm{C}=\mathrm{O}$ of imide), 1712 (symmetrical $\mathrm{C}=\mathrm{O}$ of imide), 1363 (C-N of imide), 723 (C-N-C of imide).

PI-18: $73.0 \%$ yield. IR (film, $\mathrm{cm}^{-1}$ ): 1780 (unsymmetrical $\mathrm{C}=\mathrm{O}$ of imide), 1730 (symmetrical $\mathrm{C}=\mathrm{O}$ of imide), 1377 (C-N of imide), 744 (C-N-C of imide cycle).

PI-19: $77 \%$ yield. IR (film, $\mathrm{cm}^{-1}$ ): 1776 (unsymmetrical $\mathrm{C}=\mathrm{O}$ of imide), 1714 (symmetrical $\mathrm{C}=\mathrm{O}$ of imide), 1365 (C-N of imide), 742 (C-N-C of imide). 


\section{$2.6 \quad$ References}

1. Wilson D, Stenzenberger HD, Hergenrother PM. Polyimides. Glasgow: Blackie and Son; 1990

2. Mittal KL. Polyimides: Synthesis, Characterization and Applications, vol. 1 and 2. New York and London: Plenum; 1982

3. Sroog CE. Prog. Polym. Sci. 1991;16: 561

4. Kuznetsov AA. High Perf. Polym. 2000;12: 445

5. Kim YJ, Glass TE, Lyle GD, McGrath JE. Macromolecules. 1993; 26: 1344

6. St Clair AK, Slemp WS. SAMPE J 1985; 21(4): 28 


\section{Chapter 3. Synthesis and Properties of Near-Infrared Electrochromic Polyimides}

\subsection{Rationale and Objective}

Polyimides have been demonstrated to be candidates for various high temperature applications such as microelectronics, automotive and aerospace. They have also been used as waveguide materials due to many good properties such as low optical loss [1], tunable refractive index [2], high thermal stability [3] and mechanical property [4]. Organic optoelectronic materials that can absorb and produce light efficiently in the NIR region $(800-2000 \mathrm{~nm})$ are useful for telecommunications 1300-1600 $\mathrm{nm}$ [5], thermal imaging $>1500 \mathrm{~nm}$ and solar cells $(800-2000 \mathrm{~nm})$. Among several types of NIR organic materials a series of dinuclear ruthenium complexes (DCH-Ru) with dicarbonylhydrazine (DCH) bridging ligand are a class of well-studied NIR organic materials [5,6]. Studies on DCH-Ru complexes include NIR electrochromism, the structure-property relationship between the substituents and NIR absorption [5] and the effect on polymers containing pendant DCH-Ru complex group [7]. DCH-Ru complexes can exist in three oxidation states with characteristic absorptions, $\mathrm{Ru}^{\mathrm{II}} / \mathrm{Ru}^{\mathrm{II}}(550 \mathrm{~nm}), \mathrm{Ru}^{\mathrm{II}} / \mathrm{Ru}^{\mathrm{Ill}}(1600 \mathrm{~nm})$ and $\mathrm{Ru}^{\mathrm{III}} / \mathrm{Ru}^{\mathrm{III}}(800 \mathrm{~nm})$, which correspond to metal-to-ligand charge transfer (MLCT), metalto-metal charge transfer (MMCT) transitions and ligand-to-metal charge transfer (LMCT), respectively.

The generic structure of DCH-Ru complexes is shown in Figure 3.1, in which the two substituents ( $R, \mathrm{R}^{\prime}$ ) can be alkyl, aryl, alkoxy, phenoxy, alkylamino, etc. The electrical and optical properties (e.g., NIR absorption) of these complexes depend on the electronic environment of the two metal cations and can be influenced by the coordinating ligands (e.g., bpy) and the substituents on the bridging ligand [5]. Changing 
the electron withdrawing or electron donating ability of the ligand affects the HOMO/LUMO energy levels and thus changes the NIR wavelength absorption.

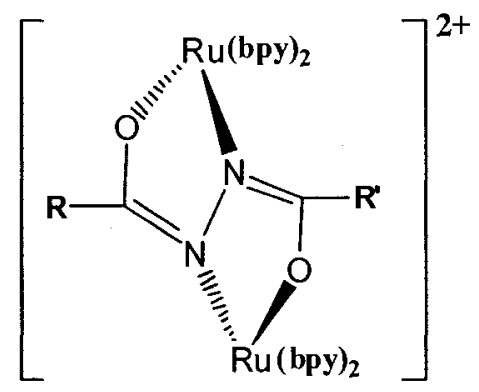

Figure 3.1. Generic structure of dinuclear DCH-Ru complex

NIR emission is interesting and useful in many applications such as optical sensors and telecommunications. To date, polymers containing DCH-Ru complex have been synthesized mainly by the addition of the complex as a pendent group. No study involves the incorporation of DCH-Ru complex into the polymer backbone or in the main chain. Polymers have the advantages of easy processing, film quality and morphology control over the small molecules. In this thesis work, incorporation of DCH-Ru complex into the polyimide backbone is further studied. The motivation for this study comes from the fact that polyimides are not NIR absorbing and the question of how to make polyimides NIR electrochromic for potential NIR applications while maintaining their excellent thermal, mechanical and optical properties.

Thus, to test the feasibility for this new type of polyimide, a new diamine monomer containing DCH-Ru is designed for polymerization with a series of readily available dianhydrides (Scheme 3.1). Initially, many questions were speculated regarding the solubility, thermal stability, basicity and polymerizability of the ruthenium complexcontaining diamine and the answers were only hypothesized to test its validity. 
<smiles>N[14CH2]N</smiles>

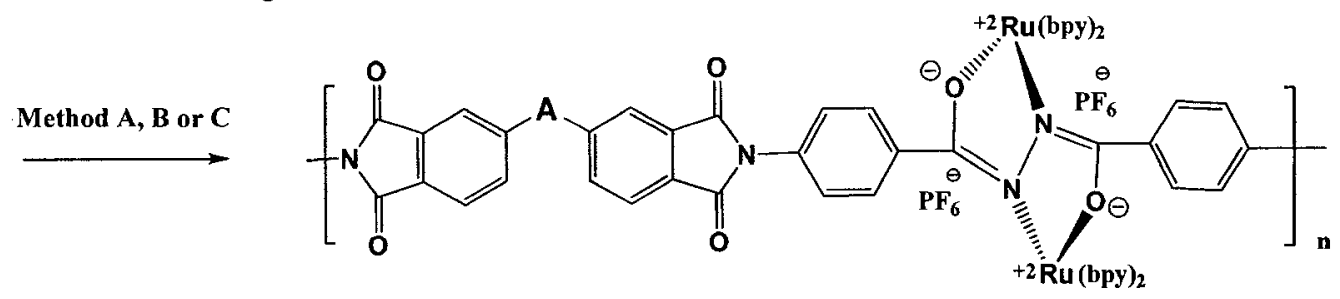

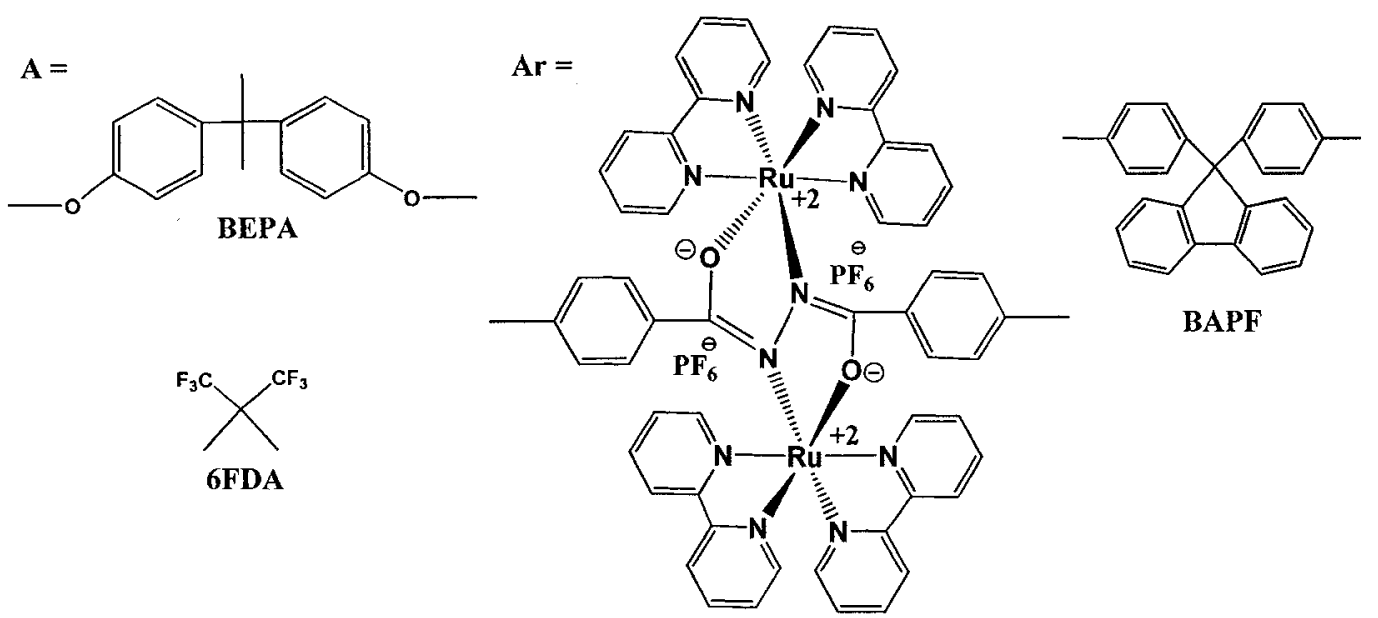

DCH-Ru DA

Scheme 3.1. Synthesis of DCH-Ru-complex polyimides by two-step method.

In this chapter, we report a new series of NIR electrochromic and luminescent polyimides containing DCH-Ru complexes in the main chain. The polyimides were synthesized and characterized and all displayed an intense absorption centered at 1600 $\mathrm{nm}$ upon the oxidation to the mixed valence state. 


\subsection{Monomer synthesis}

The symmetric ligand II was synthesized and fully characterized. It was synthesized from 4-nitrobenzoyl chloride with hydrazine hydrate solution in ethanol to give the dinitro compound I. The dinitro compound was then reduced with hydrogen using $\mathrm{PtO}_{2}$ catalyst to give II in $80 \%$ yield. Both steps were quantitative and did not require purification.

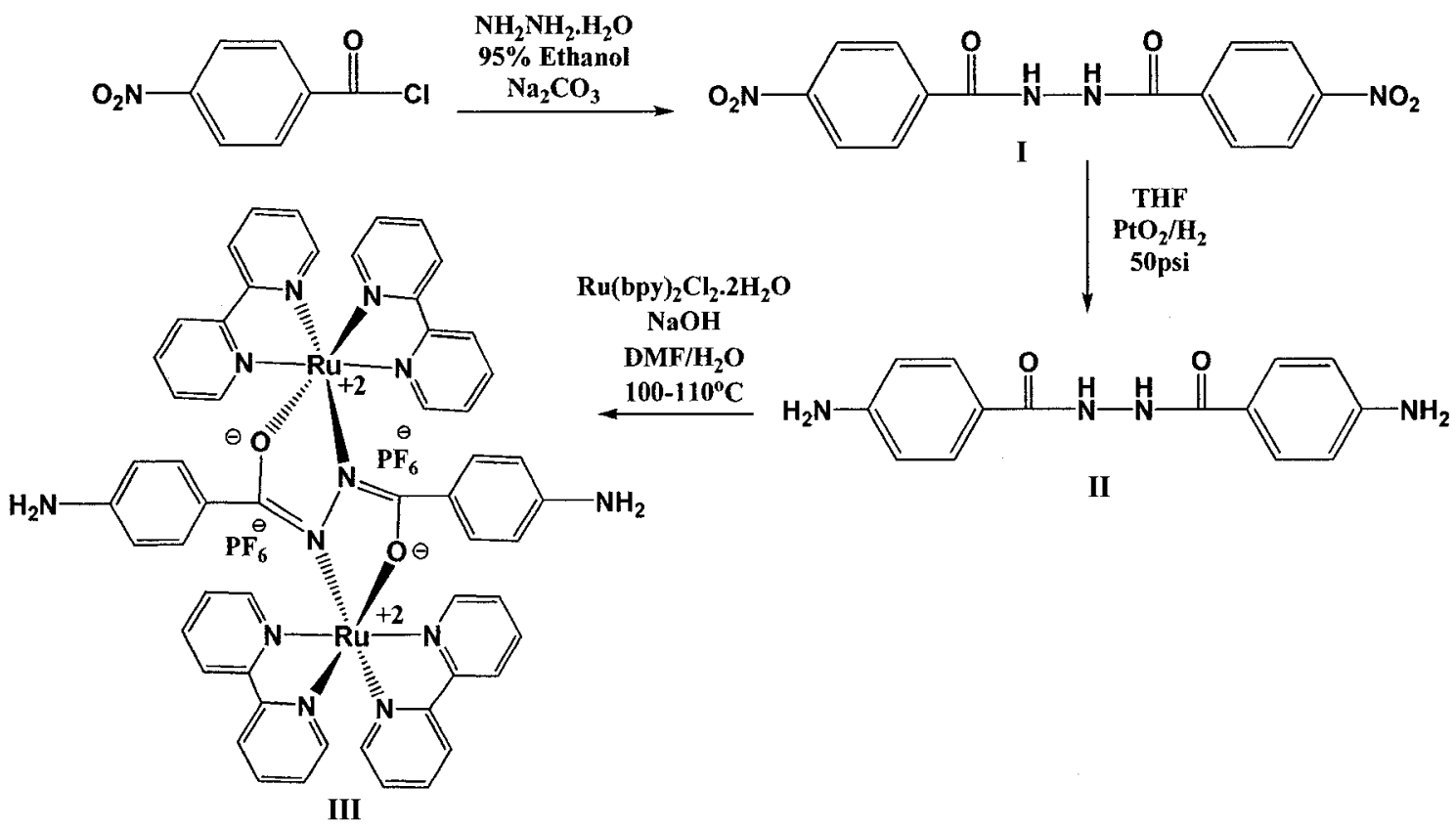

Scheme 3.2. Synthesis of the DCH-Ru diamine III

Complexation was then done by the addition of ruthenium bipyridyl dichloride dihydrate to ligand II in aqueous DMF at $100-110^{\circ} \mathrm{C}$ under argon. After 24 hours, the resulting complex III was isolated by precipitating out from ether and purified by column chromatography. Due to the complexity of the NMR spectra, the desired product could only be confirmed by mass spectrometry (Figure 3.2). The spectrum showed a peak at 
1241.0 that corresponds to the mass of the proposed structure of III missing one $\mathrm{PF}_{6}{ }^{-}$ion. Its decomposition temperature $\left(\mathrm{T}_{\mathrm{d}}\right)$ is at $387.60{ }^{\circ} \mathrm{C}$ and no melting point is shown by DSC.

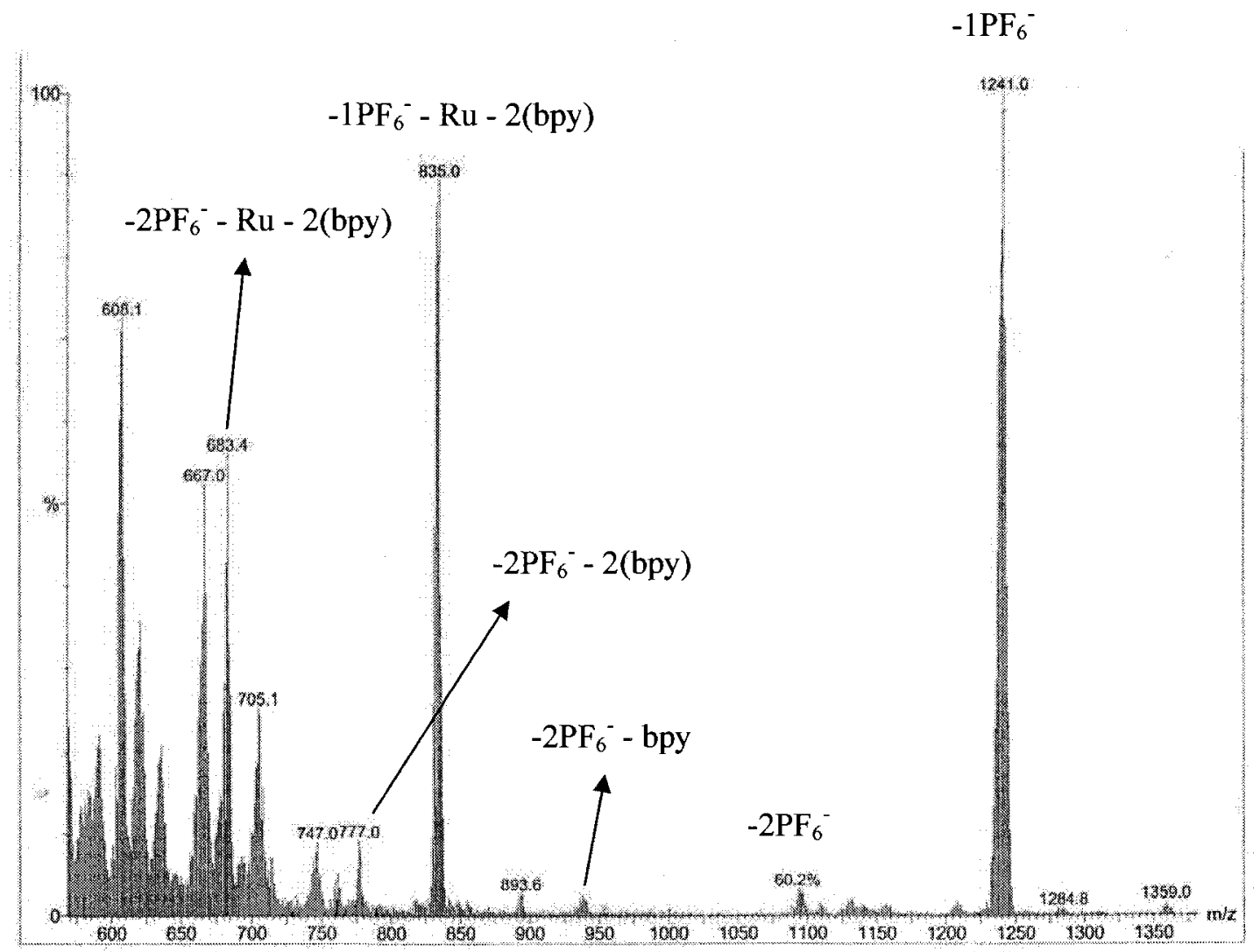

Figure 3.2. Mass spectrometry spectrum of the DCH-Ru diamine

\subsection{Polymer synthesis}

Before monomer III was subjected to polymerization, it was tested for its electrochromic property as a film. The film was prepared by mixing triisocyanate (derived from trimethylolpropane and xylene diisocyanate) with III in $500 \mu \mathrm{L}$ of acetonitrile, followed by spin coating on ITO glass. The spin-coated film was then cured at $150{ }^{\circ} \mathrm{C}$ for 3 hours followed by soaking in acetonitrile to check for leaching. The 
crosslinked film retained its electrochromic properties relative to the complex monomer (Figure 3.3).
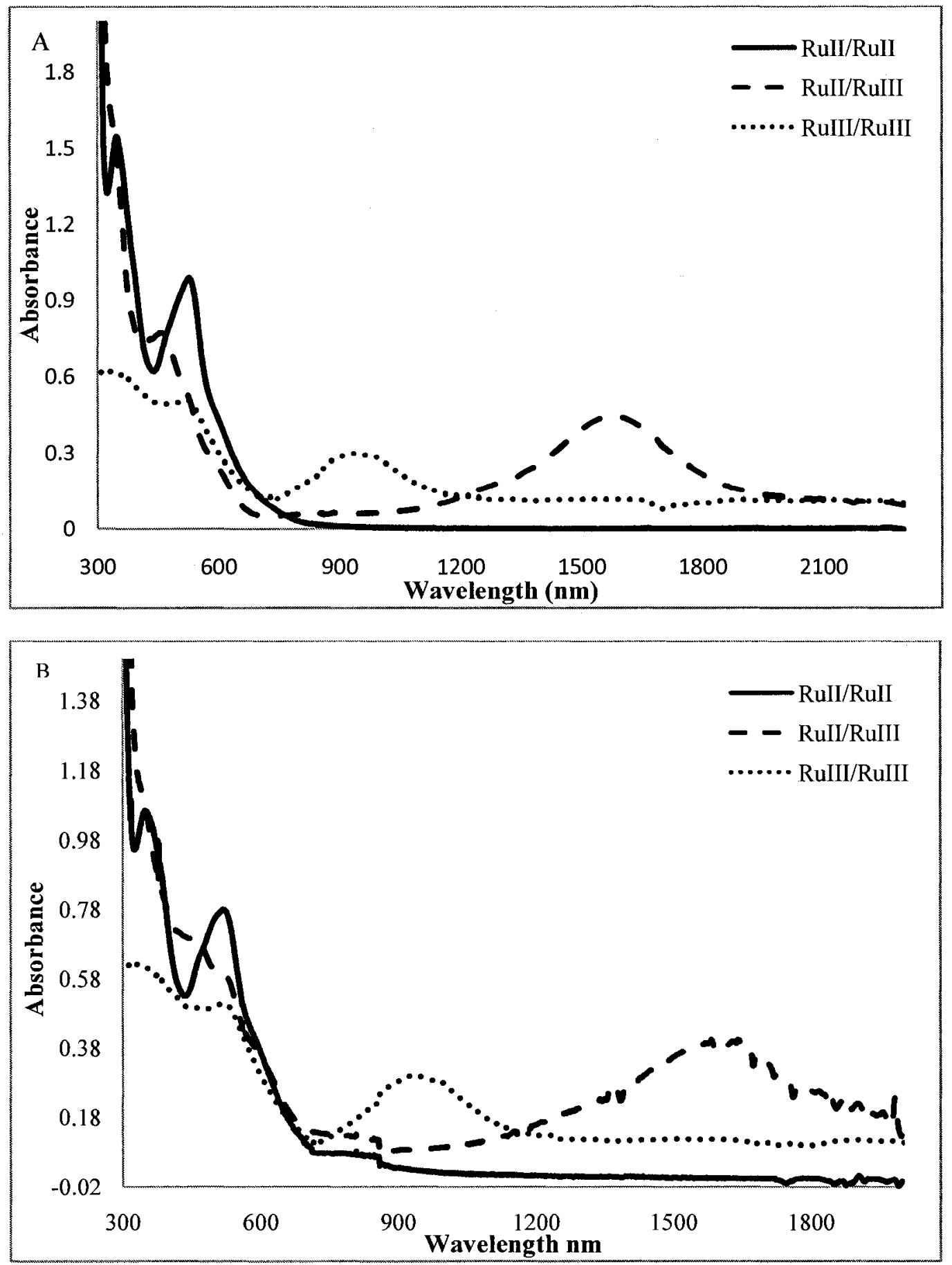

Figure 3.3. UV/vis/NIR spectra of (a) DCH-Ru diamine III with OTTLE cell and (b)

DCH-Ru diamine III in crosslinked polymer in different oxidation states 
Homopolymers and copolymer from 6FDA and BEPA and the DCH-Ru complex diamine were then synthesized and characterized (Scheme 3.1). The choice of the dianhydrides was based on the solubility of the resulting polyimides. The rigid dianhydrides will result in insoluble polyimides which would be difficult to characterize.

In order to confirm the polymerizability of the corresponding monomers, polymerization was carried out by one-step method in either m-cresol [8] at $200{ }^{\circ} \mathrm{C}$ or salicylic acid [9] at $200{ }^{\circ} \mathrm{C}$ or in two-step method using DMF as a solvent [10]. All the methods led to the formation of polyamic acid not the cyclized polyimide, as indicated by the IR spectra, which could be due to the less basic DCH-Ru diamine. The polyamic acids obtained were soluble in the reaction mixture. Imidization was then carried out by pouring the polymerization solution on glass and heating it gradually up to $200^{\circ} \mathrm{C}$ under the flow of argon. The resulting polyimides, PRu-I and PRu-II, were not soluble in common organic solvents but slowly soluble in DMF while the copolymer was soluble in $\mathrm{DMF}$ and slightly in ACN.

\subsection{Characterization}

FT-IR

The polyamic acid was characterized by FT-IR and then converted to polyimides. The imidization of the polyamic acid was verified by observing the disappearance of the amides and carboxylic acid bands and growth of the imide ring formation peaks. For example, in PRu-III (Figure 3.4) the broad peak at $3320 \mathrm{~cm}^{-1}$ and $1500-1650 \mathrm{~cm}^{-1}$

disappeared and those of the imide ring appeared near $1780 \mathrm{~cm}^{-1}$ (unsymmetrical $\mathrm{C}=\mathrm{O}$ ), $1720 \mathrm{~cm}^{-1}$ (symmetrical $\left.\mathrm{C}=\mathrm{O}\right) 1380 \mathrm{~cm}^{-1}\left(\mathrm{C}-\mathrm{N}\right.$ of imide) and $720 \mathrm{~cm}^{-1}(\mathrm{C}-\mathrm{N}-\mathrm{C}$ of imide). 


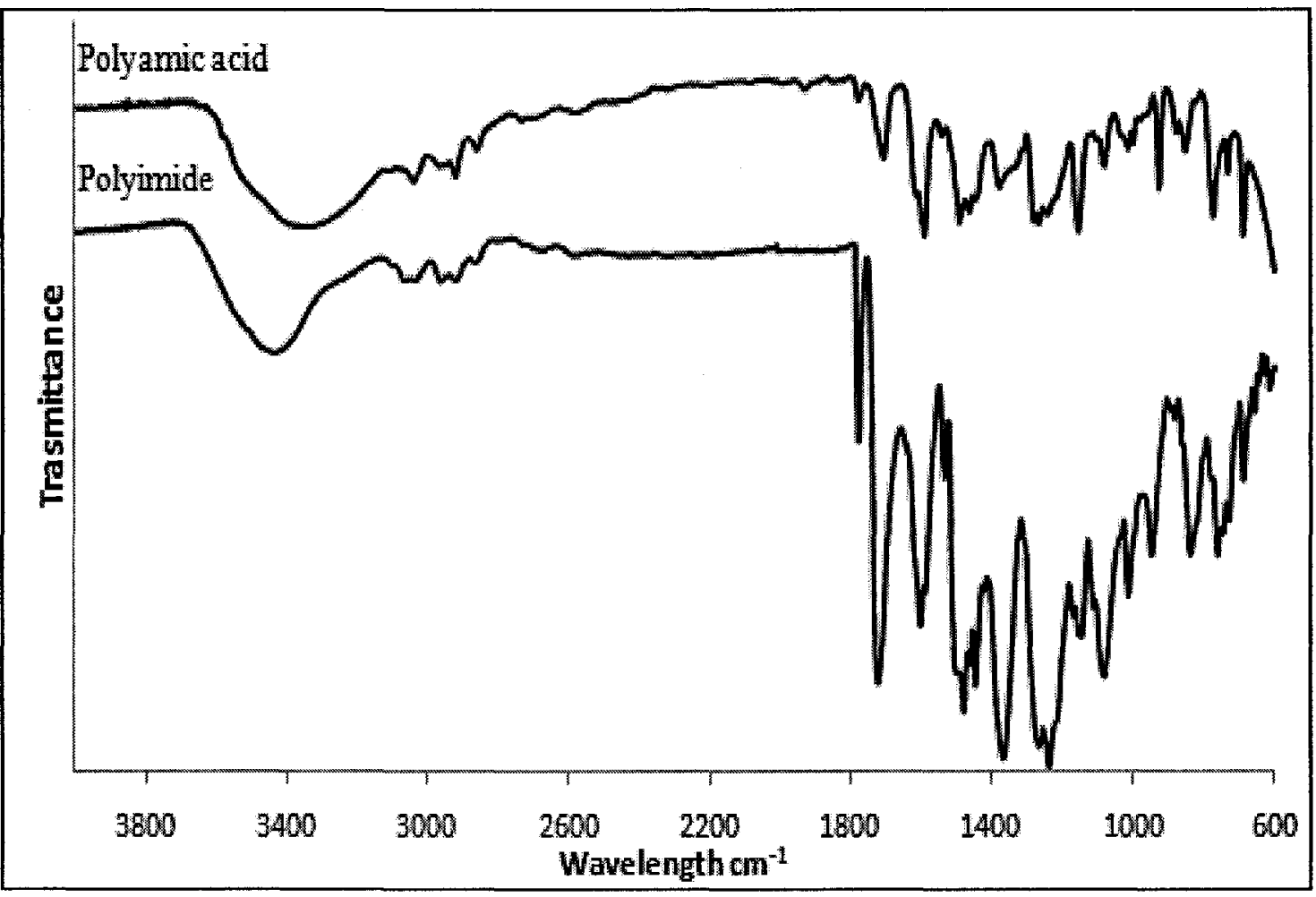

Figure 3.4. IR spectrum of PRu-III

Viscosity

The DCH-Ru-complex polyimides have rather poor solubility in many common solvents but a good solubility in DMF that allows for viscosity measurement. The viscosity data give an estimate of the polymer molecular weight (Table 3.1). The obtained polyimides had a viscosity ranging from $0.16-0.26 \mathrm{dL} / \mathrm{g}$, indicating the low molecular weight. 
Table 3.1. Characterization of the DCH-Ru polyimides synthesized in two-step method.

\begin{tabular}{ccccccc}
\hline Polymer & Dianhydride & Diamine & $\begin{array}{c}\mathbf{C o n c} \\
(\mathbf{w t} / \mathbf{v} \%)\end{array}$ & $\begin{array}{c}\boldsymbol{\eta}_{\text {inh }} \\
(\mathbf{d L} / \mathbf{g})\end{array}$ & $\begin{array}{c}\mathbf{T}_{\mathbf{d}}{ }^{\mathbf{a}} \\
\left({ }^{\circ} \mathbf{C}\right)\end{array}$ & $\begin{array}{c}\mathbf{T}_{\mathbf{g}}{ }^{\mathbf{b}} \\
\left({ }^{\circ} \mathbf{C}\right)\end{array}$ \\
\hline PRu-I & 6FDA & DCH-Ru DA & 23 & $0.26^{\mathrm{c}}$ & 232.0 & 178.2 \\
PRu-II & BEPA & DCH-Ru DA & 20 & $0.16^{\mathrm{c}}$ & 248.0 & 179.5 \\
PRu-III & 6FDA & $\begin{array}{c}\text { DCH-Ru DA } \\
+ \text { BAPF }\end{array}$ & 20 & $0.23^{\mathrm{c}}$ & 172.0 & 96.6 \\
& & & & & \\
\hline
\end{tabular}

${ }^{\mathrm{a}}$ Onset temperature for $5 \%$ weight loss by TGA in nitrogen with a heating rate of 10 ${ }^{\circ} \mathrm{C} /$ min. ${ }^{\mathrm{b}}$ Glass transition temperature by DSC in nitrogen at a heating rate of $10^{\circ} \mathrm{C} / \mathrm{min}$.

${ }^{\mathrm{c}}$ Inherent viscosity measured in DMF at $30 \pm 0.1^{\circ} \mathrm{C}$ with a concentration of $0.5 \mathrm{~g} / \mathrm{dL}$.

\section{Thermal Analysis}

The thermal properties of these polyimides were determined by TGA and DSC. The glass transition temperatures $(\mathrm{Tg})$ for the $\mathrm{DCH}-\mathrm{Ru}$ polyimides ranged from 96.0 to $179.0^{\circ} \mathrm{C}$, depending on the chemical structures of the dianhydrides and diamines used. All the polyimides were thermally stable up to $172.0^{\circ} \mathrm{C}$ in nitrogen, as assessed by TGA for the onset temperatures for $5 \%$ weight loss (Table 3.1), indicative of maintaining the high rigidity of the polymer backbone containing the DCH-Ru complex unit.

\section{Cyclic Voltammetry}

Cyclic voltammetry (CV) was used to study the electrochemical properties of DCH-Ru complex diamine and polyimides. It was done using platinum electrode against silver pseudo-reference electrode in nitrogen purged solution of $0.1 \mathrm{M}$ TBAH in acetonitrile for the complex monomer III, while the polymers were done as a thin film on 
ITO and calibrated with ferrocene/ferrocenium redox couple. The DCH-Ru complexes undergo two successive one-electron oxidation steps in the positive potential region due to the oxidation of $\mathrm{Ru}^{\mathrm{II}} / \mathrm{Ru}^{\mathrm{II}}$ to the $\mathrm{Ru}^{\mathrm{II}} / \mathrm{Ru}{ }^{\mathrm{III}}$ state (first oxidation wave ${ }^{1} \mathrm{E}_{1 / 2}$ ) and oxidation to the $\mathrm{Ru}^{\mathrm{III}} / \mathrm{Ru}^{\mathrm{III}}$ state (second oxidation wave ${ }^{2} \mathrm{E}_{1 / 2}$ ). Indeed, the complex diamine underwent two reversible oxidation steps. The ${ }^{1} \mathrm{E}_{1 / 2}$ and ${ }^{2} \mathrm{E}_{1 / 2}$ were at $445 \mathrm{mV}$ and $918 \mathrm{mV}$, respectively, similar to the other known DCH-Ru complexes. The DCH-Ru containing polyimides also underwent two successive one-electron oxidations. The half wave potentials for the first and second oxidation steps ranged from $424-627 \mathrm{mV}$ and $1015-1198 \mathrm{mV}$, hence giving a potential window of 571-591 mV. The electrochemical data for the diamine and polyimides are shown in table 3.2.

Table 3.2. Oxidation potentials for the ruthenium complex monomers and polymers

\begin{tabular}{lccccccc}
\hline & ${ }^{1} \mathbf{E}_{\mathbf{P a}}$ & ${ }^{1} \mathbf{E}_{\mathbf{P c}}$ & ${ }^{1} \mathbf{E}_{1 / 2}$ & ${ }^{2} \mathbf{E}_{\mathbf{P a}}$ & ${ }^{2} \mathbf{E}_{\mathbf{P c}}$ & ${ }^{2} \mathbf{E}_{\mathbf{1} / 2}$ & $\Delta \mathbf{E}_{1 / 2}$ \\
\hline DCH-Ru DA & 414.0 & 476.0 & 445 & 852.0 & 984.0 & 918.0 & 473.0 \\
PRu-I & 252.0 & 596.0 & 424.0 & 851.0 & 1180.0 & 1015.5 & 591.5 \\
PRu-II & 565.0 & 689.0 & 627.0 & 1129.0 & 1267.0 & 1198.0 & 571.0 \\
PRu-III & 560.0 & 619.0 & 589.5 & 1126.0 & 1186.0 & 1156.0 & 566.5 \\
\hline
\end{tabular}

Figures 3.5 shows the $\mathrm{CV}$ traces of the diamine and one selected polyimide, PRuI, with the reversible redox cycles over time, indicating the suitability for use as an electrochemical switch. 

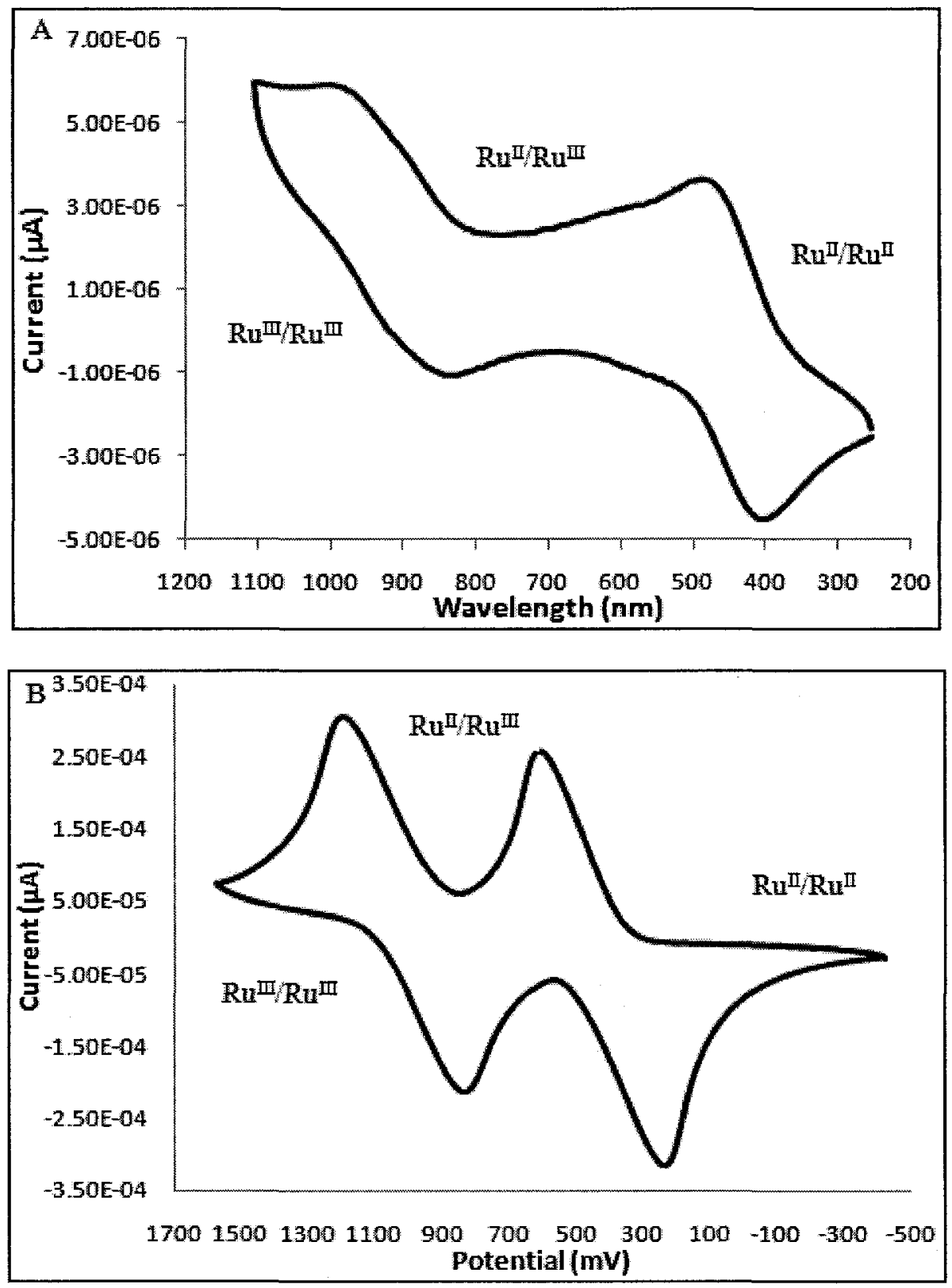

Figure 3.5. Cyclic Voltammetry spectrum of (a) DCH-Ru diamine and (b) PRu-I from the 6FDA dianhydride and DCH-Ru diamine at a scan rate of $200 \mathrm{mV} / \mathrm{s}$. 


\subsection{Spectroelectrochemical Study}

The spectroelectrochemical measurements of the complex diamine III and polyimides were performed using an OTTLE cell by applying different potentials. The UV-vis-NIR absorption spectra for the complex monomers and polymers in DMF show two intense absorptions at 350 and $520 \mathrm{~nm}$, assigned to the MLCT transition of the $\mathrm{Ru}^{\mathrm{II}} / \mathrm{Ru}^{\mathrm{II}}$ state of the complex polymers, while the broad NIR absorption at $1600 \mathrm{~nm}$ corresponds to the MMCT band of the $\mathrm{Ru}^{\mathrm{II}} / \mathrm{Ru}{ }^{\mathrm{III}}$ mixed-valence state. Upon further oxidation to the $\mathrm{Ru}^{\mathrm{III}} / \mathrm{Ru}^{\mathrm{III}}$ state, a new band at $800 \mathrm{~nm}$ should appear but was not observed. These results indicate that the complex monomer and polymers are NIR electrochromic at the telecommunication wavelength of $1550 \mathrm{~nm}$. For example, the DCH-Ru diamine III showed the $R u^{\mathrm{II}} / \mathrm{Ru} u^{\mathrm{II}}, \mathrm{Ru} u^{\mathrm{II}} / \mathrm{Ru} u^{\mathrm{III}}$ and $\mathrm{Ru}{ }^{\mathrm{III}} / \mathrm{Ru}{ }^{\mathrm{III}}$ states while $\mathrm{PRu}-\mathrm{I}$ showed only $\mathrm{Ru}^{\mathrm{II}} / \mathrm{Ru}^{\mathrm{II}}, \mathrm{Ru} / \mathrm{RI} \mathrm{R}^{\mathrm{III}}$ states (Figure 3.3 and 3.6). The UV/vis/NIR spectra of other polyimides are included in appendix B. 


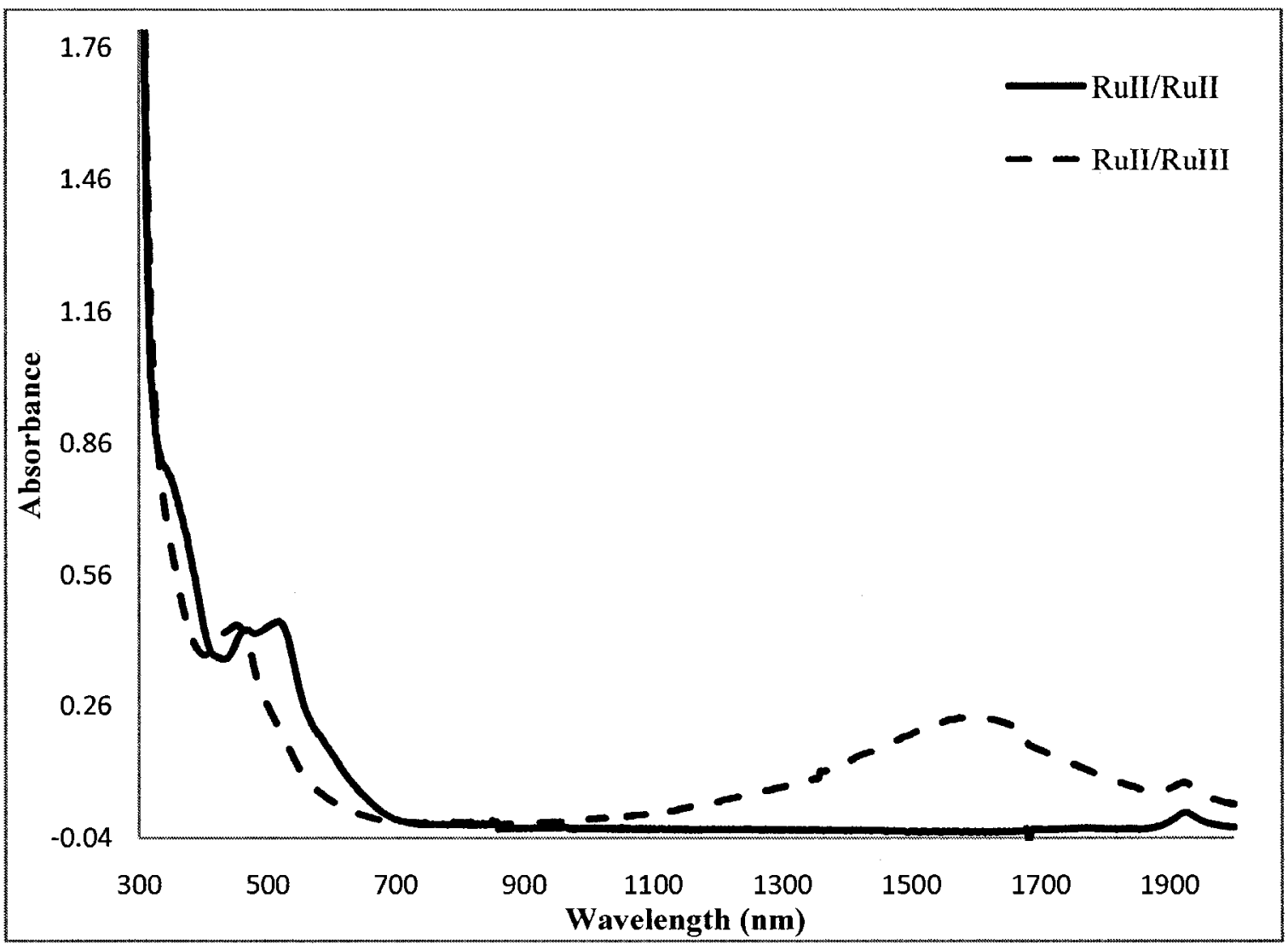

Figure 3.6. UV/vis/NIR spectra of PRu-I in different oxidation states

Since the DCH-Ru polyimides show a good electrochemical stability and strong NIR electrochromism, NIR optical attenuation has been tested by utilizing the electrochromic switch between the $\mathrm{Ru}^{\mathrm{II}} / \mathrm{Ru}^{\mathrm{II}}$ and $\mathrm{Ru}^{\mathrm{II}} / \mathrm{Ru}^{\mathrm{III}}$ states and an intense absorption of the mixed-valence state in the NIR region. The complex diamine III shows a rapid response in the NIR region to the applied potentials and reaches a dynamic range of optical attenuation of $5.3 \mathrm{~dB} / \mu \mathrm{m}$ at $1550 \mathrm{~nm}$ with a stepping time of 5 seconds (Figure 3.7 (a) and Table 3.3). The polyimide film shows a slower switching speed on the electrode as expected due to the diffusion controlled process for ions going through the polyimide film on the electrode (Figure 3.7 and appendix B). 
Table 3.3. Attenuation values of complex monomer and polymers.

\begin{tabular}{ccccc}
\hline & Monomer & PRu-I & PRu-II & PRu-III \\
\hline Attenuation (dB) & 3.2 & 0.46 & 0.22 & 0.08 \\
Film thickness (nm) & 600 & 300 & 429 & 700 \\
Attenuation/thickness (dB/ $/ \mu m)$ & 5.3 & 1.5 & 0.52 & 0.11 \\
\hline
\end{tabular}
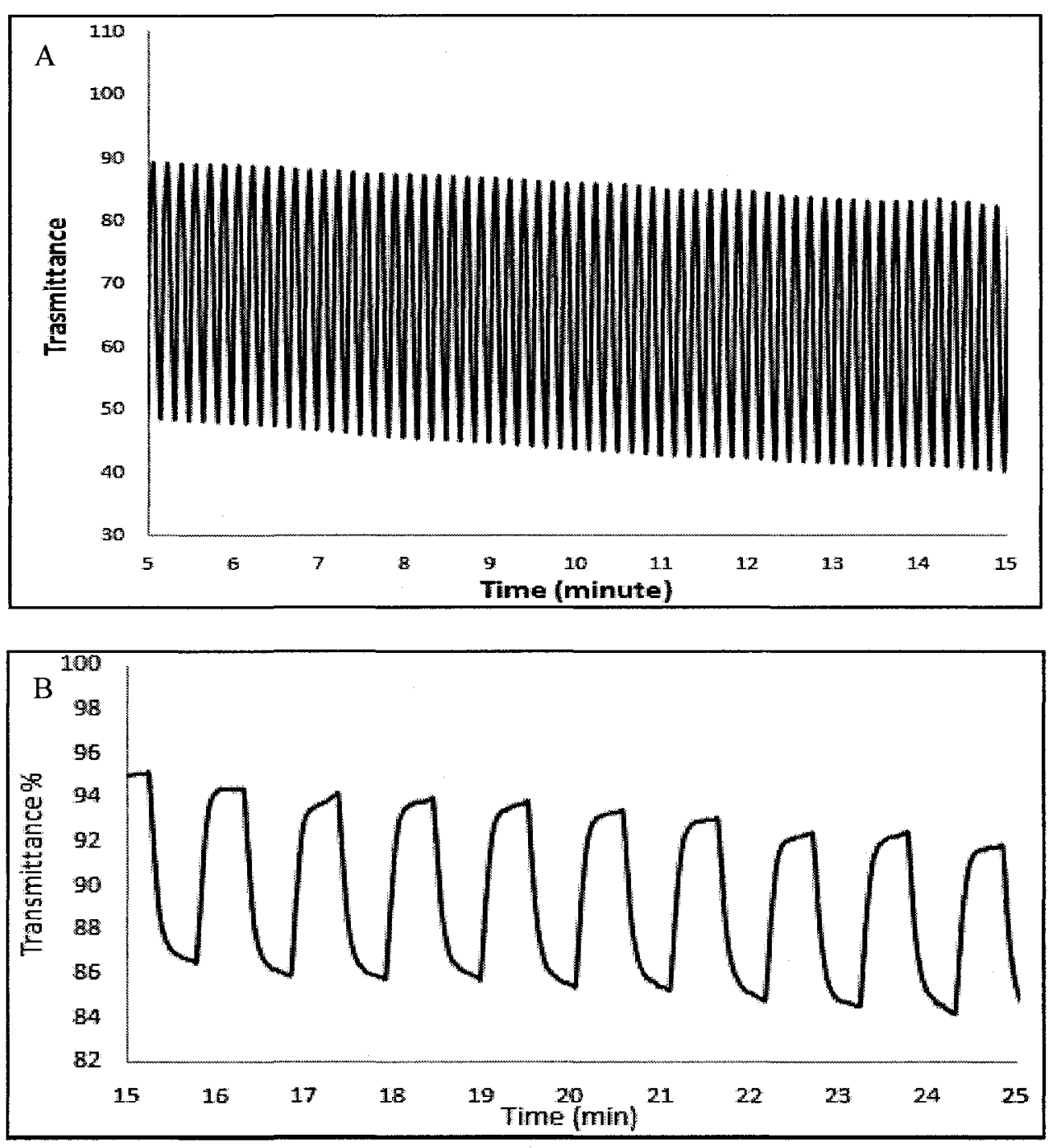

Figure 3.7. Changes in transmittance at $1550 \mathrm{~nm}$ of (a) diamine III and (b) PRu-I 


\subsection{Photoluminescent Property}

The photoluminescence (PL) of the complex monomer and polymers as thin films on ITO glass was investigated under the excitation of $520 \mathrm{~nm}$ light at room temperature. The PL spectra of the complex monomer and polyimides are very similar with a maximal peak at about $790 \mathrm{~nm}$ (Figure 3.8). The NIR PL observed in both the ruthenium complex monomer and polymers is mainly due to the excited state metal-to-ligand charge transfer (MLCT).
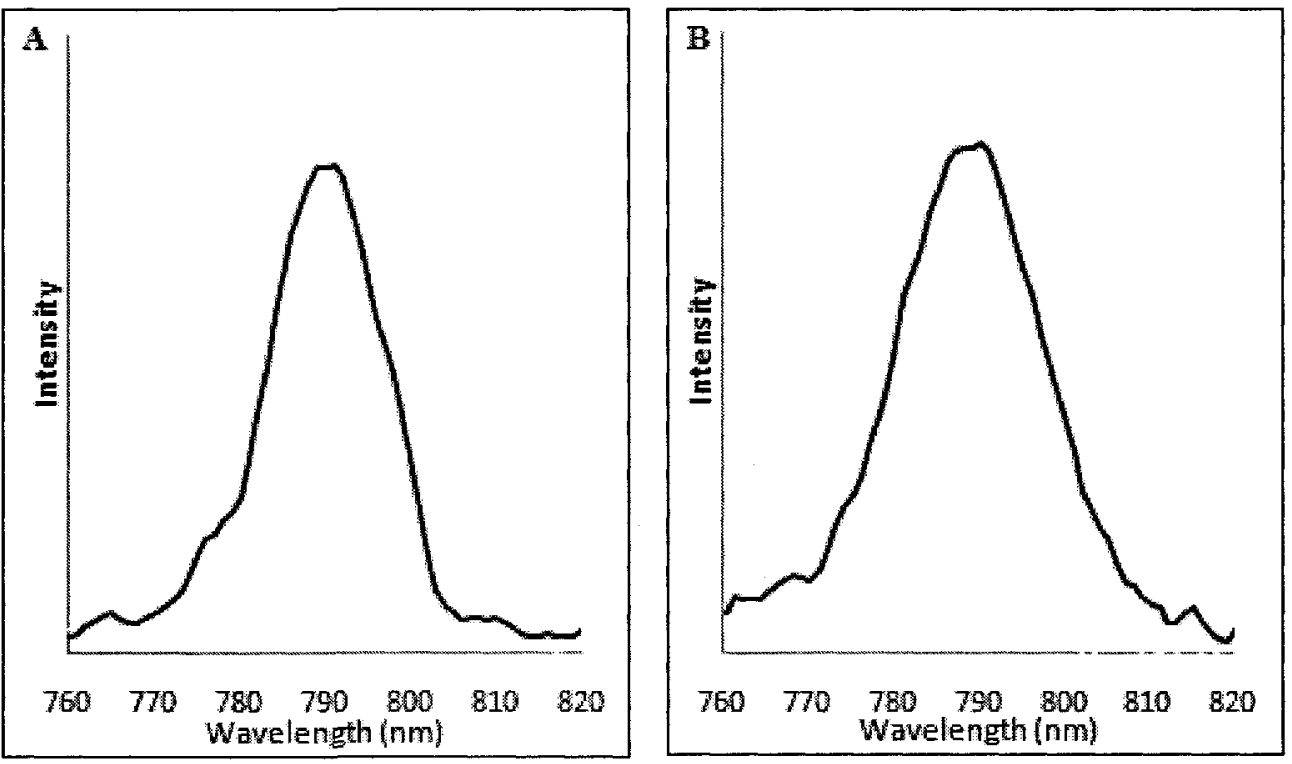

Figure 3.8. PL spectra of (a) DCH-Ru diamine III and (b) PRu-I excited at $520 \mathrm{~nm}$

\subsection{Conclusion}

Novel polyimides containing dinuclear ruthenium complex with good thermal and film forming ability were prepared and characterized. All the complex polyimides are NIR electrochromic in the mixed-valence state and show NIR photoluminescence at the wavelength around $790 \mathrm{~nm}$, which may be potentially useful for NIR optical sensor, biomedical imaging and optical attenuation applications. 


\subsection{Experimental}

\section{Materials}

4-Nitrobenzoyl chloride was purchased from Aldrich and used with no further purification. Hydrazine hydrate solution $85 \%$ (W/V) was purchased from ACP and used as received. Sodium carbonate anhydrous ACS reagent $99.5 \%$ was purchased from Aldrich and used as received. Platinum oxide was purchased from Nutritional Biochemical Corporation and used as received. Ammonium hexafluorophosphate was purchased from SynQuest Labs. Inc. Tetrahydrofuran (THF), N,N-dimethylformamide (DMF) and acetonitrile (ACN) were purchased from Caledon and used without further purification. 2,2-Bis(3,4-dicarboxyphenyl)hexafluoropropane dianhydride (6FDA) purchased from ChrisKEV company, Inc. and 4,4'-(4,4'Isopropylidenediphenoxy)bis(phthalic anhydride) 97\% (BEPA) purchased from Aldrich were recrystallized from acetic anhydride and dried at $120^{\circ} \mathrm{C}$ in vacuum oven. 9,9-Bis(4aminophenyl)fluorene (BAPF) was purchased from Ken Seika Corp and purified by recrystallization from ethanol.

\section{Characterizations}

Fourier Transform Infrared (FTIR) measurements were performed on a Bomen FTIR spectrophotometer. ${ }^{1} \mathrm{H}$ NMR and ${ }^{13} \mathrm{C}$ NMR spectra were recorded on a Bruker 300 spectrometer. The onset temperatures for $5 \%$ weight loss of the polymers were determined using a TA thermogravimetric analyzer at a heating rate of $10{ }^{\circ} \mathrm{C} / \mathrm{min}$ in nitrogen. Glass transition temperature ( $\mathrm{Tg}$ ) was determined on a TA DSC Q100 at a 
heating rate of $10^{\circ} \mathrm{C} / \mathrm{min}$ in nitrogen. Inherent viscosities of polymers were measured with an Ubbelohde capillary viscometer at $30.0 \pm 0.1{ }^{\circ} \mathrm{C}$ with a concentration of $0.5 \mathrm{~g} / \mathrm{dL}$. Cyclic voltammograms were recorded using a BAS 100B/W electrochemical station interfaced and monitored with a PC computer. A three-electrode cell configuration and $0.1 \mathrm{M}$ tetra-n-butylammonium hexafluorophosphate (TBAH) in acetonitrile as supporting electrolyte were used for all electrochemical measurements. The silver pseudo-reference electrode is calibrated with a ferrocene/ferrocenium redox couple. All the solutions were deoxygenated with nitrogen prior to electrochemical measurements. Spectroelectrochemical measurements were carried out by combining the electrochemical station with a Perkin Elmer Lambda 900 UV-vis-NIR spectrophotometer. Spectroelectrochemistry in solutions was conducted using an OTTLE cell or on ITO glass.

\section{Optical Attenuation Measurement}

In a quartz cuvette, were placed a tin-doped indium oxide (ITO) as a working electrode, a platinum counter electrode and silver reference electrode. The working electrode was coated with complex polymers or a mixture of stoichiometric amounts of DCH-Ru complex and triisocyanate (trimethylolpropane, carbamate with xylyeme diisocyanate; purchased from Aldrich) by spin coating, followed by thermal cure for 2 hours. The cuvette was fitted with a Teflon cap through which the reference electrode and counter electrode were introduced to the cell via pre-drilled holes. 
4-Nitro-N'-(4-nitrobenzoyl)benzohydrazide (I)

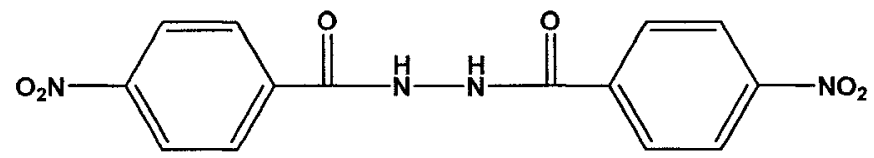

To a $100 \mathrm{~mL}$, round-bottomed flask 4-nitrobenzoyl chloride $(1.9 \mathrm{~g}, 10 \mathrm{mmol})$ was added slowly to a solution of hydrazine hydrate $(85 \% \mathrm{~W} / \mathrm{V})(0.38 \mathrm{~mL}, 10 \mathrm{mmol})$ in 30 $\mathrm{mL}$ of $95 \%$ ethanol at $15{ }^{\circ} \mathrm{C}$. To this solution, sodium carbonate $(1.06 \mathrm{~g}, 10 \mathrm{mmol})$ in 10 $\mathrm{mL}$ of water was added dropwise together with another amount of 4-nitrobenzoyl chloride (1.9 g, $10 \mathrm{mmol})$. The bright orange solution turned white-milky color with precipitate after one hour of vigorous stirring. The solution was stirred for another hour at the same temperature, then the precipitate was filtered and washed with $95 \%$ ethanol to give the desired product as off-white powders: $2.83 \mathrm{~g}$ (43\% yield); mp $295{ }^{\circ} \mathrm{C} ;{ }^{1} \mathrm{H} \mathrm{NMR}$ $\left(300 \mathrm{MHz}, \mathrm{DMSO}-\mathrm{d}_{6}\right) \delta 11.0(2 \mathrm{H}, \mathrm{S}), 8.34(4 \mathrm{H}, \mathrm{m}), 8.17(4 \mathrm{H}, \mathrm{m}) ;{ }^{13} \mathrm{C} \mathrm{NMR}(75.5 \mathrm{MHz}$, $\left.\operatorname{DMSO}_{6}\right) \delta 164.73,149.96,138.36,129.51,124.30$

\section{4-Amino-N'-(4-aminobenzoyl)benzohydrazide (II)}

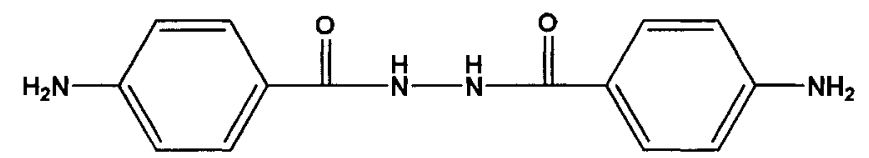

In a hydrogenation bottle, $1 \mathrm{~g}$ of 4-nitro-N'-(4-nitrobenzoyl)benzohydrazide (I) was suspended in $60 \mathrm{~mL}$ of THF. Platinum oxide $(0.1 \mathrm{~g})$ was then added and the hydrogenation shaker switched on for 4 hours at 50 psi. The mixture was then filtered and THF was evaporated to give very fine off-white powders: $0.6 \mathrm{~g}(73 \%$ yield $) ; \mathrm{mp} 272{ }^{\circ} \mathrm{C}$; 
${ }^{1} \mathrm{H}$ NMR $\left(300 \mathrm{MHz}\right.$, DMSO-d $\left.\mathrm{d}_{6}\right) \delta 11.0(2 \mathrm{H}, \mathrm{S}), 8.4(4 \mathrm{H}, \mathrm{m}), 8.2(4 \mathrm{H}, \mathrm{m}), 7.8-7.9(4 \mathrm{H}$, $\mathrm{m}) ;{ }^{13} \mathrm{C}$ NMR (75.5 MHz, DMSO-d 6 ) $\delta 164.79,150.0,138.4,129.5,124.30$

\section{DCH-Ru complex monomer (III)}

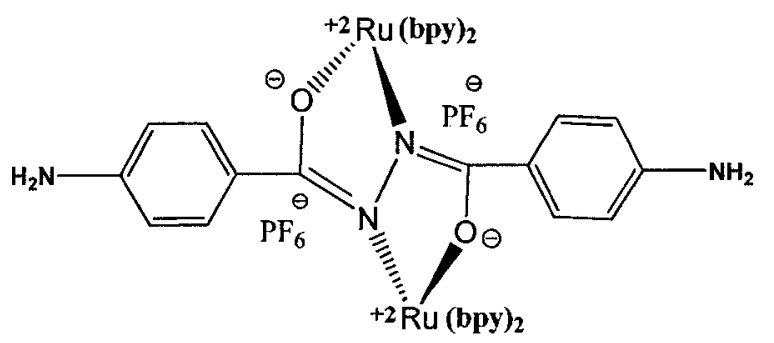

Compound II (0.27 g, $1.0 \mathrm{mmol}), \mathrm{Ru}(\mathrm{bpy})_{2} \mathrm{Cl}_{2} \cdot \mathrm{H}_{2} \mathrm{O}(1.03 \mathrm{~g}, 2 \mathrm{mmol})$ and $\mathrm{NaOH}$ $(0.18 \mathrm{~g}, 4.5 \mathrm{mmol})$ were dissolved in $\mathrm{DMF} / \mathrm{H}_{2} \mathrm{O}(2: 3 \mathrm{v} / \mathrm{v}, 25 \mathrm{~mL})$. The mixture was then refluxed at $100-110^{\circ} \mathrm{C}$ under argon for 24 hours. After cooling to room temperature, the product was precipitated out by pouring in $300 \mathrm{~mL}$ of aqueous solution of $\mathrm{NH}_{4} \mathrm{PF}_{6}$ $(0.75 \mathrm{~g}, 4.6 \mathrm{mmol})$. The product was then filtered, re-dissolved in acetonitrile and precipitated out from ether. Purification of the crude complex was done on neutral alumina column using 4:1 ACN/toluene. The purple band was collected, concentrated under reduced pressure, dissolved in ACN, precipitated out from ether and dried under vacuum overnight: $0.83 \mathrm{~g}\left(60 \%\right.$ yield); $\mathrm{MS}$ (ESI, $\left.-\mathrm{PF}_{6}{ }^{-}\right): 1241.0$ 


\section{General polymerization procedures}

Method A:

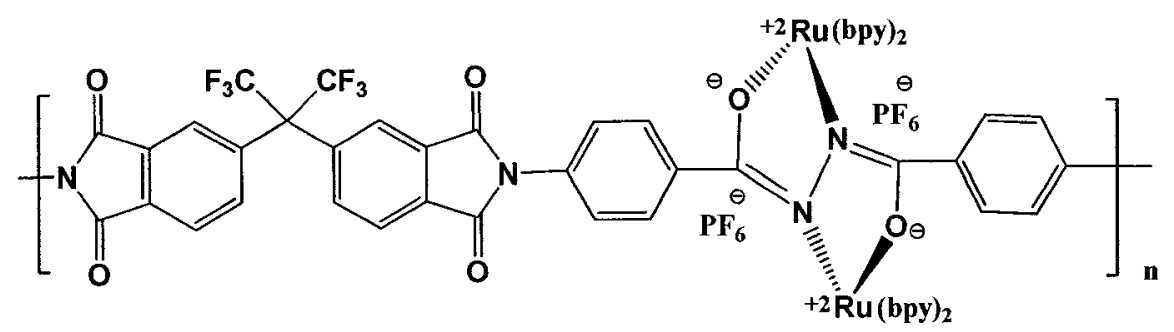

Salicylic acid $(1.77 \mathrm{~g}, 1.23 \mathrm{~mL})$ was placed in a pressure glass tube, melt and maintained at $200{ }^{\circ} \mathrm{C}$ for $10 \mathrm{~min} .6 \mathrm{FDA}(0.158 \mathrm{mmol}, 0.070 \mathrm{~g})$ and $\mathrm{DCH}-\mathrm{Ru}$ diamine $(0.158 \mathrm{mmol}, 0.219 \mathrm{~g})$ were introduced into the melt. The concentration of monomers in salicylic acid was $23 \mathrm{wt} / \mathrm{v} \%$, followed by addition of 5 drops of isoquinoline. Once all were dissolved, the reaction tube was closed tightly (with a crew cap) and the portion of the tube containing the reaction mixtures (about $1 / 3$ in length) was immersed in an oil bath at $200{ }^{\circ} \mathrm{C}$ for $2.0 \mathrm{~h}$. After cooling to about $150{ }^{\circ} \mathrm{C}$, the tube cap was removed carefully. The red viscous polyamic acid solution was poured slowly onto Pyrex plate placed on a hot plate, which was then heated slowly up $200{ }^{\circ} \mathrm{C}$ at a rate of $10^{\circ} \mathrm{C} / 5 \mathrm{~min}$ for imidization. The polymer was collected, washed with methanol/water solution and dried in vacuum oven at $120^{\circ} \mathrm{C}$.

PRu-I-acid: IR (KBr, cm $\left.{ }^{-1}\right): 3320(\mathrm{~N}-\mathrm{H}$ amide and $\mathrm{OH}$ overlapped), $1590(\mathrm{C}=\mathrm{O})$.

PRu-I: $62 \%$ yield. IR $\left(\mathrm{KBr}, \mathrm{cm}^{-1}\right): 1780$ (unsymmetrical $\mathrm{C}=\mathrm{O}$ of imide), 1720 (symmetrical $\mathrm{C}=\mathrm{O}$ of imide), 1374 (C-N of imide), 760 (C-N-C of imide). 


\section{Method B:}

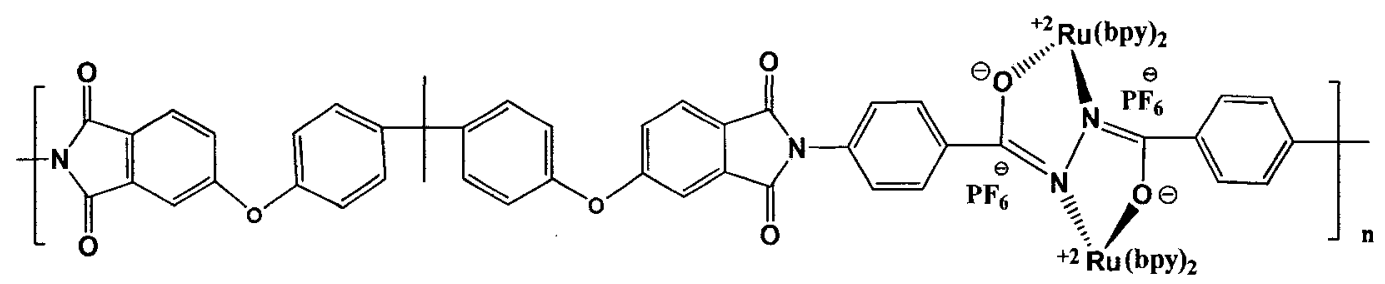

A mixture of $4,4^{\prime}-\left(4,4^{\prime}\right.$-isopropyldienediphenoxy bis(phthalic anhydride) $(0.2$ mmol, $0.1041 \mathrm{~g})$ and DCH-Ru diamine $(0.20 \mathrm{mmol}, 0.277 \mathrm{~g})$ in $1.9 \mathrm{~mL}$ of DMF was placed in a dry $10 \mathrm{~mL}$ one-neck round bottom flask. The concentration of monomers in DMF was $20 \mathrm{wt} / \mathrm{v} \%$. The reaction mixture was heated at $100{ }^{\circ} \mathrm{C}$ for 4 hours under argon. After that, the viscous polyamic acid solution was poured slowly onto Pyrex plate placed on a hot plate, which was then slowly heated up $200^{\circ} \mathrm{C}$ at a heating rate of $10^{\circ} \mathrm{C} / 5 \mathrm{~min}$ for imidization. The polymer was collected, washed with methanol/water solution and dried in vacuum oven at $120^{\circ} \mathrm{C}$.

PRu-II-acid: IR (KBr, $\left.\mathrm{cm}^{-1}\right): 1721(\mathrm{~N}-\mathrm{H}$ of amide and $\mathrm{OH}$ overlapped), $1670(\mathrm{C}=\mathrm{O})$.

PRu-II: 76\% yield. IR ( $\left.\mathrm{KBr}, \mathrm{cm}^{-1}\right): 1777$ (unsymmetrical $\mathrm{C}=\mathrm{O}$ of imide), 1721 (symmetrical $\mathrm{C}=\mathrm{O}$ of imide), 1375 (C-N of imide), 760 (C-N-C of imide).

\section{Method C (copolymerization):}

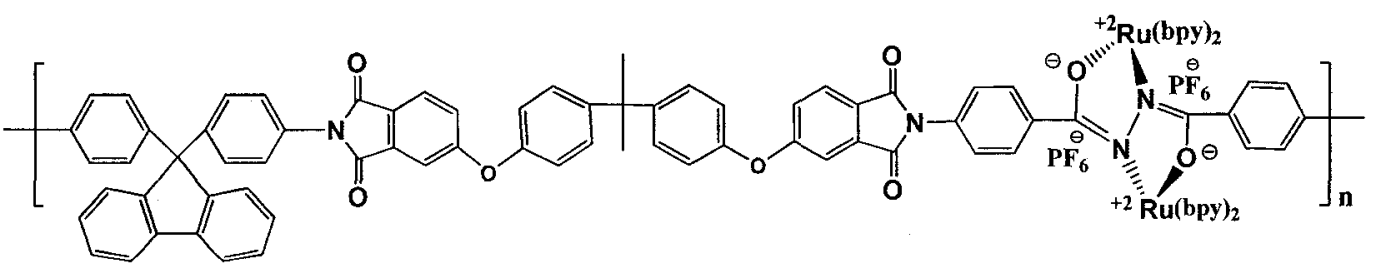

A mixture of $4,4^{\prime}-\left(4,4^{\prime}\right.$-isopropyldienediphenoxy)bis(phthalic anhydride) $(0.2$ mmol, $0.104 \mathrm{~g})$, DCH-Ru diamine III (0.10 mmol, $0.1386 \mathrm{~g})$ and 9,9-bis(4-aminophenyl) fluorene $(0.1 \mathrm{mmol}, 0.0348 \mathrm{~g})$ and $1.5 \mathrm{~mL}$ of m-cresol were placed in a dry $10 \mathrm{~mL}$ one- 
neck, round-bottomed flask, followed by addition of 5 drops of isoquinoline. The concentration of monomers in $\mathrm{m}$-cresol was $20 \mathrm{wt} / \mathrm{v} \%$. The reaction mixture was refluxed at $180^{\circ} \mathrm{C}$ for 24 hours under argon. After that, the viscous polyamic acid solution was poured slowly onto Pyrex plate placed on a hot plate, which was then heated up to $200{ }^{\circ} \mathrm{C}$ at a heating rate of $10^{\circ} \mathrm{C} / 5 \mathrm{~min}$ for imidization. The polymer was collected, washed with methanol/water solution and dries in vacuum oven at $120^{\circ} \mathrm{C}$.

PRu-III-acid: IR (KBr, $\left.\mathrm{cm}^{-1}\right): 1709$ (N-H of amide and $\mathrm{OH}$ overlapped), $1588(\mathrm{C}=\mathrm{O})$.

PRu-III: $71 \%$ yield. IR $\left(\mathrm{KBr}, \mathrm{cm}^{-1}\right): 1775$ (unsymmetrical $\mathrm{C}=\mathrm{O}$ of imide), 1720 (symmetrical $\mathrm{C}=\mathrm{O}$ of imide), 1367 (C-N of imide), 760 (C-N-C of imide). 


\subsection{References}

1. Yen CT and Chen WC. Macromolecules 2003; 36: 3315-3319

2. Ando S. J. Photopolym. Sci. Tech. 2004; 17(2): 219-232

3. Sroog CE. Prog. Polym. Sci. 1991;16: 561-694

4. Wilson D, Stenzenberger HD, Hergenrother PM. Polyimides. Glasgow: Blackie and Son; 1990.

5. Qi Y, Desjardins P and Wang ZY. J. Optics A: Pure App. Opt. 2002; 4: S273-S277

6. Wang ZY, Zhang J, Wu X, Birau M, Yu G, Qi Y, Desjardins P, Meng X, Gao JP, Todd E, Song N, Bai Y, Beaudin AM and LeClair G. Pure App. Chem. 2004; 75(78): $1435-1443$

7. Wang S, Li X, Xun S, Wan X and Wang ZY. Macromolecules 2006; 39: 7502-7507

8. Harris FW, Norris SO, Lanier LH, Reinfardt BA, Case RD, Varaprath S, Padaki SM, Torres M and Feld WA. Polyimides: Synthesis, Characterization and Applications 1984; Vol 1\&2 Ed. Mittal KL. Plenum, New York

9. Hasanain F and Wang ZY. Polymer 2008; 49: 831-835

10. Sroog CE, Endrey AL, Abramo SV, Berr CE, Edwards WM, and Olivier KL. J. Polym. Sci. Part A 1965; 3:1373-1390 


\section{Future work}

The new one-step synthetic method for polyimides in salicylic acid is very promising candidate for the synthesis of different types of polyimides such as AB-type, semicrystalline and crystalline polyimides. Pyrimidine-containing polyimides (ie. PRM diamine) are promising for high-strength fiber polyimides, therefore using the salicylic acid melt the fibers can be drawn directly for further testing. For example, the morphology and deformation for the new pyrimidine-bridged polyimide fibers can be examined by scanning electron microscopy (SEM) and wide angle X-ray diffraction (WAXD) and tensile measurements.

The question of making high molecular weight ruthenium-complex polyimides is left unresolved in this thesis. Also, different structural DCH-Ru diamines can be designed for further studies while maintaining the high thermal and electrochromic stability of the resulting polyimide. 
Appendix A (Chapter 2):

FT-IR Spectra:
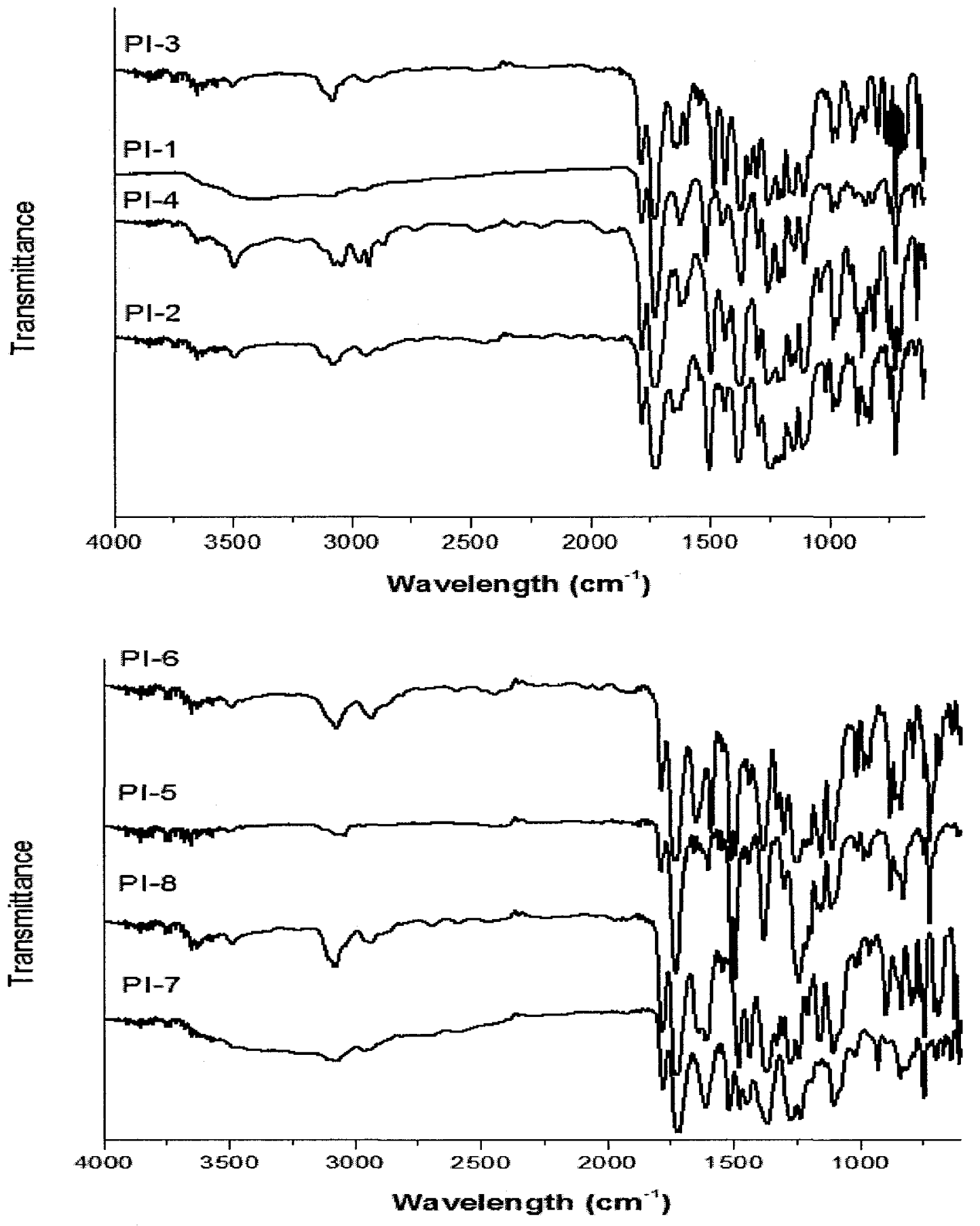

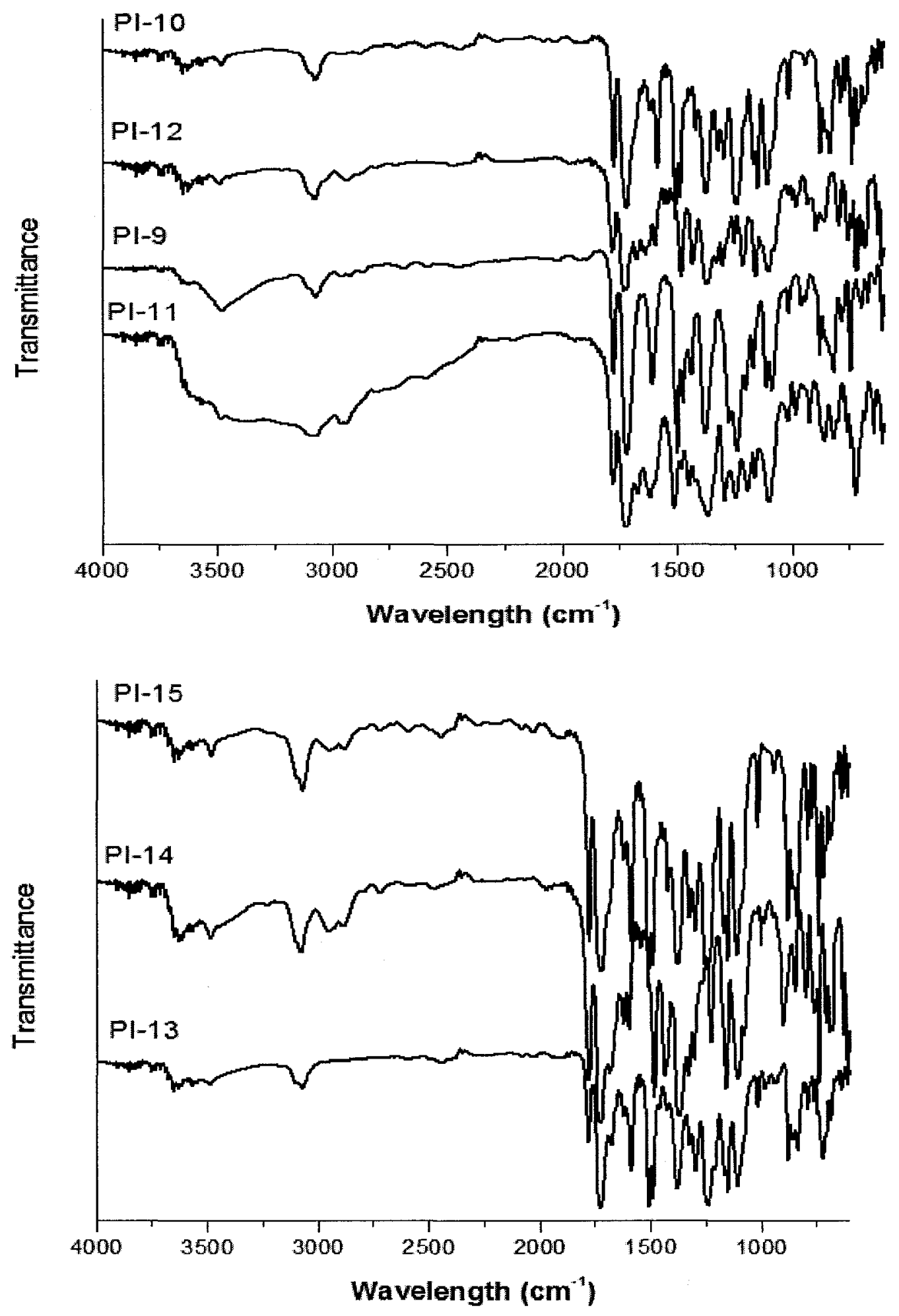

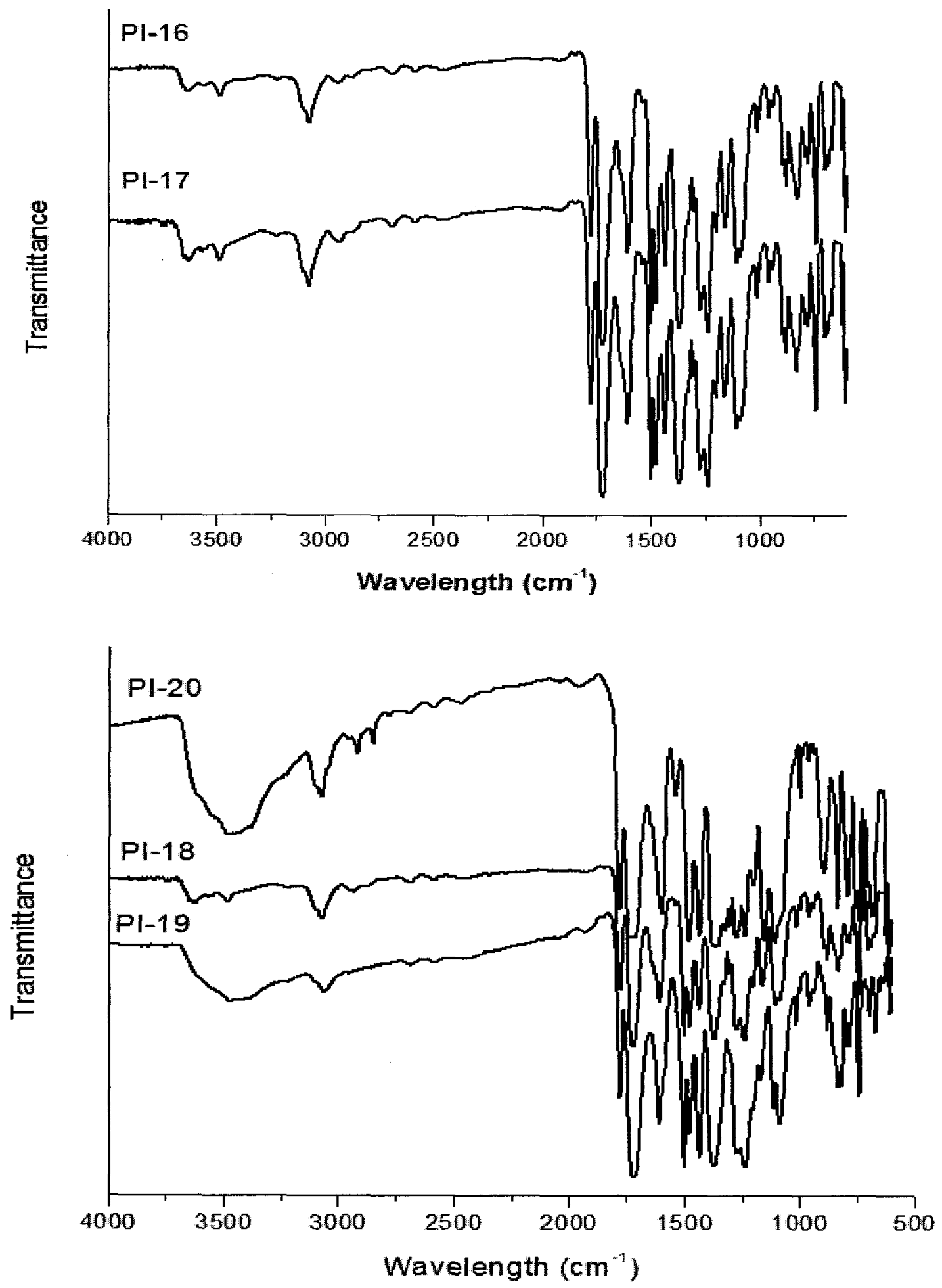

III 


\section{PRM diamine}

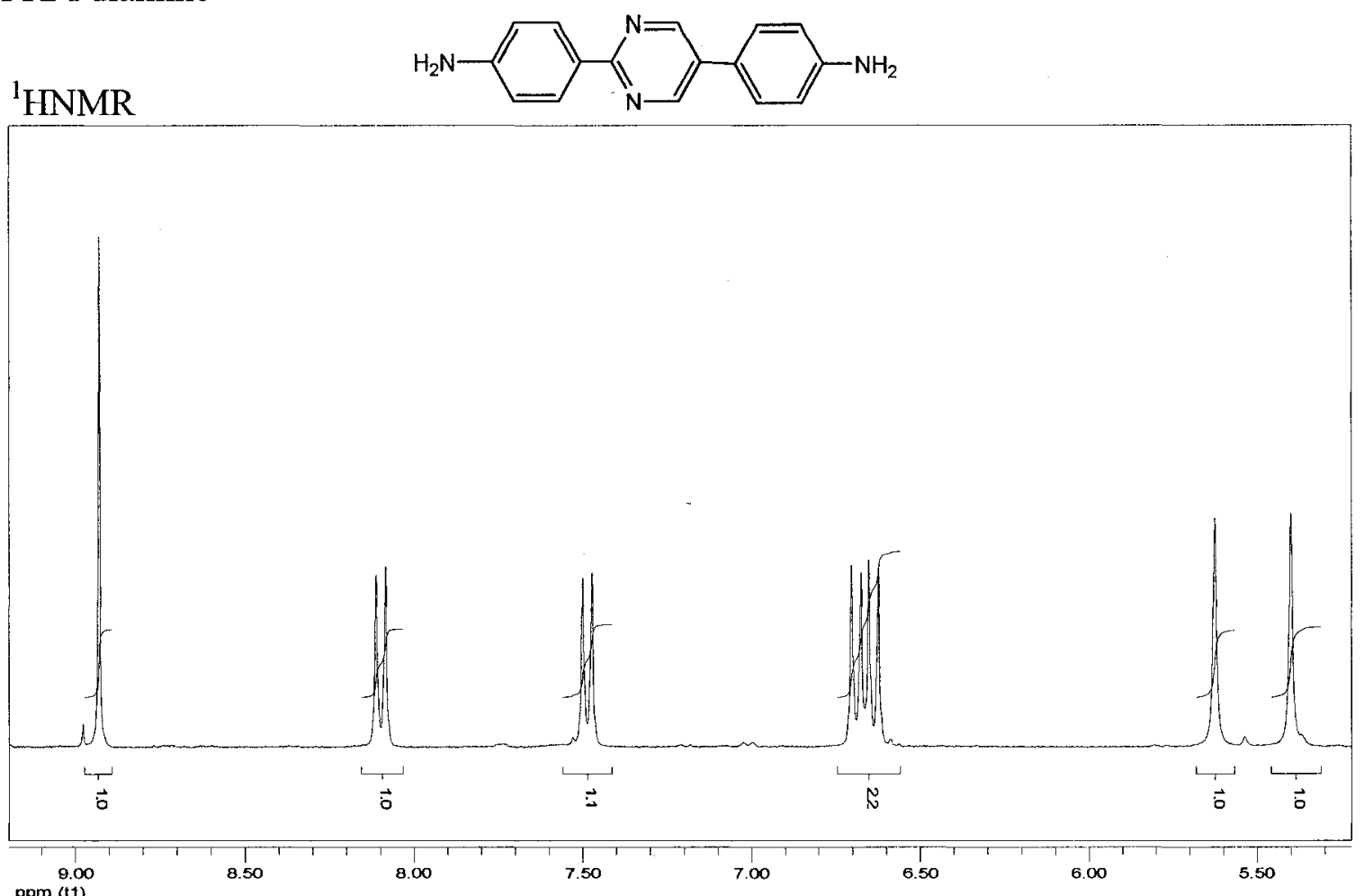

\section{${ }^{13}$ CNMR}

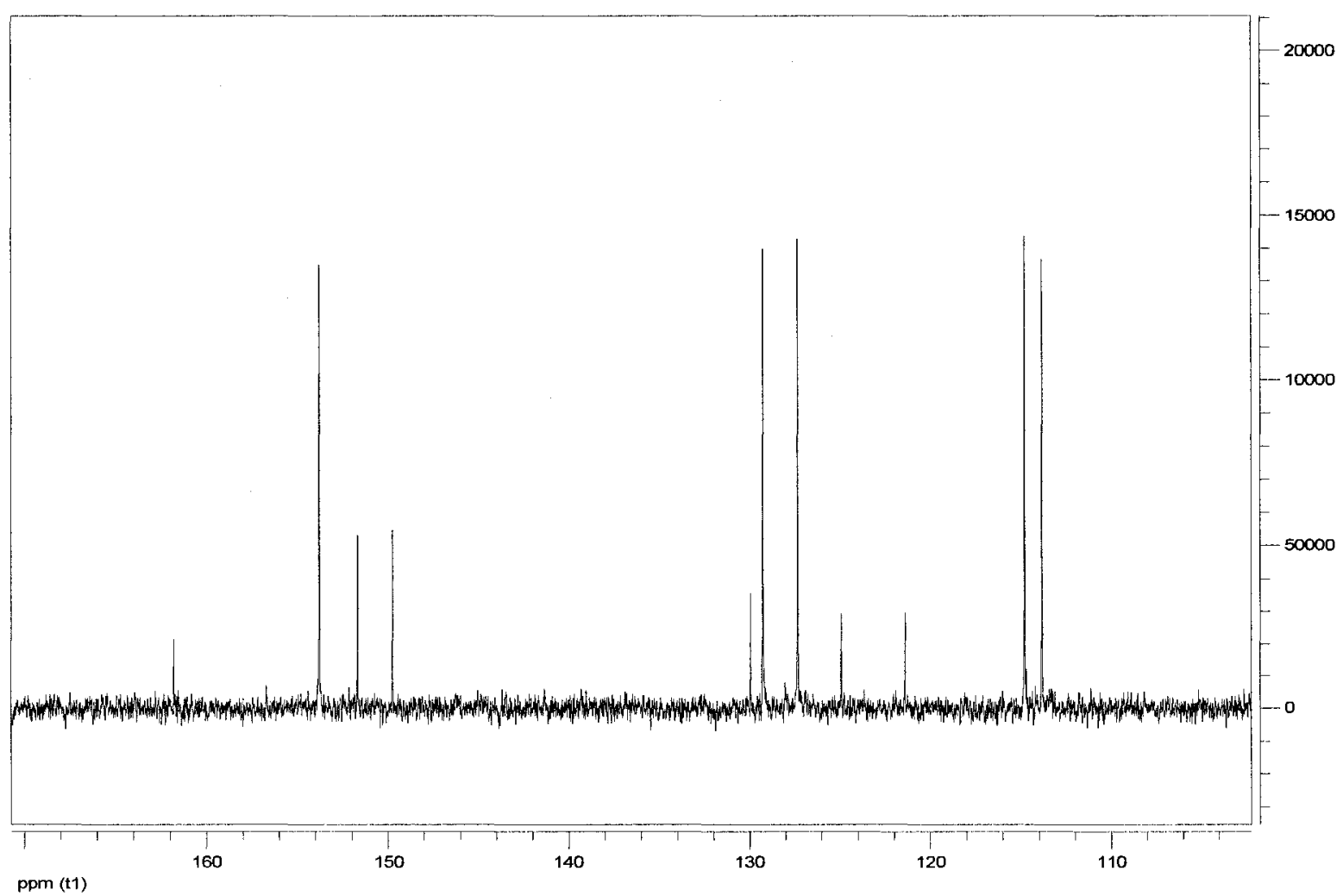




\section{Appendix B (Chapter 3):}

Compound I:

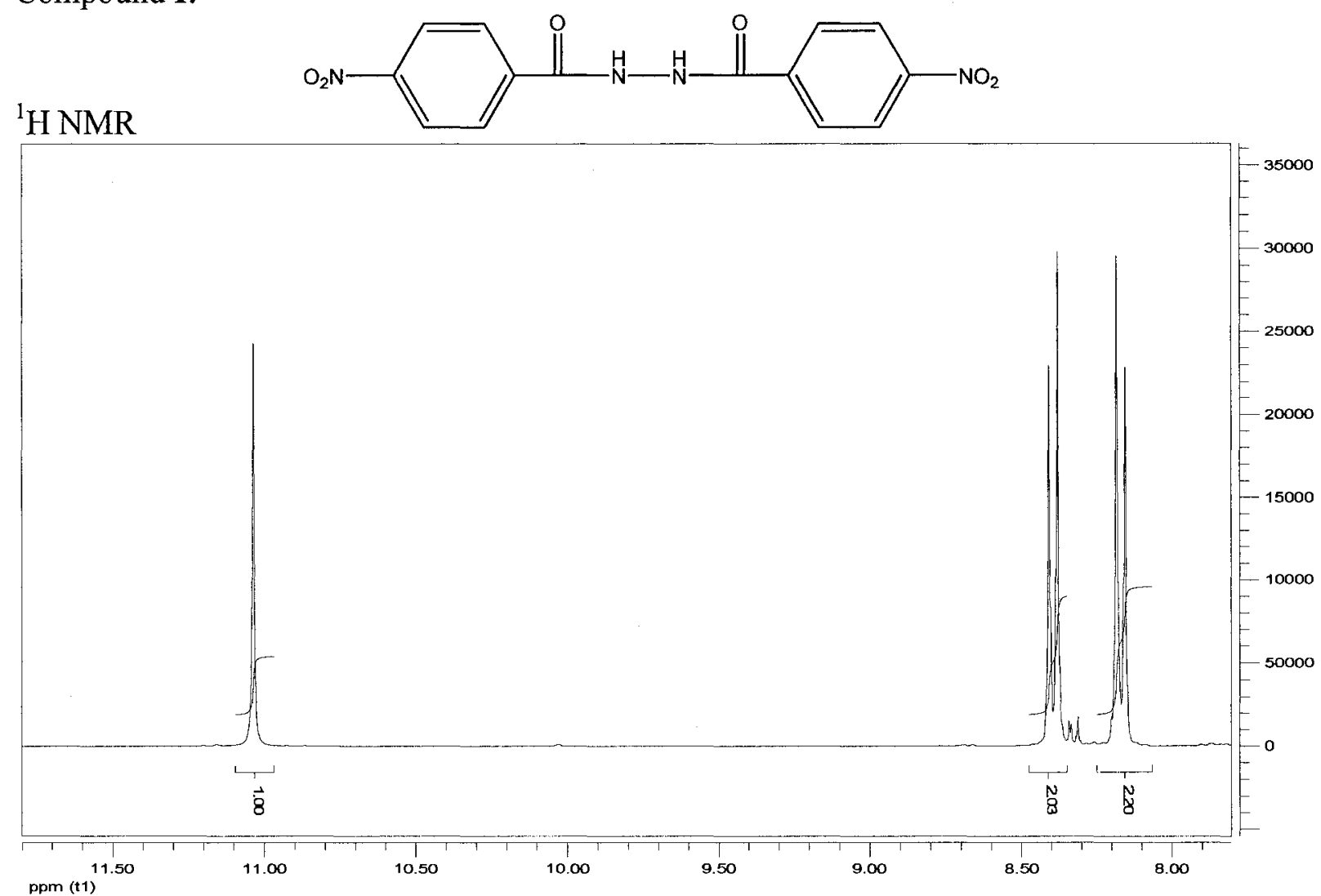

\section{${ }^{13} \mathrm{CNMR}$}

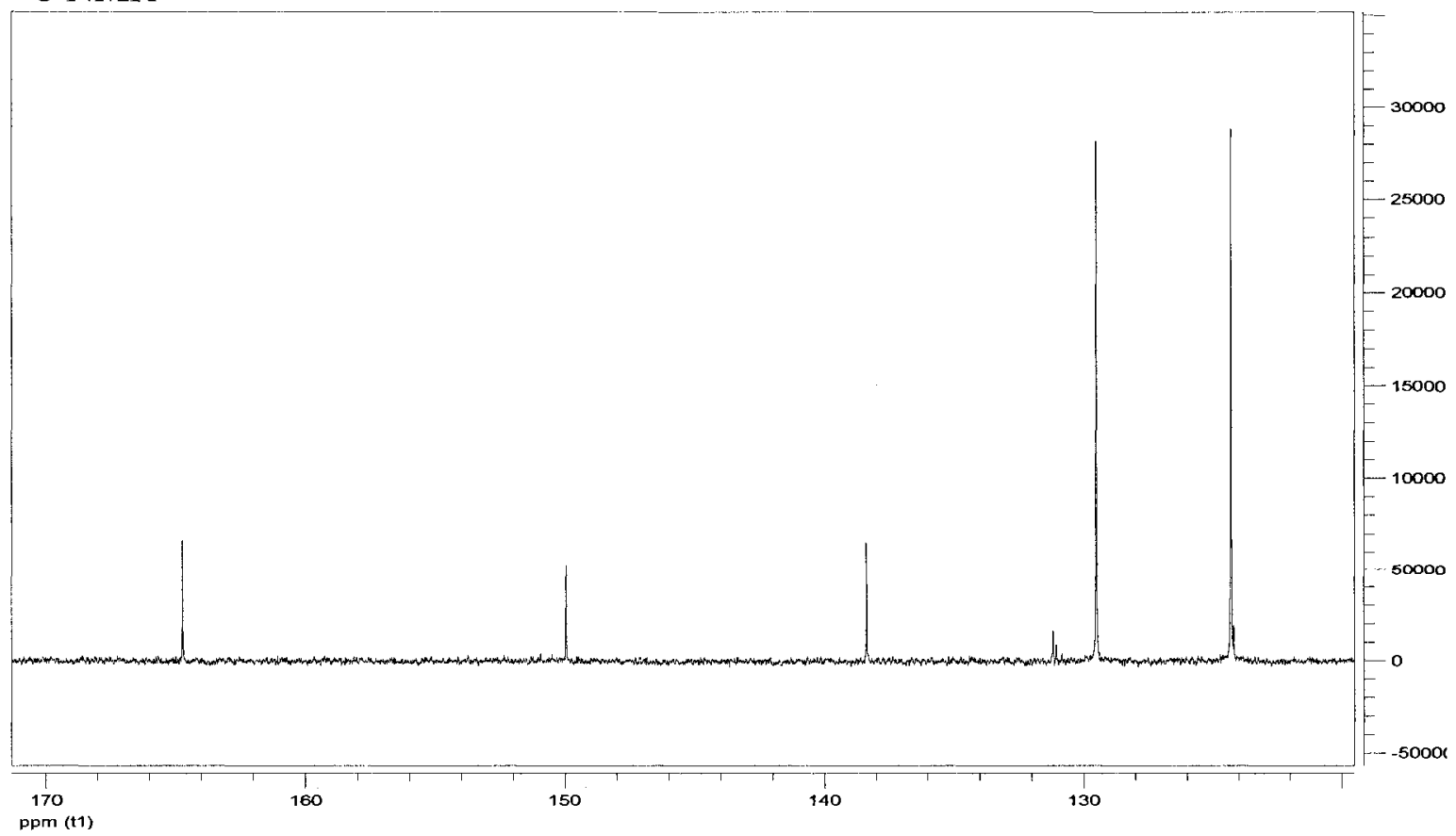




\section{Compound II:}

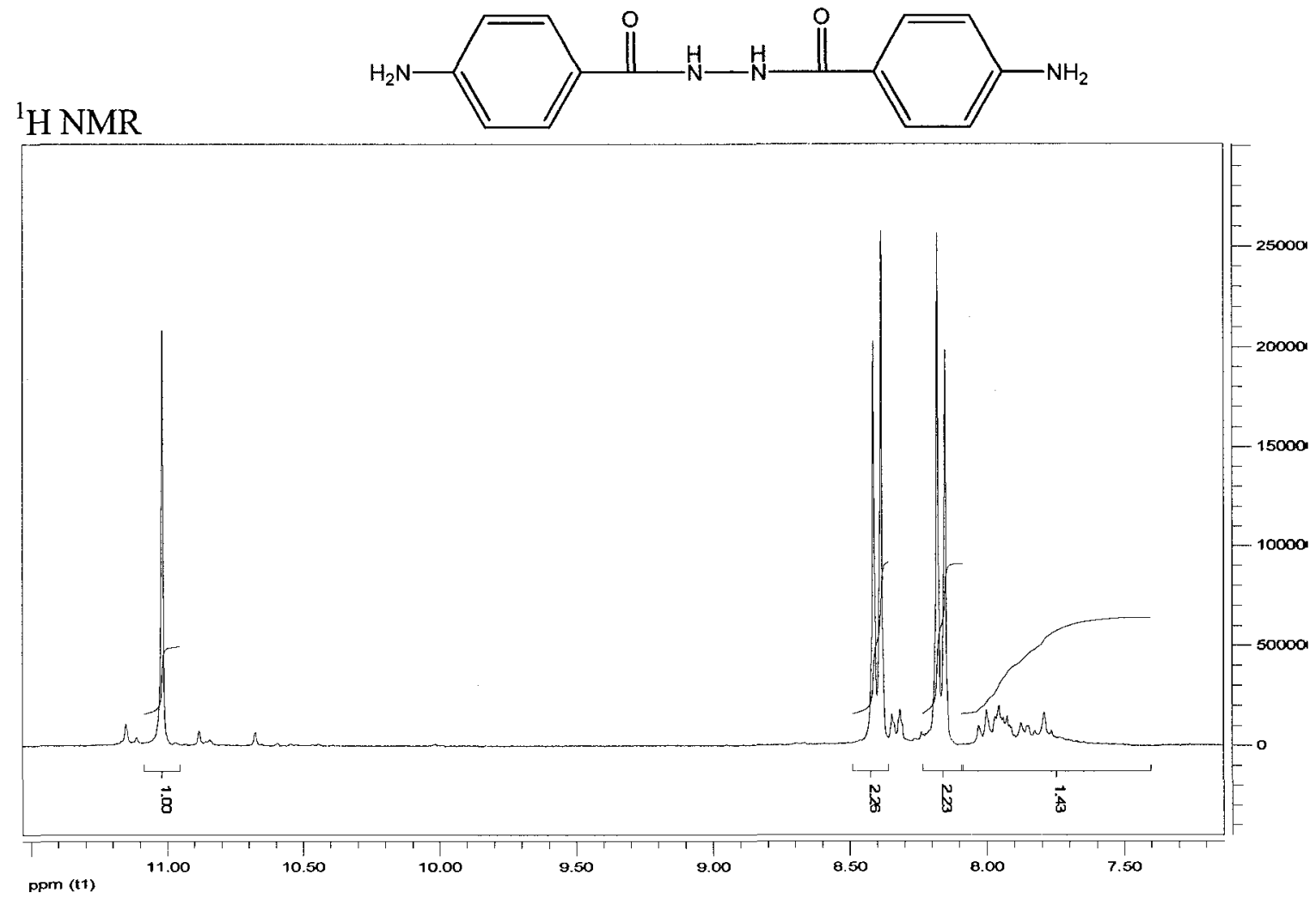

\section{${ }^{13} \mathrm{C}$ NMR}

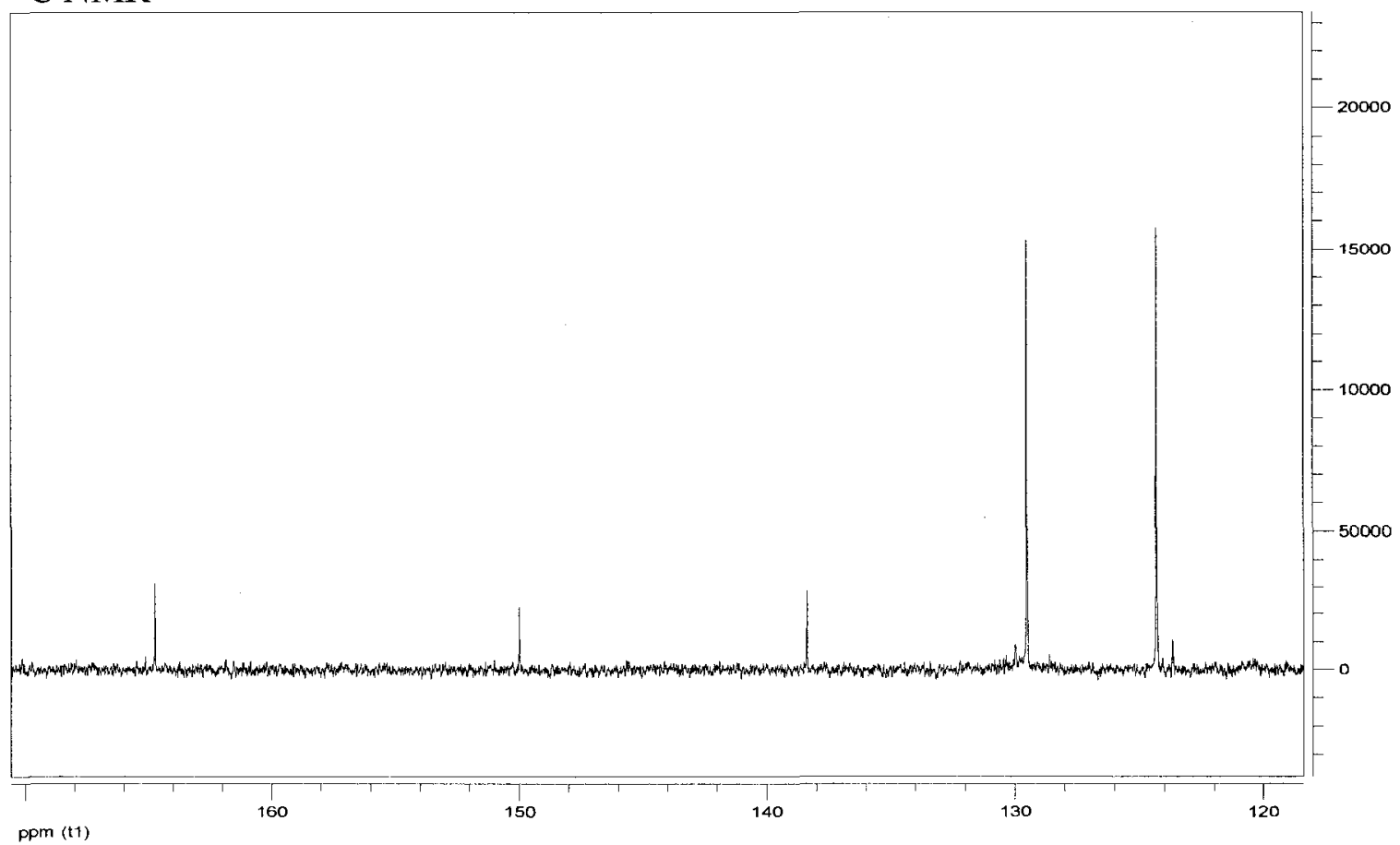


FT-IR:

PRu-I

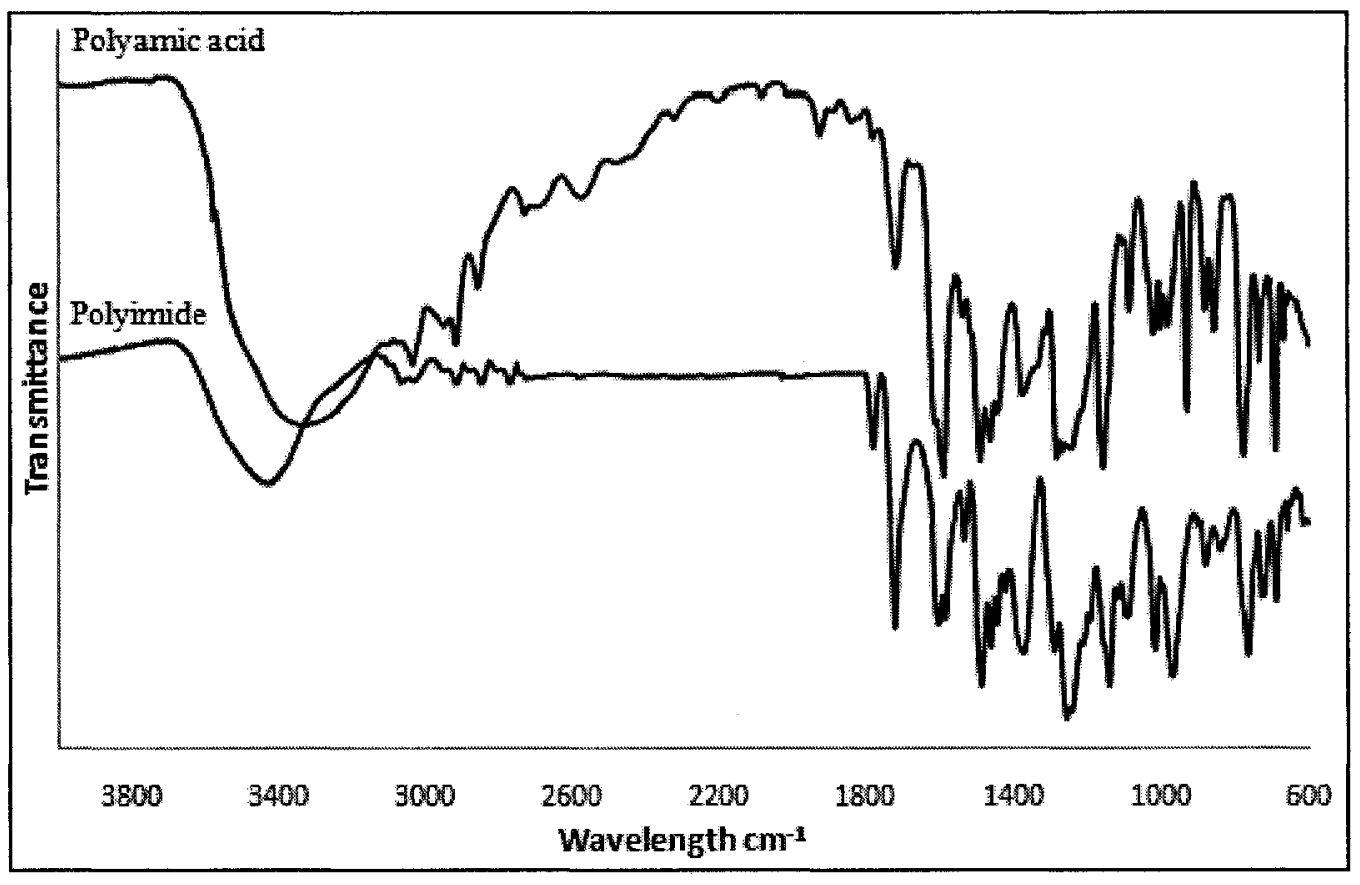

PRu-II

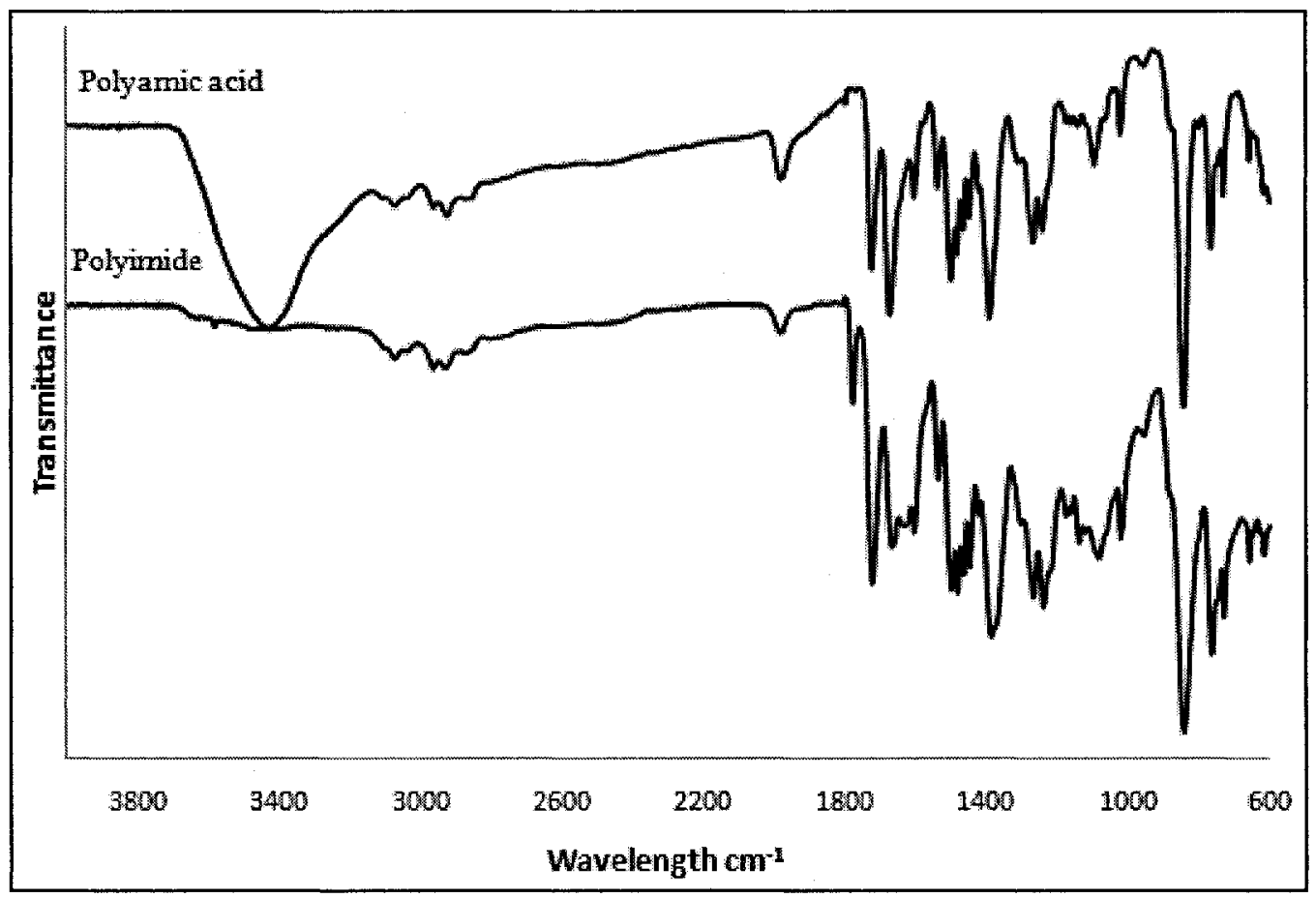


CV:

PRu-II

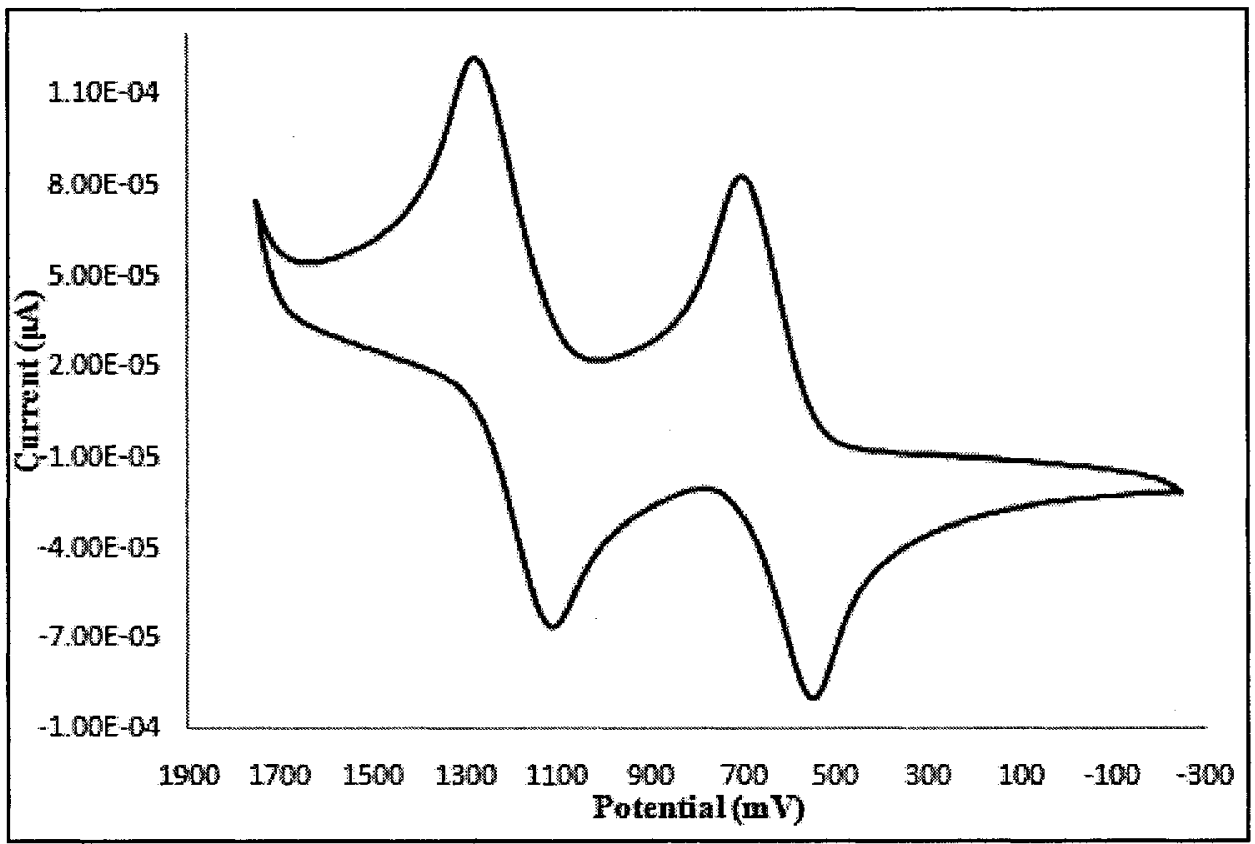

PRu-III

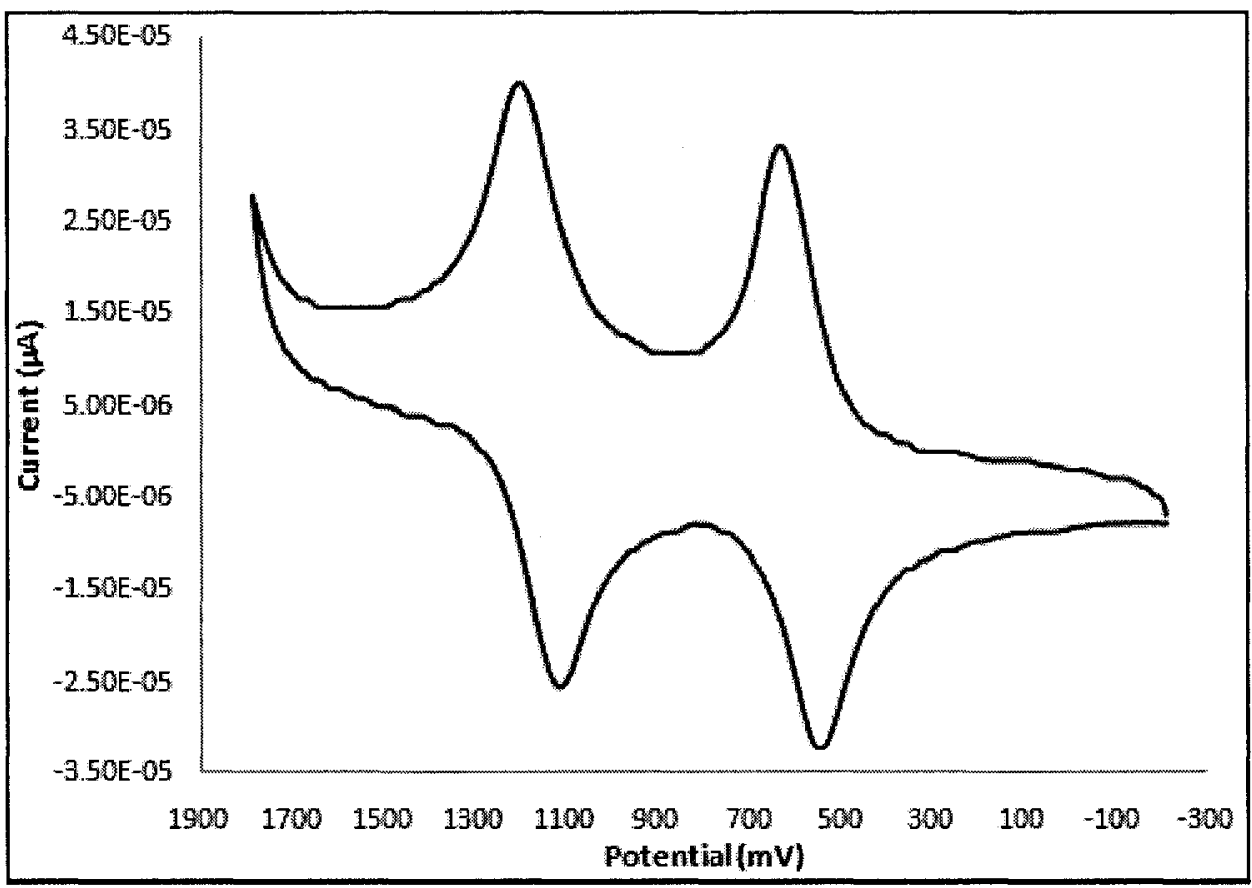


UV/vis/NIR:

PRu-II

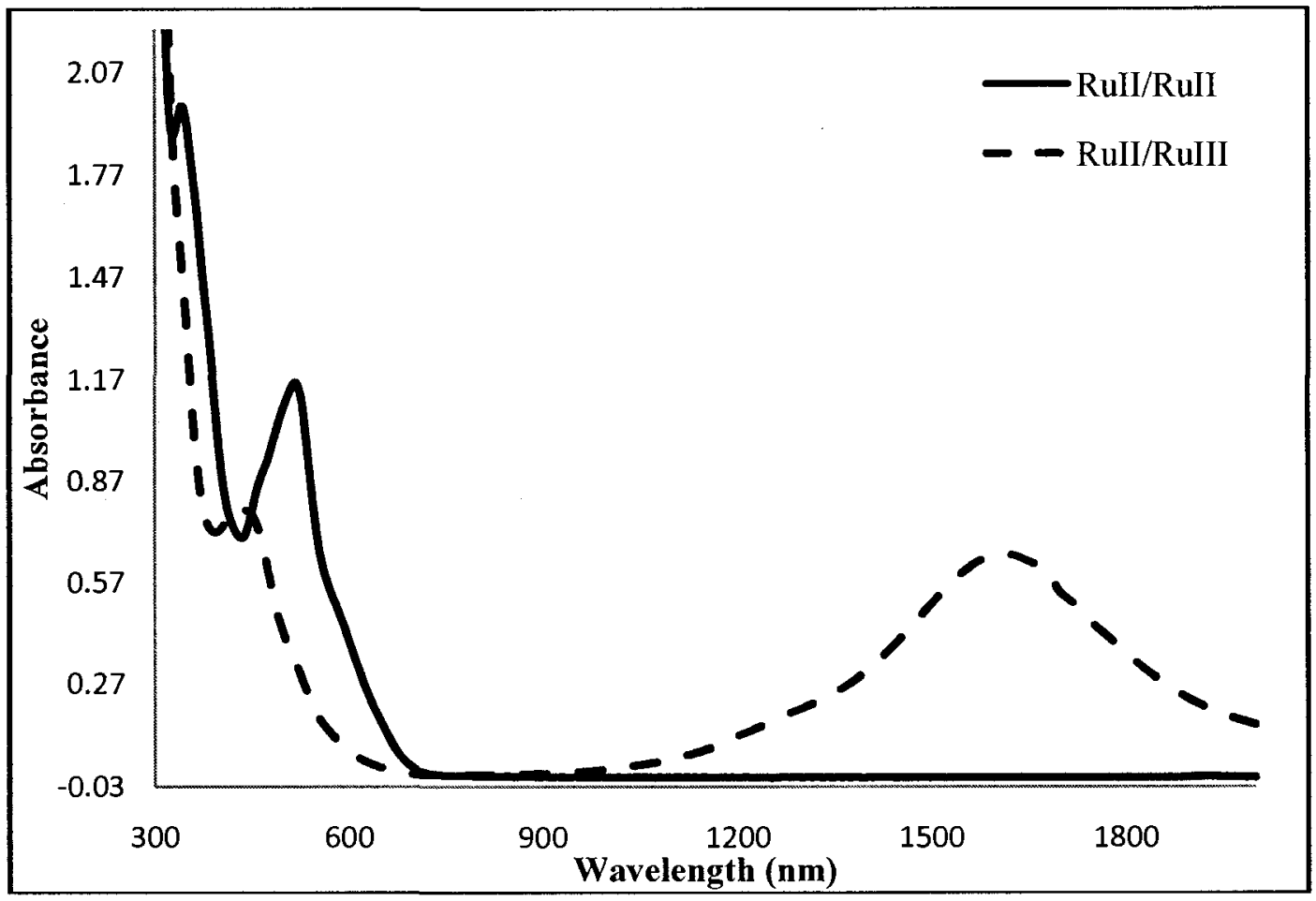

PRu-III

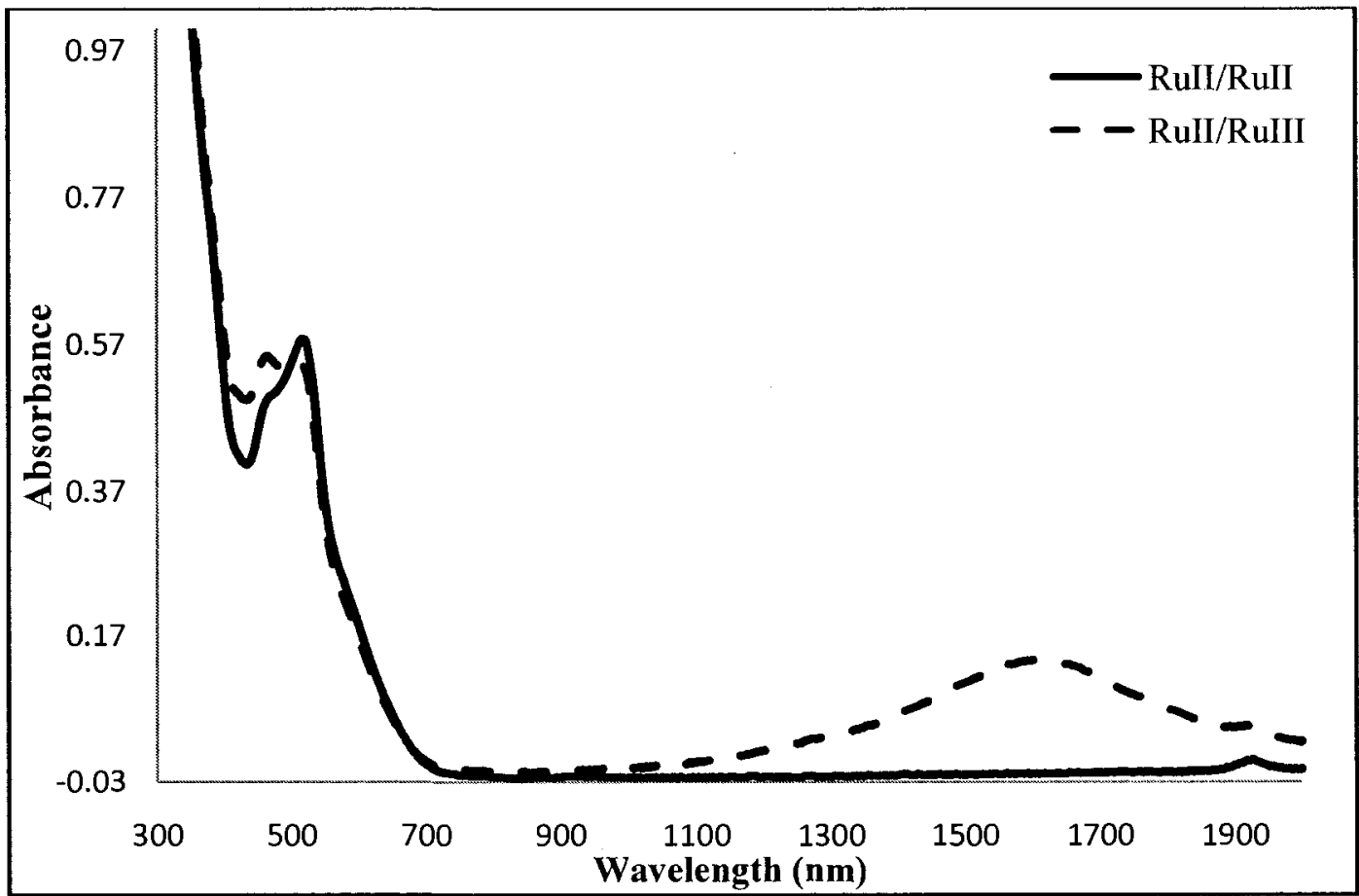


Switching cycles:

PRu-II

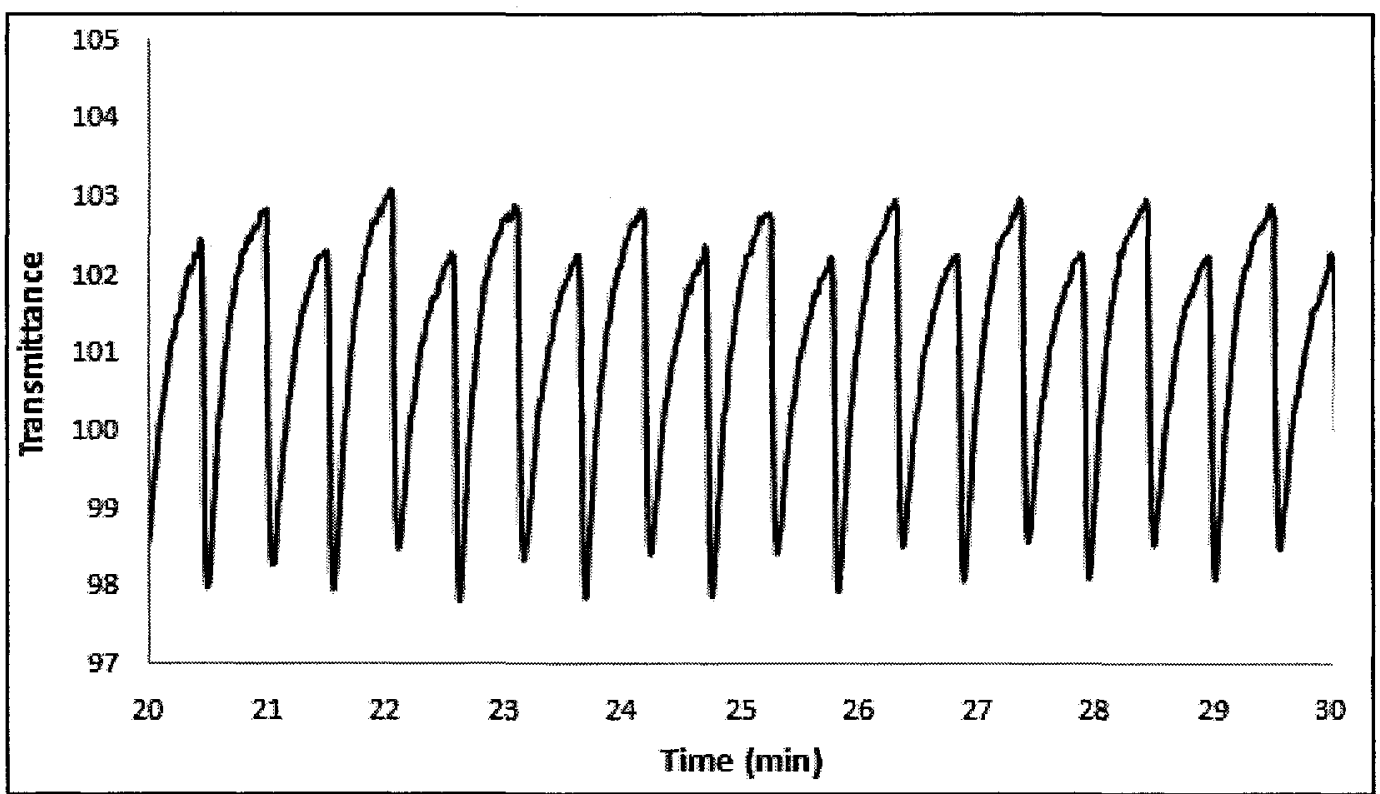

PRu-III

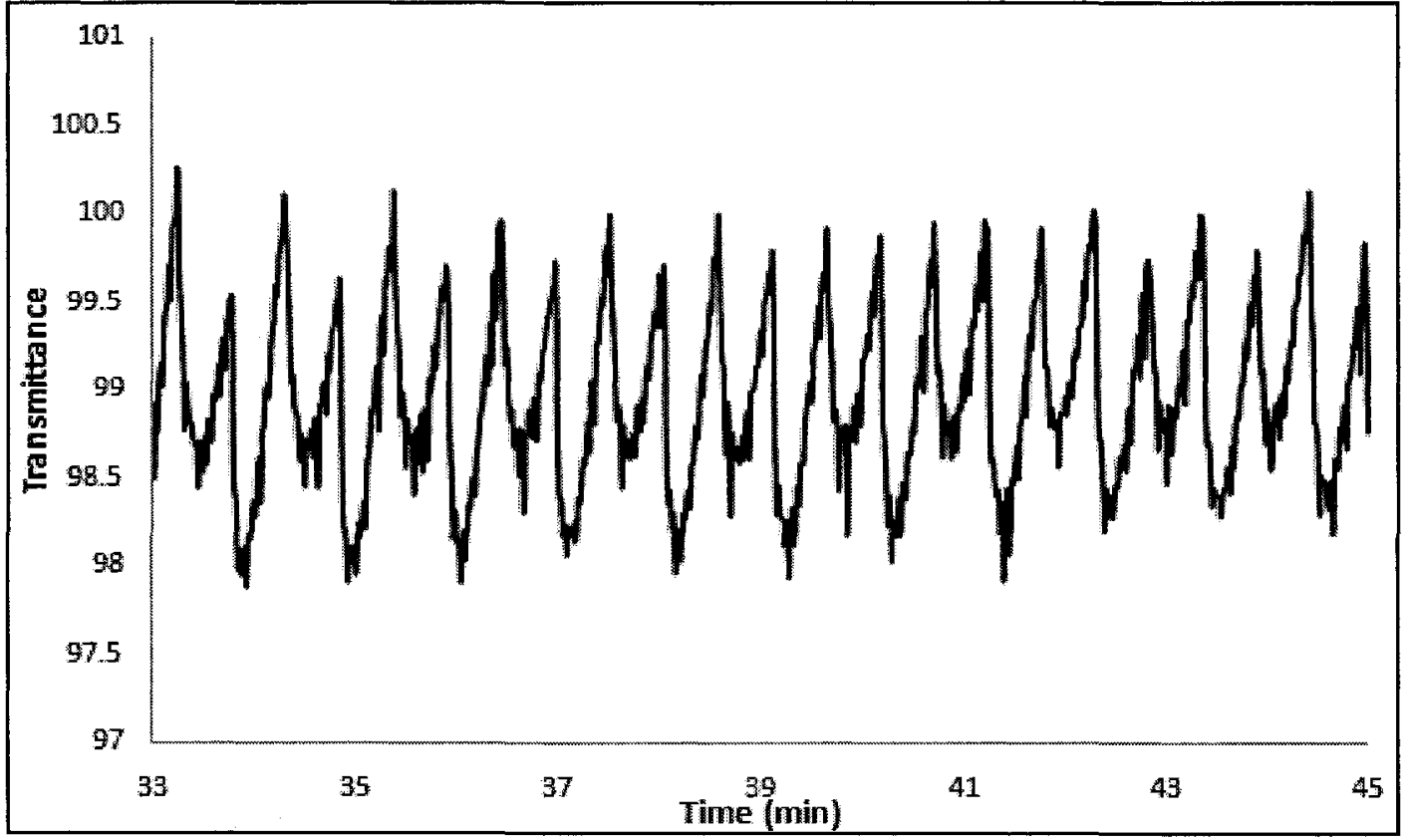


PL:

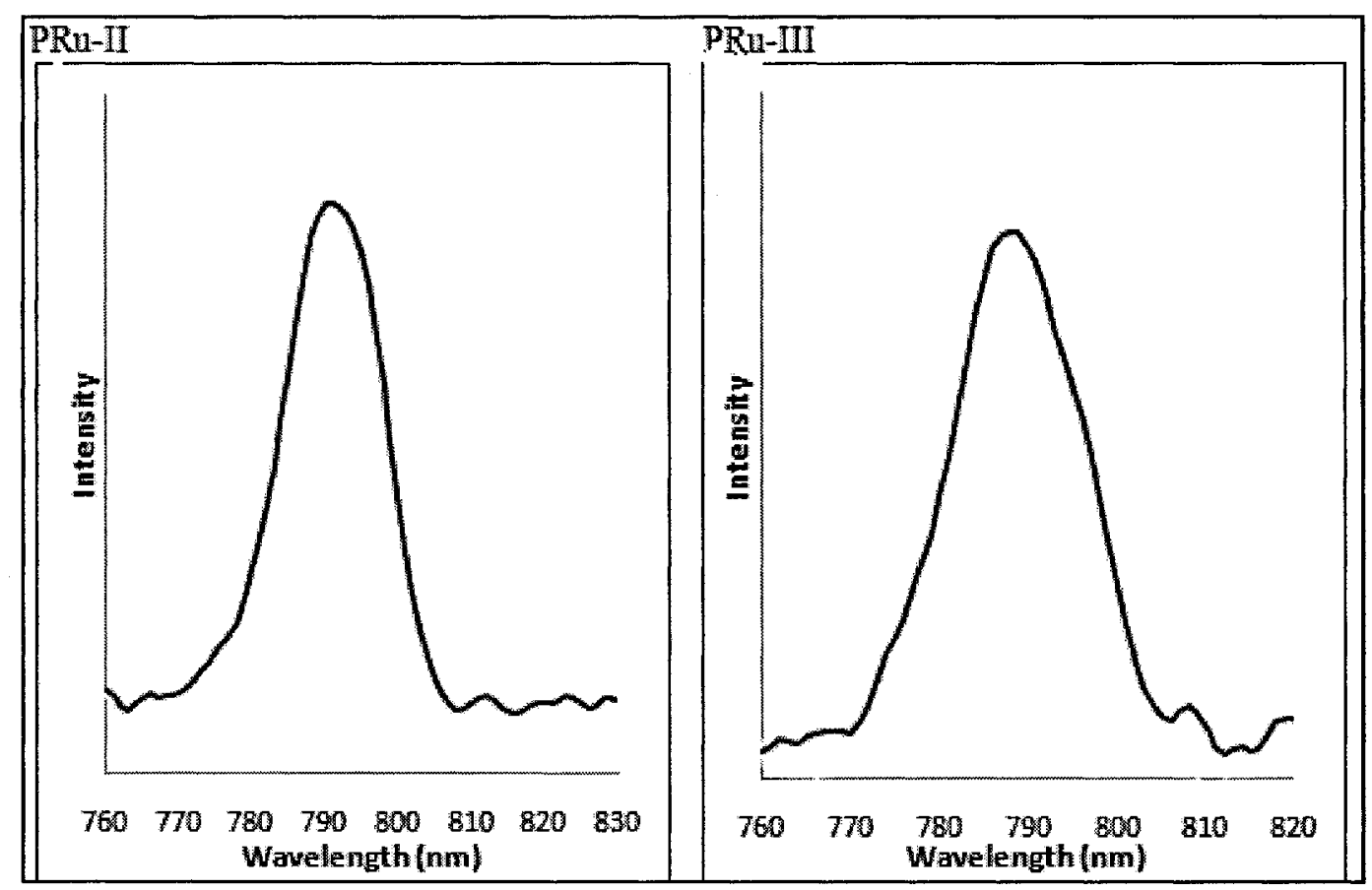

